FERNANDO KAZUYOSHI TAKIKAWA

\title{
ARQUITETURA DE SISTEMAS HIPERMÍDIA ADAPTATIVOS BASEADA EM ATRIBUTOS DE QUALIDADE
}

Dissertação apresentada à Escola

Politécnica da Universidade de São

Paulo para obtenção do título de Mestre em Engenharia 


\section{ARQUITETURA DE SISTEMAS HIPERMÍDIA ADAPTATIVOS BASEADA EM ATRIBUTOS DE QUALIDADE}

Dissertação apresentada à Escola

Politécnica da Universidade de São

Paulo para obtenção do título de Mestre em Engenharia

Área de Concentração:

Sistemas Digitais

Orientadora:

Prof $^{a}$. Dra ${ }^{a}$. Maria Alice Grigas Varella Ferreira 
Este exemplar foi revisado e alterado em relação à versão original, sob responsabilidade única do autor e com a anuência de seu orientador.

São Paulo, de maio de 2010.

Assinatura do autor

Assinatura do orientador

FICHA CATALOGRÁFICA

Takikawa, Fernando Kazuyoshi

Arquitetura de sistemas hipermídia adaptativos baseada em atributos de qualidade / F.K. Takikawa. -- ed.rev. -- São Paulo, 2010.

$135 \mathrm{p}$.

Dissertação (Mestrado) - Escola Politécnica da Universidade de São Paulo. Departamento de Engenharia de Computação e Sistemas Digitais.

1. Hipermídia 2. Arquitetura de software 3. Qualidade de software 4. Padrões de software I. Universidade de São Paulo. Escola Politécnica. Departamento de Engenharia de Computação e Sistemas Digitais II. t. 


\section{AGRADECIMENTOS}

À minha família pelo incentivo e compreensão durante este período de trabalho e algumas privações.

À professora Maria Alice pela paciência e pelas contribuições valiosas à realização desta dissertação.

À Mariza Leone e aos funcionários da Poli pela disposição em ajudar os alunos.

À professora Sandra Puga por permitir o uso do material de sua tese neste trabalho 


\section{RESUMO}

A hipermídia adaptativa permite o desenvolvimento de sistemas capazes de fornecer um conteúdo personalizado para cada usuário, baseado em suas características individuais. Essa capacidade é importante em áreas como o ensino, em que o conteúdo didático pode ser apresentado de forma individualizada, de acordo com o progresso e interesse do aluno. Dentre os diversos modelos de Sistemas Hipermídia Adaptativos, destacam-se os modelos AHAM e Munich. No entanto, as propostas de Sistemas Hipermídia Adaptativos conhecidas focam-se apenas nas funcionalidades do sistema, não apresentando maior preocupação com os requisitos não funcionais, ou seja, aqueles mais profundamente relacionados com aspectos de qualidade. $O$ desenvolvimento de uma arquitetura de software precisa considerar tantos os aspectos funcionais quanto os não funcionais e, ao ignorar esta premissa, corre-se o risco de produzir sistemas de baixa qualidade. Partindo deste cenário, este trabalho propõe o desenvolvimento de visões arquiteturais para o sistema SHASIM. SHASIM é um sistema de hipermídia adaptativa, derivado do modelo Munich, que tem como proposta ser um sistema Web adaptativo voltado à educação, adaptando o conteúdo de acordo com o estilo cognitivo e as inteligências múltiplas do aluno. Com base no levantamento dos requisitos funcionais e não-funcionais de Sistemas Hipermídia Adaptativos, este trabalho propõe visões arquiteturais que complementem a arquitetura originalmente proposta para o sistema. Essas visões contemplam um conjunto de atributos de qualidade desejáveis e não considerados na sua implementação inicial, porém fundamentais para conferir qualidade mínima a um sistema desse tipo.

Palavras-chave: Hipermídia. Arquitetura de software. Qualidade de software. Padrões de software. 


\begin{abstract}
Adaptive hypermedia supports the development of systems able to provide a personalized content for each user, based on his/her personal attributes. This feature is valuable in areas such as e-learning where the learning content can be presented individually according to the progress and interest of the student. Among the several models of Adaptive Hypermedia Systems, the most relevant ones are the AHAM and Munich models. However, the known proposals of Adaptive Hypermedia Systems focus only on functional aspects of the system and show low concern about nonfunctional requirements, i.e. those requirements more deeply related to quality aspects of the system. The development of software architecture has to consider both functional and non-functional aspects and by ignoring this premise, it assumes the risk of developing low quality systems. From this actual scenario, this dissertation proposes the development of architectural views to SHASIM system. SHASIM is an adaptive hypermedia system derived from Munich model that is a proposal for an adaptive Web system focused on learning by adapting the domain contents according to the cognitive style and multiple intelligences of the student. Based on the functional and non-functional requirement of Adaptive Hypermedia Systems, this dissertation proposes architectural views that complement the system architecture. These new views involve the desired quality attributes that were not considered during the first version of the system, but that are essential to grant the minimum quality for this class of systems.
\end{abstract}

Keywords: Hypermedia. Software architecture. Software quality. Software patterns. 


\section{LISTA DE FIGURAS}

Figura 1 - Visão "4+1" de Kruchten (1995), com destaque nas visões de AHAM-MI e

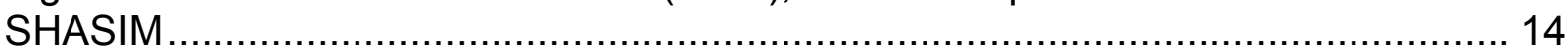

Figura 2 - Ciclo clássico do Modelo do Usuário - adaptação de BUGAY (2006) .... 20

Figura 3 - Camadas do Modelo Dexter, segundo KOCH (2000).......................... 23

Figura 4 - Mapeamento do Modelo Dexter em um sistema hipermídia, conforme (HALASZ; SCHWARTZ,1994)

Figura 5 - AHAM - Adaptive Hypermedia Application Model (WU; HOUBEN; DE

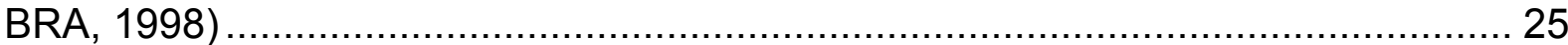

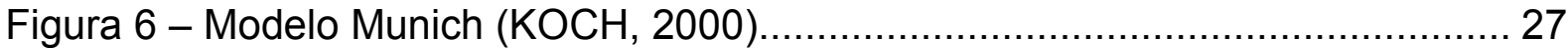

Figura 7 - Modelo Munich - extraído de PUGA $(2008$, p.58) ............................... 29

Figura 8 - Visão Geral do SHASIM - extraída de Puga (2008, p. 101) ................... 30

Figura 9 - Arquitetura do modelo SHASIM (PUGA, 2008, p. 103) ......................... 31

Figura 11 - Relacionamento entre modelo de referência, estilo de arquitetura, arquitetura de referência e a arquitetura de software (BASS; CLEMENTS; KAZMAN,

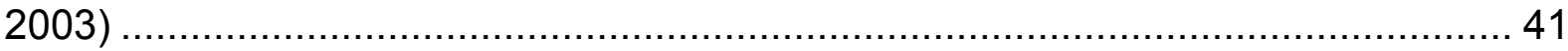

Figura 12 - Exemplo de relacionamento entre modelo de referência, estilo de arquitetura, arquitetura de referência e a arquitetura de software no caso de SOA. 42 Figura 13 - Modelo conceitual da descrição de arquitetura (ISO/IEC 42010, 2007). 45 Figura 14 - Visão “4+1" (KRUCHTEN, 1995) ................................................. 47 Figura 15 - Pontos de vista RM-ODP e ciclo de vida do sistema (RAYMOND, 1995)

Figura 16 - Modelo de qualidade para qualidade interna e externa (ISO/IEC 9126-1, 2001) 54

Figura 17 - Camadas de Execução, Adaptação, Domínio e Usuário do Modelo

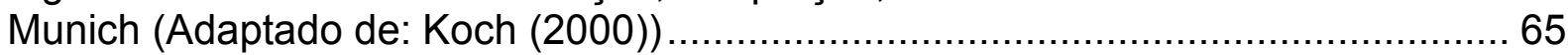

Figura 18 - Camada de Apresentação da arquitetura de referência ....................... 74

Figura 19 - Camada de Adaptação da arquitetura de referência ........................... 77

Figura 20 - Diagrama de seqüência do Modelo de Adaptação ............................. 79

Figura 21 - Módulo de Segurança da arquitetura de referência............................. 81

Figura 22 - Visão geral da arquitetura de referência proposta para o Modelo Munich

Figura 23 - Arquitetura física do sistema adaptativo baseado na Web................... 86

Figura 24 - Diagrama de casos de uso do SHASIM - extraído de Puga (2008, p. 108)

Figura 25 - Layout da interface de usuário

Figura 26 - Módulo de usuário original - extraído de Puga (2008, p. 111) .............. 97

Figura 27 - Módulo de Usuário da arquitetura proposta para o SHASIM................ 98

Figura 28 - Módulo de Segurança da arquitetura proposta para o SHASIM.......... 101

Figura 29 - Modelo de Domínio original - extraído de Puga (2008, p. 128) ........... 103

Figura 30 - Módulo de Domínio da arquitetura proposta para o SHASIM .............. 104

Figura 31 - Modelo de Domínio original - extraído de Puga (2008, p. 133) .......... 106

Figura 32 - Módulo de Adaptação da arquitetura proposta para o SHASIM .......... 107

Figura 33 - Modelo de Signos original - extraído de Puga (2008, p. 146)............. 110

Figura 34 - Módulo de Signos da arquitetura proposta para o SHASIM ............... 111 
Figura 35 - Módulo de Apresentação da arquitetura proposta para o SHASIM .... 114 Figura 36 - Interação da Camada de Apresentação com os demais módulos da arquitetura proposta

Figura 37 - Diagrama de artefatos da Visão de Implementação da arquitetura proposta para o SHASIM

Figura 38 - Diagrama de implantação da Visão Física da arquitetura proposta para o SHASIM

Figura 39 - Segunda alternativa da Visão Física da arquitetura proposta para o SHASIM 


\section{LISTA DE QUADROS}

Quadro 1 - Stakeholders e as necessidades de comunicação atendidas pela arquitetura

Quadro 2 - Correspondência entre layers de Fowler e tiers de Alur, Crupi e Malks.72 Quadro 3 - Descrição Sintética dos Casos de Uso do SHASIM (Extraído de: Puga (2008, p107)). 


\section{LISTA DE ABREVIATURAS E SIGLAS}

AHA Adaptive Hypermedia for All

AHAM Adaptive Hypermedia Application Model

API Application Programming Interface

CS Component Specification

DMZ Delimitarized Zone

EBW Educação Baseada na Web

HTML HyperText Markup Language

IHM Interface Humano-Computador

IM Inteligências Múltiplas

MU Modelo do Usuário

OCL Object Constraint Language

RM-ODP Reference Model of Open Distributed Processing

RUP Rational Unified Process

SHA Sistemas Hipermídia Adaptativos

SHASIM Sistema Hipermídia Adaptativo Baseado em Semiótica e Inteligências Múltiplas

SOA Service-Oriented Architecture

SQL $\quad$ Structured Query Language

UB User Behavior

UI User Identification

UID Unique Identifier

UML Unified Modeling Language

WBS Work Breakdown Structure

XHTML Extensible HyperText Markup Language

XML Extensible Markup Language 


\section{SUMÁRIO}

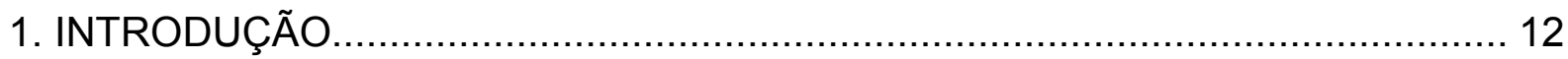

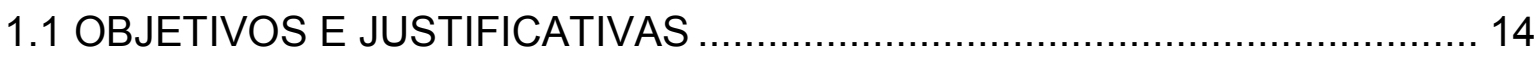

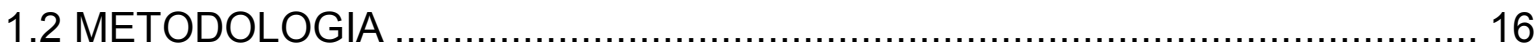

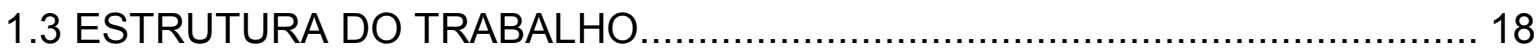

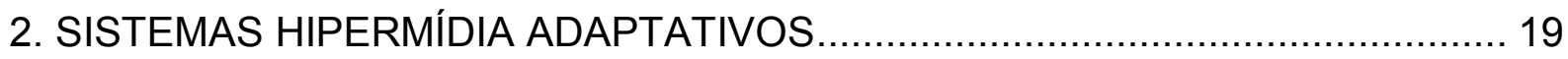

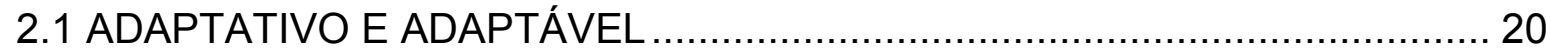

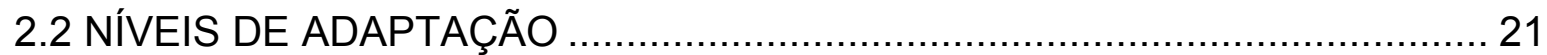

2.3 MODELOS DE REFERÊNCIA PARA SISTEMAS HIPERMÍDIA ................... 22

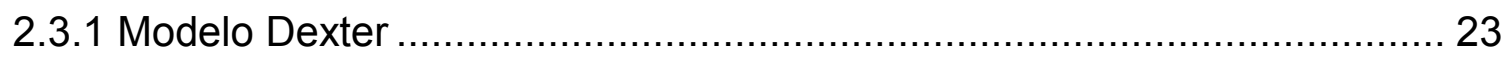

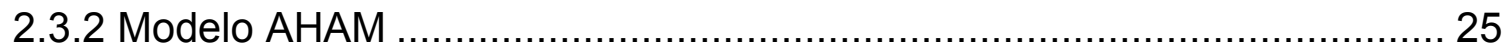

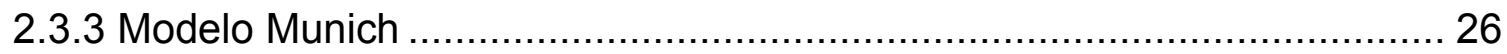

2.3.4 Modelos AHAM-MI e SHASIM ...................................................... 30

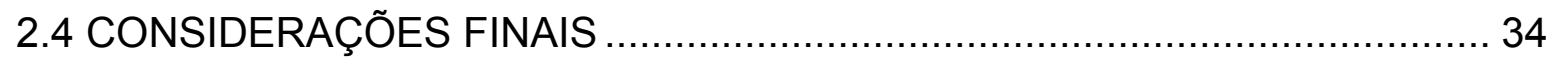

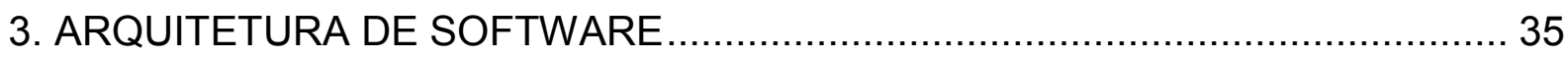

3.1 A IMPORTÂNCIA DA ARQUITETURA DE SOFTWARE ........................... 36

3.1.1 Arquitetura como um Meio de Comunicação entre os Participantes ......... 36

3.1.2 Arquitetura como Forma de Antecipação de Decisões de Projeto ............ 38

3.1.3 Arquitetura como um Modelo Reutilizável ............................................. 39

3.2 CONCEITOS EM ARQUITETURA DE SOFTWARE................................... 40

3.3 DESCRIÇÃO DE ARQUITETURA DE SOFTWARE .................................... 43

3.3.1 Norma ISO/IEC 42010 (2007) ......................................................... 44

3.4 ABORDAGENS DE VISÕES EM ARQUITETURA DE SOFTWARE …......... 46

3.4.1. Arquitetura no Processo Unificado .................................................. 46

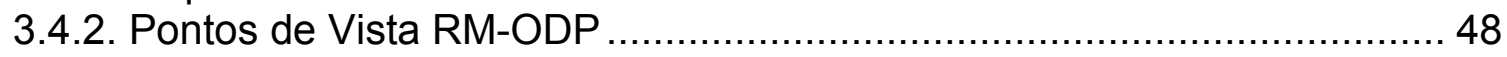

3.4.3. Outras Abordagens de Visões Arquiteturais ...................................... 50

3.4.3.1. Arquitetura de Software Segundo Bass, Clements e Kazman (2003)50

3.4.3.2. Arquitetura de Software Segundo Hofmeister, Nord e Soni (2000)... 51 3.5 CONSIDERAÇÕES FINAIS ............................................................. 52

4. ATRIBUTOS DE QUALIDADE DE SISTEMAS HIPERMÍDIA ADAPTATIVOS..... 53

4.1 MODELO DE QUALIDADE DE PRODUTO DA NORMA ISO/IEC-9126......... 53

4.2 ATRIBUTOS DE QUALIDADE DE SISTEMAS HIPERMÍDIA

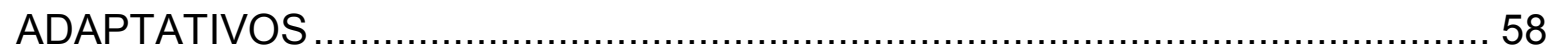

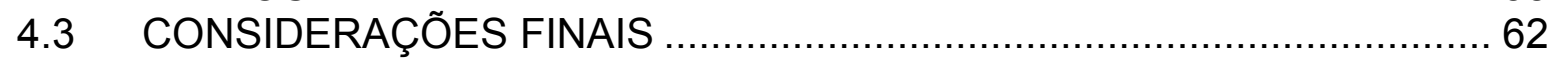

5. ARQUITETURA DE SISTEMAS HIPERMÍDIA ADAPTATIVOS .......................63

5.1 DETALHAMENTO ARQUITETURAL DO MODELO MUNICH ......................64

5.2 ARQUITETURA DE REFERÊNCIA PARA SISTEMAS ADAPTATIVOS

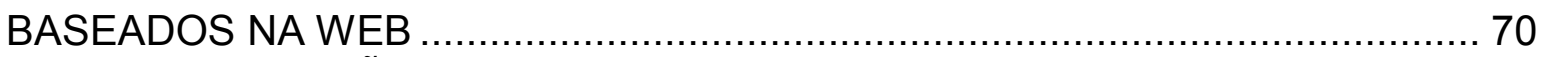

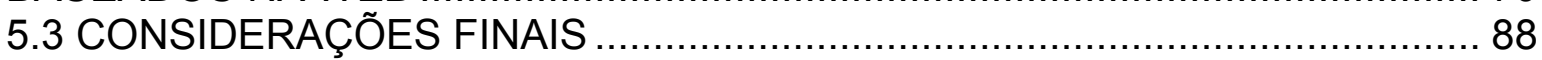

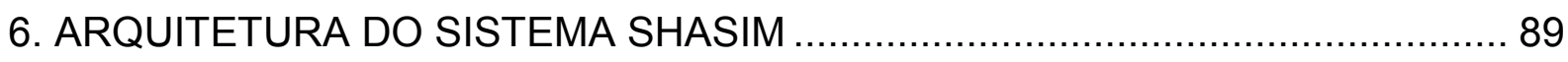

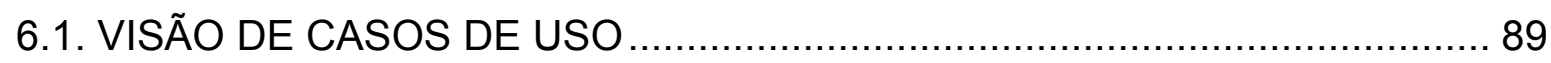




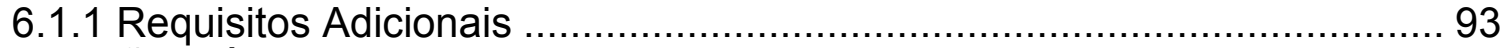

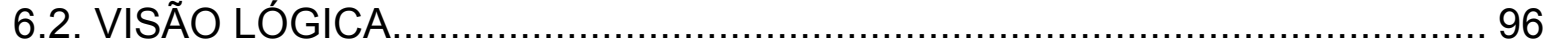

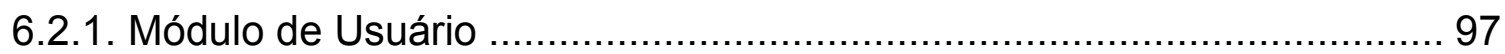

6.2.2. Módulo de Segurança ................................................................ 100

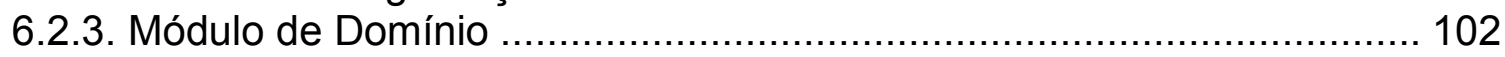

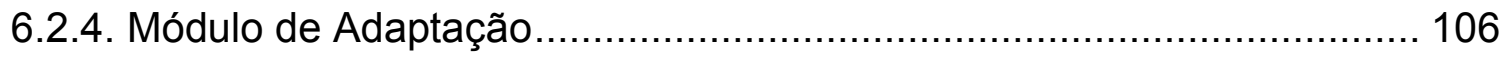

6.2.5. Módulos de Signos e Componentes .................................................... 109

6.2.6. Módulo de Apresentação.................................................................. 113

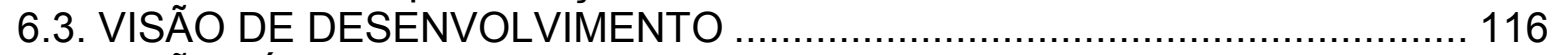

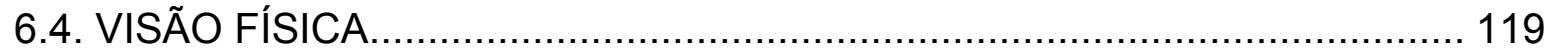

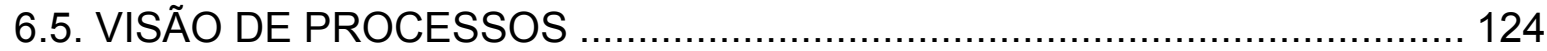

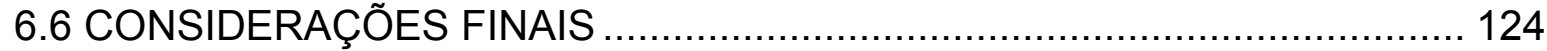

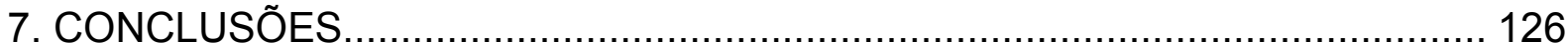

7.1 CONTRIBUIÇÕES DO TRABALHO .................................................. 126

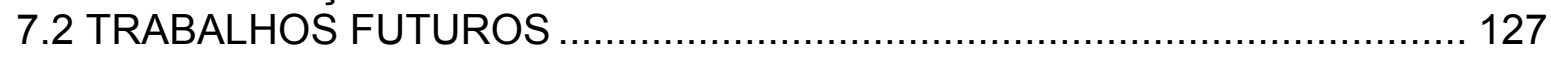

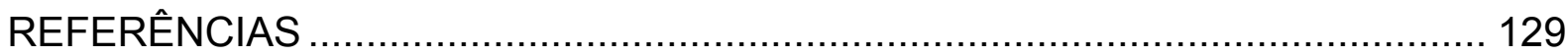

ANEXO A - AUTORIZAÇÃO DE SANDRA PUGA ........................................ 135 


\section{INTRODUÇÃO}

O intuito deste capítulo é apresentar motivações, objetivos e justificativas para a realização deste trabalho. No capítulo são descritas também a metodologia adotada e a organização do texto.

Os sistemas para a Web atuais enfrentam dificuldades em atender as necessidades e expectativas de usuários cada vez mais heterogêneos (BRUSILOVSKY; MAYBURY, 2002). Uma forma de resolver os efeitos negativos de sistemas que tratam todos os usuários da mesma forma é projetá-los com a habilidade de se adaptarem de acordo com os objetivos, interesses e outras características individuais de seus usuários. A classe de sistemas de software que possuem tal característica de adaptabilidade é a dos Sistemas Hipermídia Adaptativos (SHA). Eles constituem uma alternativa à abordagem tradicional one-size-fits-all no desenvolvimento de sistemas hipermídia (BRUSILOVSKY, 2003). O termo "hipermídia" no contexto dessa dissertação é usado para sentido tradicional, ou seja, não engloba os sistemas mais recentes - conhecidos como Web 2.0 -, nem tampouco sistemas voltados à Web Semântica, que vêm sendo denominados Web 3.0.

Sistemas Hipermídia Adaptativos constroem um modelo particular com os objetivos, preferências e conhecimento de cada usuário e usam este modelo ao longo de suas interações, a fim de adaptar o sistema às suas necessidades (BRUSILOVSKY, 1996). Por exemplo, um Sistema Hipermídia Adaptativo para fins educacionais fornecerá ao estudante uma interface adaptada especificamente ao seu nível de conhecimento sobre o assunto estudado (DE BRA; CALVI, 1997) e um conjunto sugerido de links mais relevantes para prosseguir na sua navegação (BRUSILOVSKY; EKLUND; SCHWARZ, 1998). Essa colocação diz respeito à finalidade principal do sistema - Educação -, não restringindo outras formas de adaptação possíveis como formas alternativas de apresentação ou navegação, por exemplo.

O Modelo de Referência Dexter foi o precursor entre os modelos de sistemas hipermídia (HALASZ; SCHWARTZ, 1994). Os sistemas subseqüentes utilizaram o 
modelo Dexter como base, adicionando a ele o mecanismo de adaptação da interface de usuário. Entre os principais modelos de Sistemas Hipermídia Adaptativos, destacam-se os modelos AHAM (WU; HOUBEN; DE BRA, 1998) e Munich (KOCH; WIRSING, 2002). Do ponto de vista da sua especificação, o modelo Munich apresenta as seguintes características que o diferenciam do modelo AHAM, conforme Koch (2000):

- Abordagem orientada a objetos;

- Especificação segundo a notação UML;

- Representação por um metamodelo que mostra todos os elementos e suas associações;

- Terminologia aplicável em qualquer domínio;

- Formalmente descrito por linguagem OCL (Object Constraint Language).

O modelo Munich descreve uma arquitetura de referência para Sistemas Hipermídia Adaptativos e serviu posteriormente como referência para outros sistemas mais recentes; dentre esses, destacam-se dois, voltados à Educação Baseada na Web: o AHAM-MI - Modelo de Hipermídia Adaptativa utilizando Inteligências Múltiplas -, proposto por Bugay (2006) e o SHASIM - Sistema Hipermídia Adaptativo Baseado em Semiótica e Inteligências Múltiplas -, proposto por PUGA (2008).

Todas estas propostas descrevem basicamente os SHAs do ponto de vista funcional, isto é, visam atender aos requisitos funcionais do sistema, não apresentando igual preocupação formal na descrição da arquitetura, ou seja, na descrição de requisitos não funcionais, que normalmente influem nela, diretamente. Apresentam, assim, apenas sua visão estática como uma decomposição em elementos funcionais e suas associações. Esta perspectiva do sistema corresponde à visão lógica da clássica abordagem de arquitetura "4+1", proposta por Kruchten (1995), usada como referência na metodologia orientada a objetos $(\mathrm{BOOCH}$; RUMBAUGH; JACOBSON,2005). Algumas propostas como o SHASIM (PUGA, 2008) e o AHAM-MI (BUGAY, 2006) fornecem ainda um modelo de casos de uso, acrescentando a essa visão uma nova perspectiva, conforme a Figura 1. Essas duas visões (lógica e de cenários) de Kruchten estão relacionadas apenas com os requisitos funcionais colocados para o sistema. 
Entretanto, os requisitos não funcionais são tão importantes para a qualidade da aplicação quanto os requisitos funcionais $\mathrm{e}$, portanto, também devem ser considerados no momento da concepção de um sistema (BUSCHMANN et al., 1996). Sistemas são freqüentemente reprojetados, não porque são funcionalmente deficientes, mas porque são difíceis de manter, têm péssima portabilidade ou escalabilidade, são freqüentemente lentos ou são suscetíveis a ataques de hackers (BASS; CLEMENTS; KAZMAN, 2003).

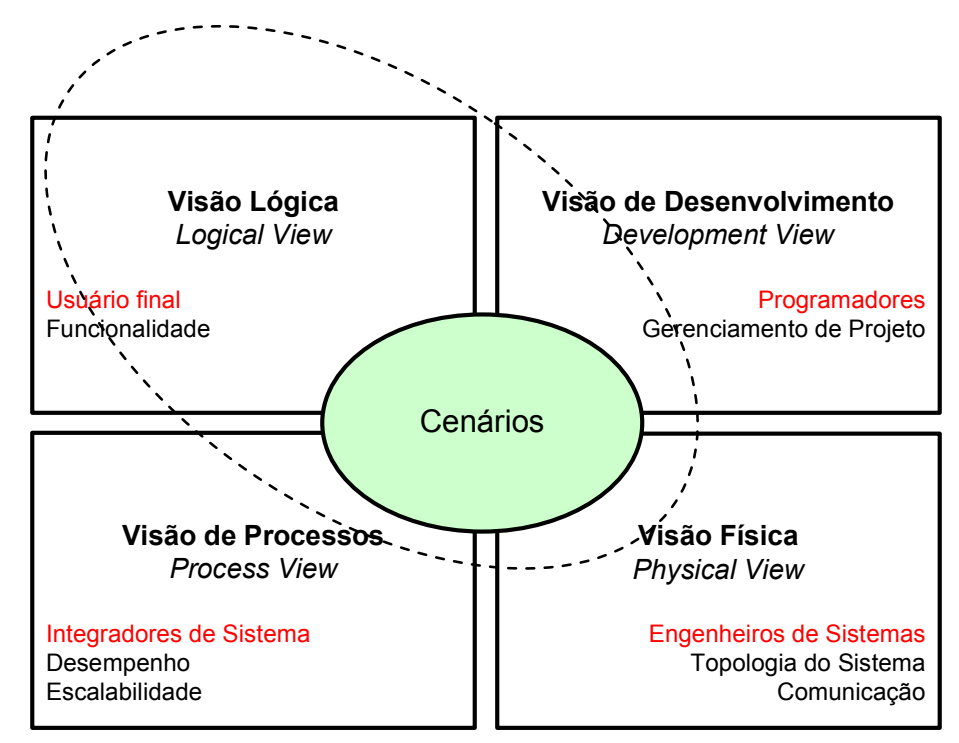

Figura 1 - Visão "4+1" de Kruchten (1995), com destaque nas visões de AHAM-MI e SHASIM

Apesar da importância de levantamento de requisitos não funcionais durante a fase de elicitação de requisitos, estes são quase sempre verificados apenas quando a implementação é finalizada. Entretanto, a análise e modelagem de requisitos não funcionais em arquiteturas de software reduzem os problemas de erros de requisitos em estágios avançados de desenvolvimento (XU et al., 2005).

\subsection{OBJETIVOS E JUSTIFICATIVAS}

O objetivo deste trabalho é descrever, através de visões arquiteturais, a arquitetura de Sistemas Hipermídia Adaptativos. Como a Web é hoje a forma de hipermídia mais conhecida e utilizada, para este trabalho será considerada a arquitetura de Sistemas Web Adaptativos. Os modelos propostos mais relevantes (HALASZ; 
SCHWARTZ, 1994; WU; HOUBEN; DE BRA, 1998; KOCH; WIRSING, 2002; BUGAY, 2006; PUGA, 2008) são trabalhos cujo foco é a adaptabilidade como um requisito funcional do sistema, deixando a arquitetura do software em segundo plano.

A arquitetura de software tem sido reconhecida nos últimos anos como um elemento indispensável no desenvolvimento de sistemas de software (SHAW; CLEMENTS, 2006). Compreender a finalidade da arquitetura é essencial, pois sua forma de utilização determina como deverá ser formulada. Clements et al. (2003) definem fundamentalmente três tipos de uso para a arquitetura:

- Arquitetura servindo como um meio de introdução de novos participantes (stakeholders) ao sistema - a arquitetura, por ser um desenho de alto nível do sistema, permite que seja utilizada como forma de introduzir o sistema a novas pessoas, como: novos membros da equipe, analistas externos ou arquitetos, que com ele terão de interagir;

- Arquitetura servindo como um veículo de comunicação entre os participantes no desenvolvimento (stakeholders) - o uso preciso da arquitetura como meio de comunicação depende de cada tipo de participante. Por exemplo, arquitetos e engenheiros de requisitos podem utilizá-la como um meio de comparar e negociar requisitos conflitantes. Para testadores e integradores, fornece uma especificação do comportamento dos módulos do sistema que serão testados ou integrados a outros sistemas externos. Pode fornecer ainda subsídios para o planejamento das atividades de desenvolvimento e manutenção do sistema.

- Arquitetura servindo como base para a análise do sistema - para suportar a análise, a documentação da arquitetura deve conter a informação necessária para a análise sendo realizada. Para engenheiros de sistemas, a arquitetura fornece um modelo formal que direcionará as ferramentas para análise de consumo de recursos, dependências, gargalos de processamento etc. Pode proporcionar também uma forma de avaliação da arquitetura com respeito aos atributos de qualidade requeridos tais com segurança, desempenho, usabilidade, disponibilidade e modificabilidade.

A partir de arcabouços de arquitetura tais como o "4+1" (KRUCHTEN, P., 1995) e de técnicas de modelagem de hipermídia adaptativa $(\mathrm{KOCH}, 2000)$, seleciona-se um 
conjunto de pontos de vista que compõem a documentação da arquitetura de Sistemas Hipermídia Adaptativos. A escolha dos pontos de vista baseia-se na norma ISO/IEC 42010 (2007), que padroniza elementos e práticas para a descrição da arquitetura de sistemas de software.

O trabalho apresenta uma parte prática que consiste na definição de visões da macro arquitetura do sistema SHASIM, que de acordo com a sua especificação leva em consideração somente aspectos funcionais. O sistema SHASIM (PUGA, 2008) foi escolhido como alvo do estudo de arquitetura devido ao pouco enfoque que foi dado à descrição da arquitetura na proposta original, que se concentrou nas funções do sistema e, principalmente, na adaptabilidade baseada nas características cognitivas do aluno derivadas de Inteligências Múltiplas (GARDNER, 1995). Na tese em que descreve o sistema, Puga (2008) destaca apenas os modelos de casos de uso e de classes utilizados, pois não foram considerados os requisitos não funcionais. Uma menção sobre segurança e privacidade foi considerada em Puga e Ferreira (2007), porém, no trabalho final, nenhuma consideração adicional foi inserida.

\subsection{METODOLOGIA}

Para o desenvolvimento do trabalho, foram utilizados quatro passos principais, conforme se descreve a seguir.

1. Revisão bibliográfica: consistiu na análise de pesquisas nas áreas de hipermídia adaptativa, qualidade e arquitetura de software. Coletou-se, com base nesses estudos, um conjunto de termos e conceitos específicos utilizados no domínio citado. A norma ISO/IEC-9126 foi utilizada como referência para o levantamento dos atributos de qualidade do software, os quais direcionaram a definição da arquitetura. Realizou-se também uma ampla análise de processos e modelos de arquitetura de software. Tais termos, conceitos e modelos serviram para a redação dos capítulos 2 e 3 dessa dissertação. 
2. Revisão de Visões Arquiteturais: aprofundaram-se, então, os estudos sobre os principais arcabouços de arquitetura existentes: "4+1" (KRUCHTEN, 1995), RMODP (ISO/IEC-19476-3, 1995), de Bass, Clements e Kazman (2003) e de Hofmeister, Nord e Soni (2000), tendo como base a norma ISO/IEC 42010 (2007), utilizada para descrição de arquiteturas de sistemas de software. Este estudo permitiu completar a redação do capítulo 3.

3. Elicitação de requisitos não funcionais: foram analisados os atributos de qualidade definidos na norma ISO/IEC 9126-1 (2001), os quais foram considerados na identificação dos principais atributos de qualidade para SHAs. Estes atributos serviram de base para a definição da arquitetura do sistema. Esse estudo permitiu a redação do capítulo 4.

4. Concepção da Arquitetura de Software: propôs-se, então, a arquitetura de SHAs baseada no modelo Munich (KOCH; WIRSING, 2002), desenvolvendo-se novas perspectivas arquiteturais a partir dos requisitos levantados na fase anterior. Como forma de aplicação prática da arquitetura proposta define-se, nesta etapa, novas visões arquiteturais para o sistema SHASIM. A primeira versão do sistema SHASIM serviu apenas como prova de conceito para o modelo proposto e por isso não considerou todos os atributos de qualidade requeridos de um sistema de software, conforme define a norma ISO/IEC-9126. Por exemplo, o requisito de manutenibilidade não foi considerado, já que muitas regras de negócio foram implementadas na camada de banco de dados, o que torna mais difícil a manutenção. Assim, este trabalho é dedicado à apresentação desses outros aspectos, o que levou à elaboração de novas visões da macro arquitetura do SHASIM que abordam tanto os requisitos funcionais quanto os novos atributos de qualidade analisados. Essa etapa permitiu o desenvolvimento da prova de conceito da presente dissertação e encontra-se descrita no capítulo 6. 


\subsection{ESTRUTURA DO TRABALHO}

Este trabalho está estruturado da seguinte forma:

- Capítulo 1 - Consiste na introdução do trabalho, em que estão descritos os objetivos e as justificativas.

- Capítulo 2 - É realizada uma revisão da pesquisa sobre os Sistemas Hipermídia Adaptativos, apresentando-se os principais conceitos na área e os modelos de hipermídia adaptativos mais relevantes.

- Capítulo 3 - Neste capítulo são apresentados os conceitos sobre arquitetura, a importância da arquitetura de software e uma revisão das principais abordagens de desenvolvimento de arquitetura baseadas em visões.

- Capítulo 4 - Descreve-se neste capítulo a norma ISO/IEC 9126 (2001) e os atributos de qualidade necessários para Sistemas Hipermídia Adaptativos.

- Capítulo 5 - Neste capítulo, é definida a arquitetura para Sistemas Hipermídia Adaptativos.

- Capítulo 6 - Neste capítulo é realizada uma formalização da arquitetura do sistema SHASIM, com a descrição através de visões arquiteturais segundo o modelo " $4+1$ ". 


\section{SISTEMAS HIPERMÍDIA ADAPTATIVOS}

O objetivo deste capítulo é apresentar os principais conceitos relacionados à hipermídia adaptativa. São apresentados os modelos de referência mais conhecidos de Sistemas Hipermídia Adaptativos, destacando-se as características principais de cada um. Dentre os modelos apresentados, descreve-se o modelo SHASIM, alvo do estudo de arquitetura de software deste trabalho.

Define-se Sistema Hipermídia Adaptativo como "um sistema que constrói um modelo para cada usuário a partir de seus desejos, preferências e conhecimento e o aplica na adaptação de diversos aspectos visíveis do sistema" (BRUSILOVSKY, 1996). Usuários com diferentes objetivos e nível de conhecimento podem estar interessados em diferentes informações apresentadas em uma página Web e podem usar diferentes links para navegação. O SHA tenta solucionar este problema utilizando o conhecimento representado no Modelo do Usuário (MU) para adaptar as informações e links sendo apresentados para um usuário.

De acordo com Eklund e Zeiliger (1997), as cinco principais características que são representadas no Modelo de Usuário são:

- Objetivo ou tarefa atual do usuário;

- Conhecimento do usuário no domínio apresentado na hipermídia;

- Nível de conhecimento geral do usuário;

- Experiência do usuário no uso de aplicações similares ou em hipermídia;

- Preferências ou interesses do usuário.

Puga (2008) destaca para o SHASIM, nesse modelo, as inteligências múltiplas (IM) mais destacadas no usuário, segundo a classificação de Gardner (1995).

O ciclo clássico descrito por Brusilovsky (1996) é mostrado na Figura 2. 


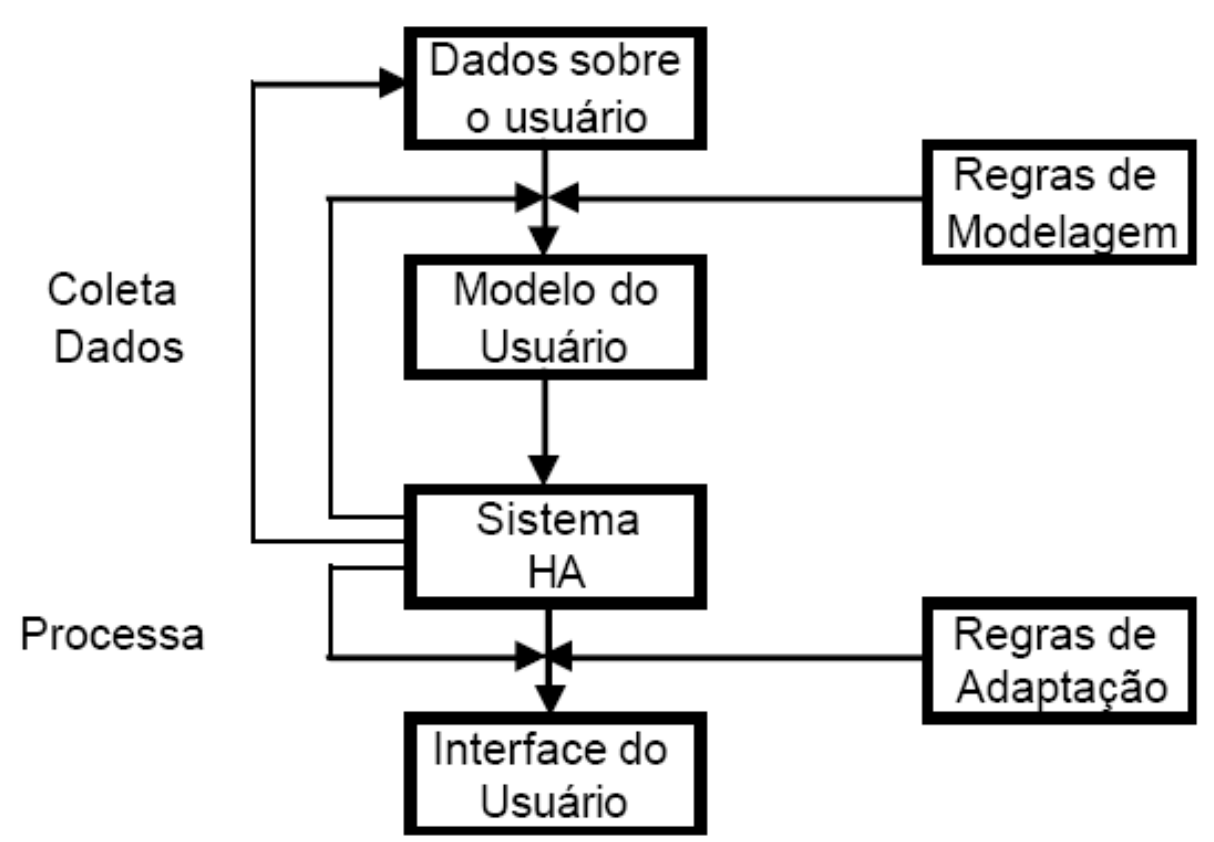

Figura 2 - Ciclo clássico do Modelo do Usuário - adaptação de BUGAY (2006)

O Sistema Hipermídia Adaptativo coleta informações sobre o comportamento do usuário, atualiza o modelo de usuário e, com estes novos dados, gera o efeito de adaptação de apresentação do conteúdo (BUGAY, 2006).

\subsection{ADAPTATIVO E ADAPTÁVEL}

Koch (2000) diz que uma clara distinção deve ser feita entre sistemas hipermídia que são customizáveis - chamados sistemas adaptáveis - e sistemas hipermídia adaptativos. Em ambos os casos, o usuário desempenha um papel central e o maior objetivo é oferecer-Ihe um sistema personalizado. Ambos diferem no modo como a adaptação é realizada.

- Um sistema hipermídia adaptável permite que o usuário configure o sistema mudando alguns parâmetros e o sistema, então, consegue adaptar seu comportamento de acordo com a nova configuração fornecida. É uma adaptação externa, ou seja, é o usuário que decide quando o modelo de usuário deve ser mudado, por exemplo, no início de uma sessão. Esta 
modalidade consiste em configuração de preferências, através da alteração de um conjunto de parâmetros do sistema, numa etapa anterior à de utilização principal do sistema.

- Um sistema hipermídia adaptativo ou SHA é um sistema hipermídia que se adapta de forma autônoma. Ele monitora o comportamento do usuário, registra este comportamento no Modelo do Usuário e adapta o sistema dinamicamente de acordo como o estado atual do modelo. O sistema usa as ações de navegação, respostas a questionários e a informação inicial que o usuário pode prover para atualizar o Modelo do Usuário e adaptar a navegação. É um processo interno, independente da vontade do usuário que, entretanto, pode ser combinado com o processo externo, caso o usuário assim o desejar.

A maior parte dos SHAs possui tanto características adaptativas como adaptáveis, seja pelo cadastramento inicial utilizado para inicializar o Modelo do Usuário, ou através de componentes que permitem que os usuários modifiquem o próprio Modelo do Usuário quando julgarem necessário.

\subsection{NÍVEIS DE ADAPTAÇÃO}

Koch (2000) classifica as possibilidades de adaptação em três níveis: conteúdo adaptativo, apresentação adaptativa e navegação adaptativa.

- Conteúdo Adaptativo - consiste na seleção de informações diferentes, tais como diferentes textos, imagens, vídeos, animação etc., dependendo do estado atual do Modelo do Usuário. Por exemplo, para um usuário experiente em certo domínio, o SHA fornece mais informações sobre um determinado assunto do que as fornecidas para um iniciante no assunto.

- Apresentação Adaptativa - o sistema mostra diferentes layouts de elementos de interface perceptíveis pelo usuário, tais como diferentes tipos de mídia, ordenação ou cores diferentes, tamanho e tipos de fonte de letras ou tamanho de imagem. 
- Navegação Adaptativa - o sistema muda a organização da navegação do usuário, alterando a aparência, destino, quantidade e ordenação dos links exibidos.

No caso do sistema SHASIM - que será usado na prova de conceito desse trabalho - a ênfase maior na adaptação se dá quanto aos signos adaptados. O SHASIM é um sistema com finalidades educacionais, voltado ao aprendizado pró-ativo do aluno, ou seja, este interage com a fonte de conhecimentos no seu próprio ritmo, acessando material de aprendizagem a ele disponibilizado. Esse material de aprendizagem - evita-se aqui, deliberadamente, o termo "objeto de aprendizagem" será denominado signo instrucional. Conforme Puga (2008, p. 30), "[...] o processo de catalogação do SHA-EBW proposto adicionou à lista de atributos recomendados pelos diferentes padrões de objetos de aprendizagem (LOM, SCORM etc.) a necessidade de atributos para representação dos aspectos perceptuais e funcionaisoperacionais dos signos instrucionais, com base na associação da Semiótica às Inteligências Múltiplas de Gardner. Considera-se que tais aspectos são melhor inferidos pelo próprio designer, quando da geração de material didático". Dessa forma, a adaptação nesse sistema tem foco maior na adaptação de conteúdo ou de apresentação.

\subsection{MODELOS DE REFERÊNCIA PARA SISTEMAS HIPERMÍDIA}

O objetivo dos modelos de referência de sistemas hipermídia é de capturar abstrações importantes encontradas em aplicações hipermídia atuais e descrever os conceitos básicos destes sistemas a fim de estabelecer um padrão como base de comparação. Dentre os modelos de referência e implementações existentes, podese destacar os modelos Dexter (HALASZ; SCHWARTZ, 1994), AHAM (WU; HOUBEN; DE BRA, 1998), Munich (KOCH, 2000), AHAM-MI (BUGAY, 2006) e SHASIM (PUGA, 2008). Boa parte desses modelos, como será visto nos itens que se seguem, estão voltados para as aplicações de cunho educacionais. 


\subsubsection{Modelo Dexter}

O Modelo de Referência Dexter proposto por Halasz e Schwartz (1994) serviu de base para diversos outros modelos de hipermídia posteriores. O modelo divide 0 sistema hipertexto em três camadas, conforme a Figura 3: a Camada de Execução (Run-Time Layer), a Camada de Armazenamento (Storage Layer) e a Camada Interna de Componentes (Within-Component Layer). Um aspecto importante do modelo é a definição de interfaces entre as camadas, colocadas na cor cinza: Especificação da Apresentação e Ancoragem. Descreve-se a seguir cada uma das camadas.

\begin{tabular}{|c|}
\hline $\begin{array}{c}\text { Camada de Execução } \\
\text { Apresentação do hipertexto } \\
\text { Interação do usuário }\end{array}$ \\
\hline Especificação da Apresentação \\
\hline Camada de Armazenamento \\
Redes de nós e links \\
\hline Ancoragem \\
Camada Interna de Componentes \\
Conteúdo/estrutura dentro dos nós \\
\hline
\end{tabular}

Figura 3 - Camadas do Modelo Dexter, segundo KOCH (2000)

- Camada de Execução - representa a camada de interação com usuário, onde é apresentado o hipertexto. Consiste de ferramentas para acesso, visualização e manipulação de hipermídia. O modelo não fornece detalhes de mecanismos de apresentação, devido à grande abrangência existente. A Especificação da Apresentação é a interface entre as Camadas de Armazenamento e Execução, uma vez que passa informações para a Camada de Execução, apresentando o componente para o usuário.

- Camada de Armazenamento - É a foco do modelo, responsável por modelar a hierarquia de componentes de informações inter-relacionados por links. Nesta camada, os componentes são tratados como recipientes genéricos de dados, sem especificar a estrutura interna. Assim, não faz diferenciação entre componentes de texto ou gráficos, focando-se principalmente no mecanismo pelo qual os componentes e links são unidos para formar a rede de hipertexto. 
- Camada Interna de Componentes - Trata do conteúdo e da estrutura interna dos componentes da camada de armazenamento. Devido à amplitude de possíveis conteúdos, que podem ser incluídos em um componente, o modelo Dexter considera esta camada fora do escopo do modelo. A interface entre a Camada de Armazenamento e a Camada Interna de Componentes, denominada Ancoragem, é crítica e examina o mecanismo de endereços de localização ou itens dentro do conteúdo de cada componente individual.

A Figura 4 mapeia as camadas do modelo Dexter em elementos de um sistema hipermídia típico.

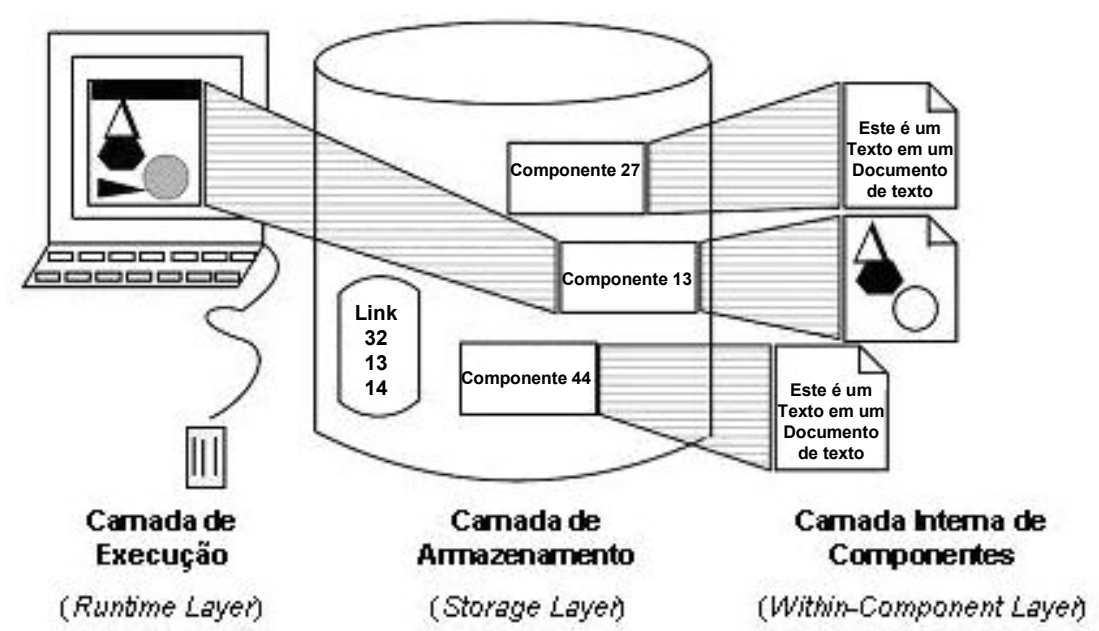

Figura 4 - Mapeamento do Modelo Dexter em um sistema hipermídia, conforme (HALASZ; SCHWARTZ,1994)

A Camada de Armazenamento contém quatro entidades: três componentes (nós) e um link. O conteúdo (texto e gráficos) para os componentes estão localizados à direita da Camada de Armazenamento, na Camada Interna de Componentes. Na Camada de Execução, o componente gráfico está sendo apresentado para o usuário. 


\subsubsection{Modelo AHAM}

O modelo AHAM (Adaptive Hypermedia Application Model) apresentado por Wu, Houben e De Bra (1998) divide os Sistemas Hipermídia Adaptativos nas mesmas três camadas do modelo Dexter, conforme pode ser constatado na Figura 5. O seu grande diferencial em relação ao modelo Dexter é detalhar o mecanismo de adaptação. Além disso, ele apresenta ainda um modelo para fins educacionais, apesar de não ter sido concebido apenas para tais aplicações. Isso implica em alterações na Camada de Armazenamento apenas, mantendo-se as demais camadas.

A Camada de Armazenamento do AHAM é também uma rede de nós e links e consiste de três elementos: Modelo de Domínio, Modelo de Usuário e Modelo de Adaptação, conforme se descreve a seguir.

- Modelo de Domínio - descreve a estrutura do domínio da aplicação, tanto em nível conceitual como de fragmentos de informações e páginas;

- Modelo de Usuário - descreve o conhecimento que o usuário possui sobre os conceitos do domínio da aplicação e demais informações relevantes a seu respeito

- Modelo de Ensino ou Adaptação - possui regras de adaptação utilizadas para adaptar os conteúdos e links, com base nos modelos de Domínio e do Usuário. Muitas regras derivam diretamente dos relacionamentos estruturais entre conceitos, porém o autor da hipermídia pode definir regras adicionais.

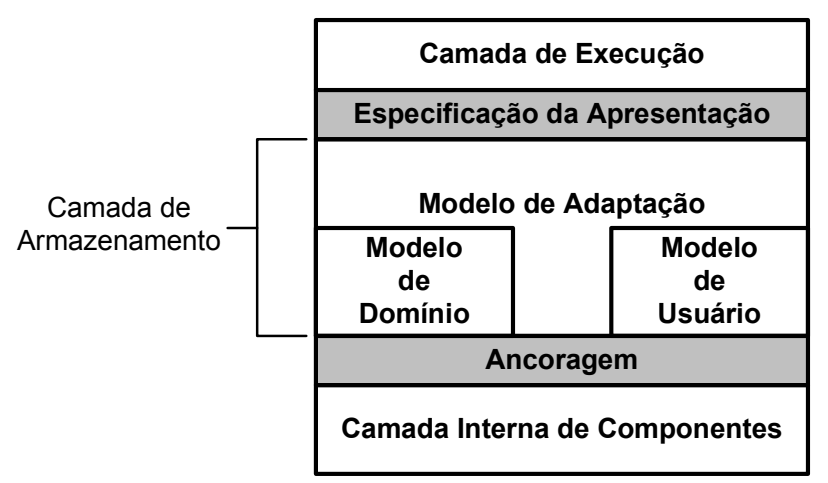

Figura 5 - AHAM - Adaptive Hypermedia Application Model (WU; HOUBEN; DE BRA, 1998) 
O mecanismo de adaptação é o ambiente de software usado para criar e adaptar o conteúdo e a navegação. Este mecanismo é parte da chamada Especificação de Apresentação definida para o sistema e oferece uma biblioteca de funções para construção de páginas a partir de "fragmentos de informação", baseando-se nos elementos do Modelo do Domínio, Modelo do Usuário e Modelo de Aprendizado. O mecanismo também atualiza o Modelo do Usuário observando o seu comportamento e alterando seu conhecimento sobre o domínio.

O AHAM é um modelo de Hipermídia Adaptativa semi-formal, definido com tuplas, adotando uma abordagem da área de banco de dados $(\mathrm{KOCH}, 2002)$. O modelo descreve características de aplicações de hipermídia em nível conceitual e não em nível de implementação. A construção de páginas e as técnicas utilizadas para manipular links, atualmente dependem da linguagem e dos recursos oferecidos pelo mecanismo de adaptação (BUGAY, 2006).

\subsubsection{Modelo Munich}

O Modelo de Referência Munich foi apresentado por Koch e Wirsing na $2^{a}$ Conferência Internacional de Hipermídia Adaptativa e Sistemas Adaptativos baseados na Web, em 2002, em Málaga, na Espanha. Os principais objetivos que guiaram a elaboração deste modelo foram os seguintes $(\mathrm{KOCH}, 2000)$ :

- Desenvolver um modelo para aplicações de hipermídia adaptativo baseado no Modelo de Referência Dexter;

- Incluir o Modelo de Usuário no modelo de referência;

- Modelar a funcionalidade e as regras de adaptação;

- Utilizar abordagem orientada a objetos;

- Elaborar uma especificação formal deste metamodelo;

- Usar terminologia geral, independente do domínio da aplicação.

O resultado foi uma especificação formal, orientada a objetos, baseada em modelos UML e na linguagem OCL (Object Constraint Language). 
O modelo Munich manteve a arquitetura de três camadas do modelo Dexter, incorporando, na Camada de Armazenamento, os modelos de Domínio, de Usuário e de Adaptação e mantendo as interfaces de Apresentação e Ancoragem, conforme a Figura 6. Descreve-se, a seguir, cada uma das camadas.

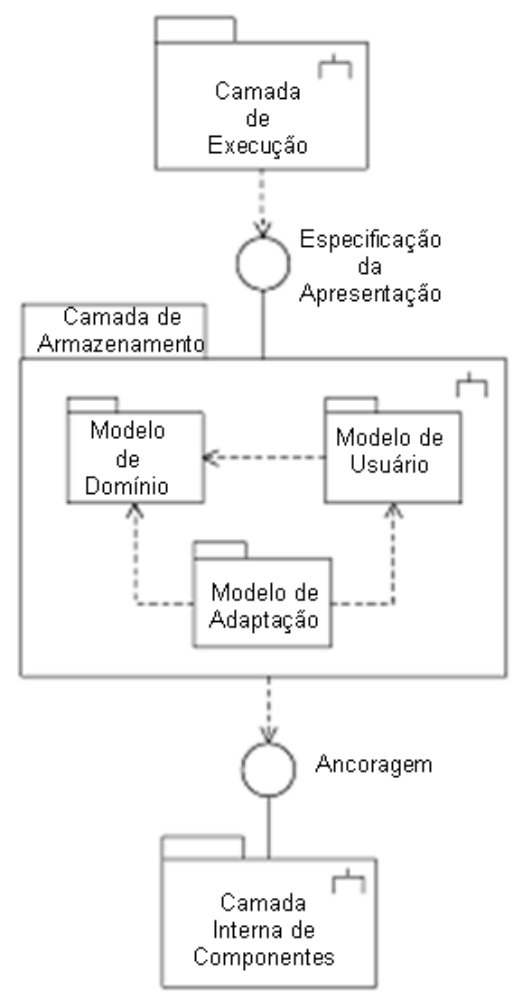

Figura 6 - Modelo Munich (KOCH, 2000)

- Camada de Execução - camada responsável pelo gerenciamento de diferentes sessões para os usuários, gerando e apresentando instâncias de páginas e armazenando as modificações na Camada de Armazenamento ( $\mathrm{KOCH}, 2000)$.

- Camada de Armazenamento - diferentemente do modelo Dexter, esta camada tem mais responsabilidade do que apenas armazenar informação sobre a estrutura hipermídia. Para suportar adaptação, a Camada de Armazenamento consiste de três subsistemas - ou modelos -: o Modelo de Domínio, o Modelo de Usuário e o Modelo de Adaptação (BUGAY, 2006; KOCH, 2000).

- Modelo de Domínio: responsável pelo gerenciamento do mecanismo da estrutura do sistema hipermídia pelo qual os links e os nós são relacionados para compor a navegação. Os nós são tratados neste modelo como recipientes de dados gerais. 
- Modelo de Usuário: gerencia os usuários do sistema, bem como os atributos e valores de seus atributos que representam as características e conhecimentos de cada usuário. Estes atributos são classificados como dependentes e independentes do domínio.

- Modelo de Adaptação: consiste de um grupo de regras que fornecem a funcionalidade adaptativa ao sistema, além de personalizar a aplicação. Estas regras são "disparadas" pelo comportamento do usuário, monitorado pela Camada de Execução ou por outras regras. Diferentemente do Modelo AHAM, que separa as regras de adaptação no Modelo de Aprendizado e a funcionalidade adaptativa no mecanismo de adaptação, o Munich adota uma abordagem orientada a objetos em que os dados e as funcionalidades se concentram nesta camada $(\mathrm{KOCH}, 2002)$.

- Camada Interna de Componentes - contém o conteúdo e a estrutura da hipermídia e, desta forma, depende de cada aplicação. Assim como nos modelos Dexter e AHAM, esta camada não foi modelada no Munich (BUGAY, 2006).

Conforme descrito por Bugay (2006), o modelo inclui ainda duas interfaces: a Especificação de Apresentação e a Ancoragem.

- Especificação da Apresentação - cria as páginas que serão apresentadas ao usuário, a partir dos fragmentos que as compõe, baseado nas regras do Modelo de Adaptação.

- Ancoragem - é o mecanismo de endereçamento indireto que determina um ponto fixo a ser usado pela camada de armazenamento, o qual é combinado com um campo variável usado pela camada interna de componentes.

Na Figura 7 apresenta-se o diagrama de classes especificado por Koch e Wirsing (2002), adaptado por Puga (2008, p. 58), por meio do qual se pode observar a relação entre as camadas do modelo Munich, bem como as funcionalidades acrescidas a cada camada. 


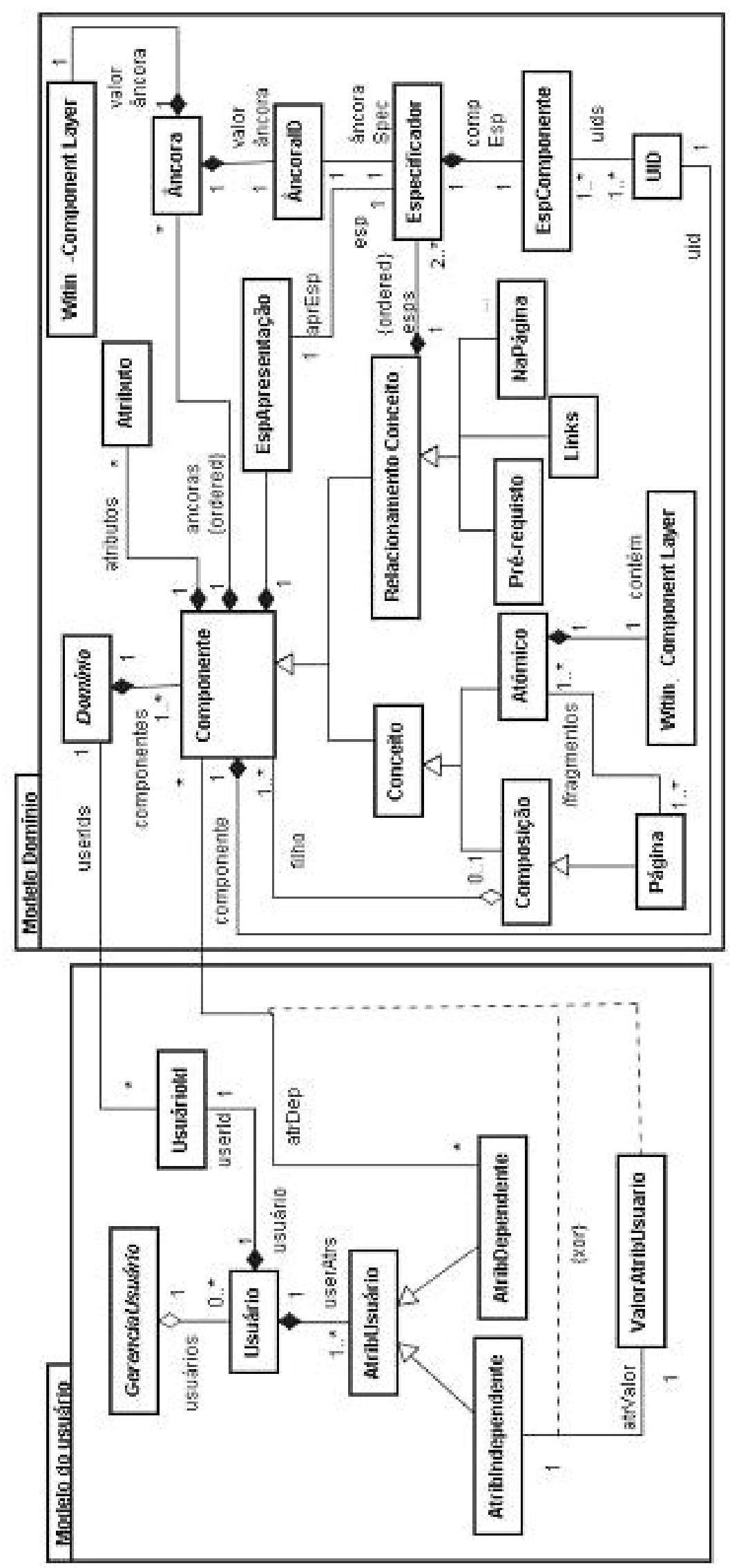

Figura 7 - Modelo Munich - extraído de PUGA (2008, p.58) 


\subsubsection{Modelos AHAM-MI e SHASIM}

O Modelo AHAM-MI, proposto por Bugay (2006) baseia-se nos três modelos anteriores e, como o AHAM, destina-se a sistemas educacionais. Utiliza para a adaptação, além dos níveis de adaptação discutidos em 2.2, o conceito de Inteligência Múltipla de Gardner; Bugay considera para o efeito adaptativo a inteligência mais evidenciada no aluno como, por exemplo, a visual ou auditiva.

O SHASIM é um sistema para EBW desenvolvido por Puga (2008), que considera as características relacionadas às Inteligências Múltiplas do aluno para direcionar a adaptação, bem como aplica os conceitos de Semiótica para estruturar a interface humano-computador. Esta adaptação é concebida em nível de interação e de conteúdo instrucional, tendo como base o Modelo de Usuário. No nível de interação são adaptados os signos com os quais o aluno poderá interagir para realizar alguma tarefa, e no nível de conteúdo instrucional são adaptados os signos para estudos. A Figura 8 ilustra o processo de interação do aluno com o SHASIM (PUGA, 2008, p.101).

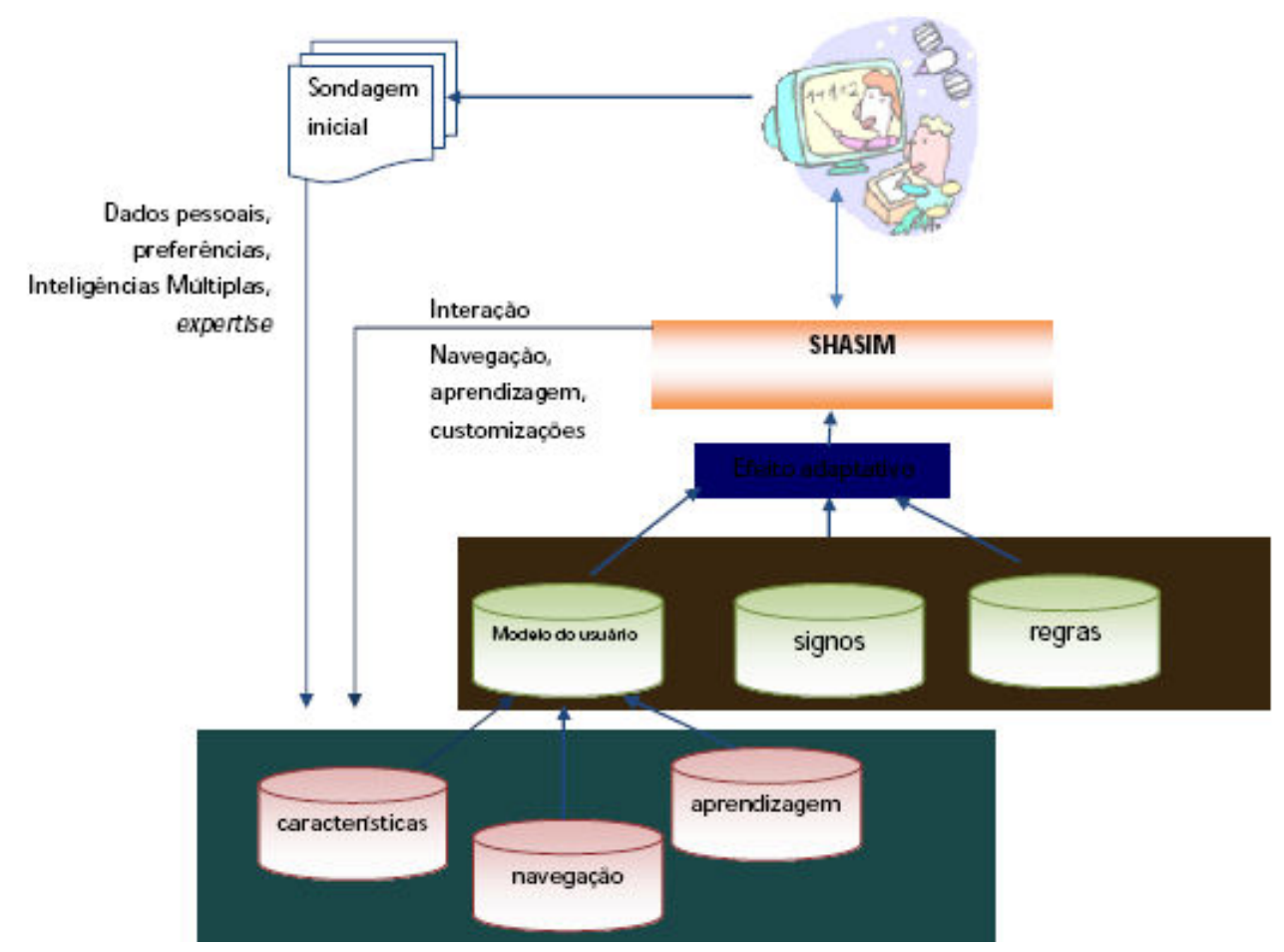

Figura 8 - Visão Geral do SHASIM - extraída de Puga (2008, p. 101) 
A arquitetura do SHASIM está baseada no modelo Munich, que sofreu modificações para atender às peculiaridades do domínio educacional. Foi acrescido ao modelo Munich o Subsistema de Signos, cujo objetivo é permitir a configuração da interface humano-computador (IHC), que será apresentada ao aluno (PUGA, 2008). Na Figura 9 é apresentado esse modelo.

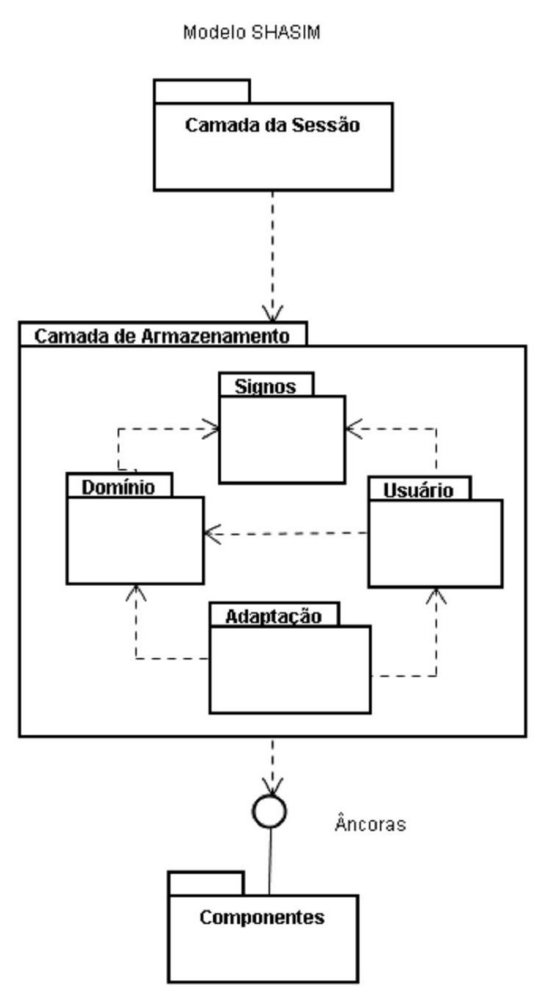

Figura 9 - Arquitetura do modelo SHASIM (PUGA, 2008, p. 103)

A Camada de Sessão é responsável pelo gerenciamento da conexão entre o usuário e o servidor da aplicação. Uma sessão é iniciada quando o usuário acessa o SHASIM e a sua autenticação (Run-rime layer).

A Camada de Armazenamento, que corresponde ao nível Storage Layer do Modelo Munich, foi dividida nos principais subsistemas:

- O Modelo do Usuário - ou MU - mantém armazenados e atualizados os dados sobre as características do usuário (no caso, o aluno), suas preferências, conhecimentos sobre o domínio, necessidades especiais e alguns dados pessoais;

- O Modelo do Domínio - contempla dados sobre os cursos e os planos de estudos estabelecidos para alunos de uma disciplina ou curso; 
- O Modelo de Adaptação - é responsável pelas regras que mantém os dados do Modelo do Usuário atualizados e pelas regras que direcionam a seleção dos signos para configuração da interface humano-computador do aluno;

- O Modelo de Signos - é responsável pela manutenção, seleção e composição dos signos que serão utilizados para realizar o efeito adaptativo. Este sistema substitui a Interface de Especificação de Apresentação (Presentation Specification Interface) do modelo Munich, sendo ele responsável pela configuração da interface.

A Camada de Componentes é responsável pela estrutura dos componentes que serão utilizados na interface, mas não é alvo de especificação da arquitetura.

A Camada de Armazenamento do SHASIM está representada na Figura 10, onde está ilustrada de maneira simplificada a relação entre as camadas. 


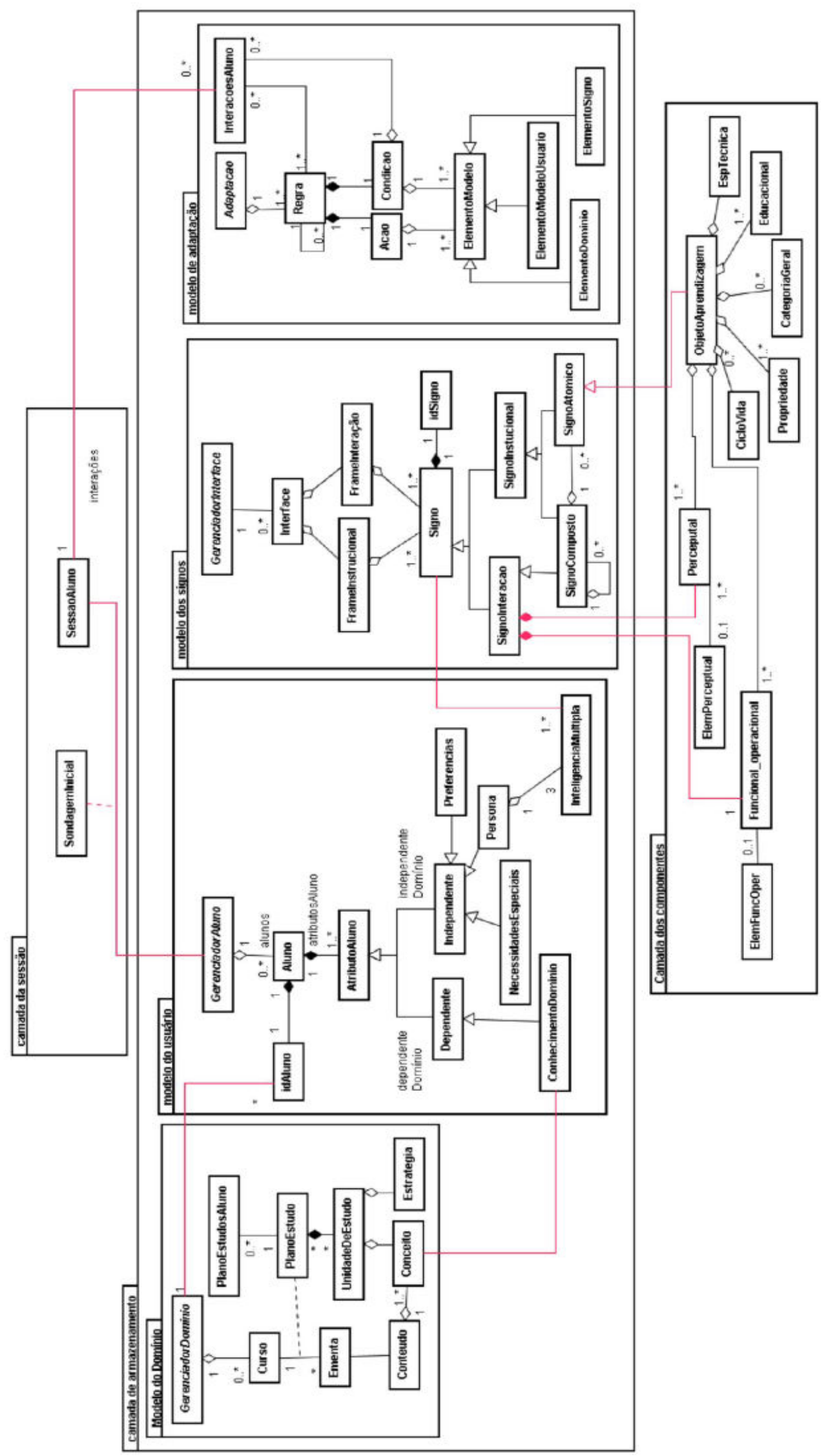

Figura 10 - Modelo SHASIM - Visão geral (PUGA, 2008, p. 105 


\subsection{CONSIDERAÇÕES FINAIS}

Neste capítulo, foram apresentados os principais conceitos e terminologias utilizados no campo da hipermídia adaptativa. É comum a confusão que se faz em relação a sistemas adaptáveis e adaptativos e a diferenciação dos termos é necessária para o entendimento da proposta do trabalho.

Foram introduzidos os modelos mais relevantes na área de hipermídia adaptativa. O modelo Dexter, apesar de não possuir a característica adaptativa, foi a base para as propostas posteriores com seu modelo de três camadas. Os modelos AHAM e Munich apresentam similaridades como a decomposição da Camada de Armazenamento em Modelos de Usuário, Domínio e Adaptação. A diferenciação ocorre na forma como é estruturada a Camada de Adaptação, enquanto no AHAM as regras e o mecanismo de adaptação são elementos separados, no Munich os dados e o comportamento são modelados por classes, pois adota uma abordagem orientada a objetos.

O modelo SHASIM é derivado do modelo Munich, ao qual se acrescentou o tipo de inteligência do aluno, para a modelagem do usuário, e o Modelo de Signos, para composição da interface de acordo com o perfil do usuário. 


\section{ARQUITETURA DE SOFTWARE}

O objetivo deste capítulo é mostrar as variações em torno da definição do termo "arquitetura de software" e destacar a importância de se considerar a arquitetura no processo de desenvolvimento de um sistema.

A representação da arquitetura deve seguir regras e convenções, que podem ser encontradas na norma ISO/IEC 42010 (2007). São descritos também os modelos de arquitetura de software mais relevantes, que servirão de base para a arquitetura do sistema SHASIM.

Referências à arquitetura de software são utilizadas com muita freqüência na área de software e frequentemente assume-se que o seu significado é totalmente compreendido. Entretanto, não existe uma definição totalmente aceita de arquitetura de software (KRUCHTEN, 2001).

Os pesquisadores Mary Shawn e David Garlan, da Universidade Carnegie, foram os primeiros a tratar a arquitetura de software como uma disciplina. Shawn e Garlan (1996) dizem que a arquitetura de software define o que o sistema é em termos de componentes computacionais e os relacionamentos entre estes componentes. Já, segundo Bass, Clements, Kazman (2003), a arquitetura de software de um sistema computacional são a estrutura ou estruturas do sistema, que incluem elementos de software, as propriedades visíveis externamente daqueles elementos e os relacionamentos entre eles.

Uma definição, muito comum, de que arquitetura é um projeto (design) de alto nível pode induzir a conclusões erradas. Arquitetura é um aspecto do projeto, focando-se nos elementos estruturalmente mais importantes, mas também naqueles que causam mais impacto no desempenho, confiabilidade, custo e adaptabilidade do sistema. Arquitetura é a escolha de um conjunto de mecanismos, padrões e estilos que permearão pelo restante do projeto e concederão integridade a este (KRUCHTEN, 2001). Algumas tarefas associadas ao projeto, tais como a escolha do encapsulamento de importantes estruturas de dados, não são questões arquiteturais. Entretanto, a interface entre as estruturas de dados pode ser considerada uma decisão arquitetural (BASS; CLEMENTS; KAZMAN, 2003). 
Kruchten (2001) diz que a arquitetura não se restringe somente à infra-estrutura ou tecnologia. A infra-estrutura e a tecnologia são partes importantes da arquitetura, mas não se deve ficar restrito somente às escolhas da plataforma, sistema operacional, banco de dados ou servidor de aplicação. A equipe de arquitetura que ignorar o domínio do problema e o sistema como um todo, incluindo todas as aplicações, pode acabar construindo a infra-estrutura errada para o problema em questão.

A dificuldade de se encontrar uma definição única para "arquitetura de software" está no fato de que a arquitetura é um modelo multidimensional composto por diversas visões para o mesmo sistema, conforme descrito na norma ISO/IEC 42010 (2007). A arquitetura não pode se restringir somente aos elementos computacionais, suas funções e relacionamentos, como definem Shawn e Garlan (1996) e Bass, Clements, Kazman (2003). A arquitetura de software é uma representação do sistema de software composto por visões, de maneira que todos os atributos de qualidade requeridos e todas as restrições impostas pelo ambiente e pelos stakeholders estejam representados.

\subsection{A IMPORTÂNCIA DA ARQUITETURA DE SOFTWARE}

Nesta seção, descrevem-se os principais fatores que reforçam a importância da arquitetura de software.

\subsubsection{Arquitetura como um Meio de Comunicação entre os Participantes}

Cada participante de um sistema de software está interessado em diferentes aspectos do sistema que são afetados pela arquitetura. Por exemplo, o usuário pode estar preocupado que o sistema seja confiável e esteja disponível quando necessário, enquanto que o cliente do projeto pode estar preocupado que a arquitetura seja implementada conforme o planejado e dentro do orçamento previsto. 
A arquitetura fornece uma linguagem comum em que diferentes preocupações podem ser expressas, negociadas e resolvidas em um nível que é gerenciável, mesmo para sistemas complexos (BASS; CLEMENTS; KAZMAN, 2003).

O uso preciso da arquitetura como um veículo de comunicação depende de quais stakeholders estão envolvidos. Alguns exemplos de uso estão descritos no Quadro1. 
Quadro1 - Stakeholders e as necessidades de comunicação atendidas pela arquitetura

\begin{tabular}{|l|l|}
\hline \multicolumn{1}{|c|}{ Stakeholder } & \multicolumn{1}{|c|}{ Uso } \\
\hline $\begin{array}{l}\text { Arquiteto e engenheiros de } \\
\text { requisitos }\end{array}$ & Um fórum para negociar requisitos conflitantes. \\
\hline $\begin{array}{l}\text { Arquiteto e projetistas de } \\
\text { componentes do sistema }\end{array}$ & $\begin{array}{l}\text { Resolver questões de consumo de recursos, } \\
\text { desempenho etc. }\end{array}$ \\
\hline Desenvolvedores & $\begin{array}{l}\text { Fornecer restrições e orientações para as atividades } \\
\text { de desenvolvimento. }\end{array}$ \\
\hline Testadores e integradores & $\begin{array}{l}\text { Especificar o comportamento correto de "caixa-preta" } \\
\text { das peças que devem se integrar corretamente. }\end{array}$ \\
\hline Mantenedores & $\begin{array}{l}\text { Um ponto de partida para as atividades de } \\
\text { manutenção, revelando como uma mudança pode } \\
\text { afetar o sistema. }\end{array}$ \\
\hline $\begin{array}{l}\text { Projetistas de outros } \\
\text { sistemas externos }\end{array}$ & $\begin{array}{l}\text { Definir um conjunto de operações fornecidas e } \\
\text { requeridas e os protocolos para estas operações. }\end{array}$ \\
\hline Gerentes & $\begin{array}{l}\text { Uma base para formar as equipes de } \\
\text { desenvolvimento de acordo com as alocações de } \\
\text { tarefas identificadas, WBS (Work Breakdown } \\
\text { Structure), planejamento e acompanhamento do } \\
\text { progresso das equipes. }\end{array}$ \\
\hline $\begin{array}{l}\text { Gerentes de linha de } \\
\text { produtos }\end{array}$ & $\begin{array}{l}\text { Determinar se um potencial novo membro da linha de } \\
\text { produto está ou não por dentro do seu escopo, e se } \\
\text { estiver por fora, de quanto é o seu desvio. }\end{array}$ \\
\hline $\begin{array}{l}\text { Equipe de Garantia da } \\
\text { Qualidade }\end{array}$ & $\begin{array}{l}\text { Base para checagem de conformidade, para garantir } \\
\text { que as implementações respeitaram as prescrições } \\
\text { arquiteturais. }\end{array}$ \\
\hline
\end{tabular}

\subsubsection{Arquitetura como Forma de Antecipação de Decisões de Projeto}

A arquitetura define restrições técnicas e funcionais sobre a implementação, o que permite a antecipação na alocação de capacidades pessoais e computacionais. A arquitetura também inclui a decomposição de alto nível do sistema, tornando-a uma referência para o planejamento das demais atividades do projeto.

A propriedade do sistema em manifestar um atributo de qualidade desejado é também influenciada pela sua arquitetura. Entretanto, para garantir a qualidade do sistema, uma arquitetura adequada não é suficiente, pois qualidade depende do processo de desenvolvimento ao longo de todo o ciclo de vida, desde o planejamento inicial até a construção do produto final. 
Em sistemas de software típicos, cerca de $80 \%$ do custo do sistema ocorre após a implantação inicial (BASS; CLEMENTS; KAZMAN, 2003), ou seja, após a liberação do produto. A arquitetura pode ser utilizada como um meio para avaliação do impacto que uma mudança pode ocasionar, os riscos envolvidos e a melhor estratégia a ser adotada.

As estimativas de custo e esforço de um projeto são essenciais para o seu planejamento. Estimativas baseadas no entendimento dos módulos do sistema são inerentemente mais precisas que aquelas baseadas no conhecimento geral do sistema (BASS; CLEMENTS; KAZMAN, 2003). A arquitetura fornece a organização estrutural do sistema e seus requisitos, fornecendo subsídios para tornar as estimativas mais próximas da realidade.

\subsubsection{Arquitetura como um Modelo Reutilizável}

O reuso é uma característica desejável em um sistema, pois traz benefícios em termos de tempo e custo de desenvolvimento do sistema. O reuso de arquitetura torna as Linhas de Produto de Software (Software Product Lines) viáveis, em que uma mesma arquitetura central pode ser compartilhada por todos os membros de uma mesma família de produtos.

Um aspecto chave da arquitetura que favorece o reuso de elementos de software é sua organização baseada em estrutura de elementos, interfaces e conceitos operacionais. Esta decomposição em abstrações bem delimitadas torna os elementos estruturais intercambiáveis. 


\subsection{CONCEITOS EM ARQUITETURA DE SOFTWARE}

Segundo Bass, Clements e Kazman (2003), existem alguns conceitos relacionados à arquitetura de software, utilizados com freqüência, mas que podem ser confundidos com a definição de arquitetura. São eles:

- Modelo de Referência - É uma divisão de funcionalidade em elementos, juntamente com o fluxo de dados entre eles. Um modelo de referência é uma decomposição de um problema conhecido em partes que cooperam entre si para resolver um determinado problema. Por exemplo, conhecemos as partes de um compilador ou um gerenciador de banco de dados e como elas se interagem porque temos conhecimento do modelo de referência destas aplicações.

- Estilo ou Padrão de Arquitetura - Descrição de elementos e seus relacionamentos juntamente com um conjunto de restrições de como podem ser usados. Por exemplo, cliente-servidor é um padrão arquitetural em que o cliente e o servidor são dois tipos de elementos cuja coordenação é descrita pelo protocolo que o servidor utiliza para se comunicar com cada um dos clientes. Inúmeras arquiteturas são implementadas seguindo o padrão cliente-servidor, entretanto são diferentes umas das outras. Um padrão arquitetural não é uma arquitetura, mas uma forma de mostrar como as decisões arquiteturais são influenciadas pelos atributos de qualidade do sistema. Alguns padrões representam soluções conhecidas para problemas de desempenho, segurança ou alta disponibilidade. $\mathrm{O}$ termo estilo arquitetural tem sido amplamente usado para descrever o mesmo conceito.

- Arquitetura de Referência - É um modelo de referência mapeado em elementos de software, que cooperativamente implementam a funcionalidade definida no modelo de referência. Enquanto o modelo de referência divide a funcionalidade, uma arquitetura de referência é o mapeamento daquela funcionalidade em uma decomposição de sistema.

Modelos de referência, padrões de arquitetura e arquiteturas de referência não são arquiteturas, mas sim conceitos úteis que capturam elementos de uma arquitetura. $\mathrm{O}$ relacionamento entre estes elementos é mostrado na Figura 11. 


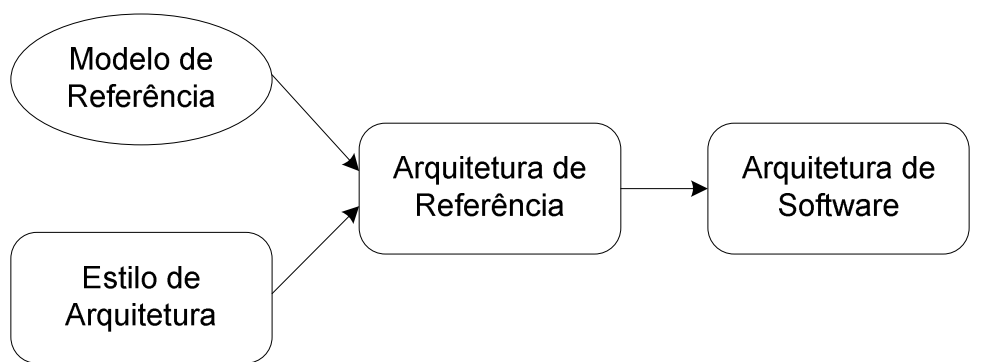

Figura 11 - Relacionamento entre modelo de referência, estilo de arquitetura, arquitetura de referência e a arquitetura de software (BASS; CLEMENTS; KAZMAN, 2003)

A fim de ilustrar os conceitos de arquitetura apresentados, é utilizado a Modelo de Referência Munich (KOCH, 2000).

O Modelo de Referência Munich $(\mathrm{KOCH}, 2000)$ descreve um Sistema Hipermídia Adaptativo como uma composição de elementos funcionais e seus relacionamentos. O modelo não define a utilização de nenhum padrão arquitetural, ou seja, poderia ser implementado de forma monolítica ou utilizar qualquer outro estilo, como, por exemplo, a arquitetura cliente-servidor. Este mapeamento dos elementos funcionais do Modelo de Referência em elementos arquiteturais, representados na Figura 11 pelo Estilo de Arquitetura, definirá uma Arquitetura de Referência.

Uma Arquitetura de Referência não necessariamente precisa considerar todos os requisitos do sistema, nem precisa especificar todas as tecnologias, componentes e seus relacionamentos em um nível de detalhe capaz de permitir o projeto do sistema. Esta função cabe à arquitetura concreta do sistema (ESTEFAN et al., 2008), representada na Figura 11 pelo bloco Arquitetura de Software. A Figura 12 mostra um exemplo de como os assuntos referentes à arquitetura se relacionam no caso da Arquitetura Orientada a Serviço (Service Oriented Architecture - SOA). A Arquitetura Orientada a Serviço é apenas citada neste trabalho para ilustrar os conceitos descritos neste capítulo e não será utilizada na arquitetura de SHA. 


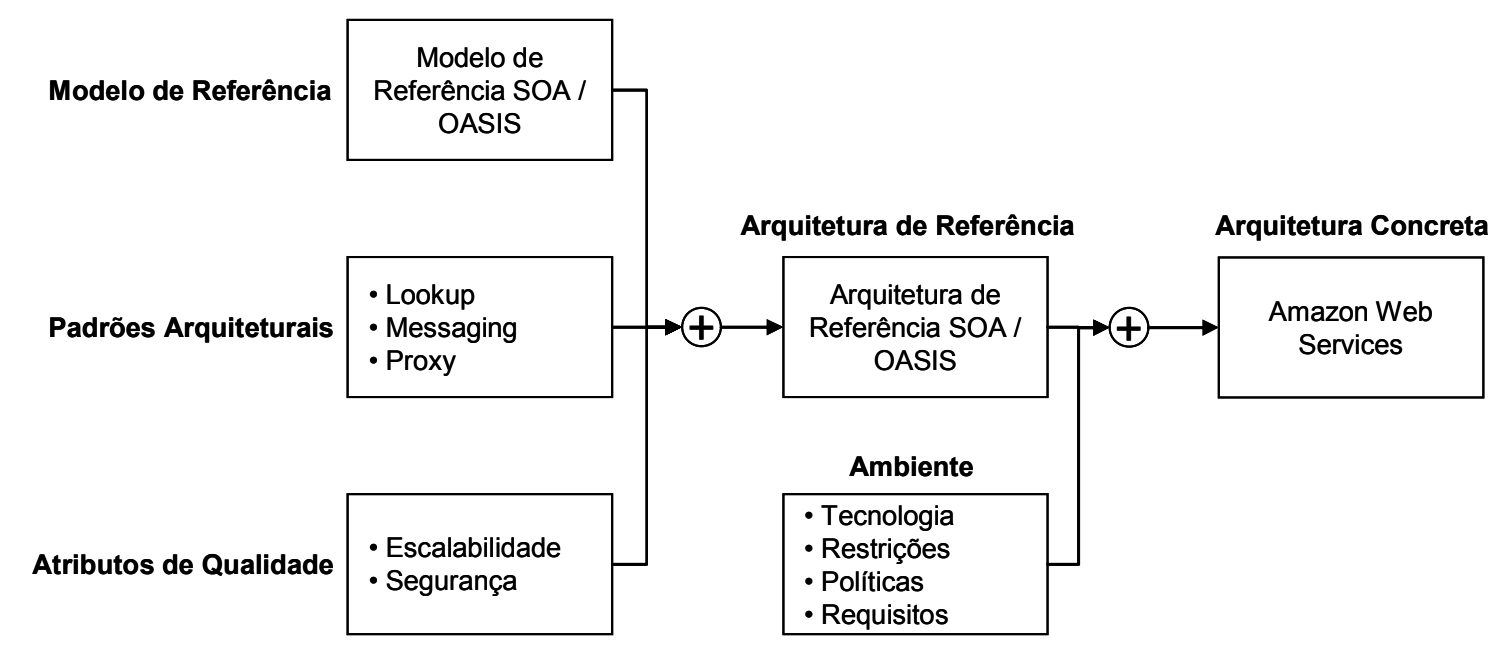

Figura 12 - Exemplo de relacionamento entre modelo de referência, estilo de arquitetura, arquitetura de referência e a arquitetura de software no caso de SOA

SOA é um paradigma para a organização e utilização de capacidades distribuídas na forma de serviços que podem estar sob controle de diferentes domínios (MACKENZIE et al., 2006). O Modelo de Referência SOA (MACKENZIE et al., 2006) identifica as principais características e motivações de SOA, bem como a definição e interação das contrapartes que fazem parte do modelo (provedor e consumidor do serviço). No Modelo de Referência o serviço é definido como um mecanismo que permite o acesso a uma ou mais capacidades e é acessível através de uma interface com regras e políticas especificadas. SOA é tratado no maior nível de abstração, não havendo detalhamento dos módulos que formam um serviço, nem de suas características de qualidade.

A Arquitetura de Referência SOA (ESTEFAN et al., 2008) proporciona maior detalhamento funcional ao Modelo de Referência, mostrando o que está envolvido na realização das entidades do modelo. Na Arquitetura de Referência, a composição e interação entre os três principais participantes - consumidor, mediador e provedor - é formalizada. Para a realização de alguns mecanismos da arquitetura, são utilizados padrões arquiteturais conhecidos. A comunicação entre os participantes do modelo é baseada em troca de mensagens (padrão messaging, segundo Buschmann, Henney e Schmidt (2007), o que facilita a integração em um ambiente distribuído. O mediador é o elemento que se situa entre o consumidor e o provedor do serviço. Uma de suas funções é a de oferecer a facilidade de registro e busca por um serviço (padrão lookup, segundo Buschmann, Henney e Schmidt (2007). Além disso, o mediador pode servir como um elemento representativo de uma das 
contrapartes, funcionando como um proxy (padrão Proxy, segundo Buschmann, Henney e Schmidt (2007). Um proxy do lado do consumidor, por exemplo, funciona como um elemento que representa o serviço requisitado. O proxy, neste caso, é responsável por tratar dos detalhes de busca do serviço e da comunicação entre o consumidor e provedor. A Arquitetura de Referência SOA também preocupa-se com a questão da qualidade do sistema; escalabilidade e segurança são algumas das questões tratadas. A composição do Modelo de Referência SOA, de Padrões Arquiteturais e Atributos de Qualidade conduz a Arquitetura de Referência SOA, conforme mostrado na Figura 12.

A Arquitetura de Referência modela os elementos arquiteturais abstratos do domínio, independentemente da tecnologia, protocolos ou produtos necessários para a implementação da arquitetura. A arquitetura de Web Services da Amazon ${ }^{1}$ é um exemplo de arquitetura concreta baseada em SOA. A Arquitetura de Referência SOA representa o pilar da arquitetura de Web Services da Amazon. Entretanto, elementos específicos do ambiente tais como a tecnologia utilizada (Web Service), a forma de uso (restrições e políticas), as funcionalidades e a qualidade dos serviços (requisitos) são considerados na criação da arquitetura final do sistema.

\subsection{DESCRIÇÃO DE ARQUITETURA DE SOFTWARE}

O objetivo deste capítulo é mostrar as formas de se descrever uma arquitetura de software, com base em visões arquiteturais. A arquitetura de um sistema é um modelo multidimensional, em que cada visão pode atender às necessidades de um ou mais participantes (stakeholder). Neste capítulo são apresentados os modelos de visões mais relevantes como a visão "4+1" (KRUCHTEN, 1995), os pontos de vista RM-ODP (ISO/IEC-10476, 1995) e as propostas de Bass, Clements e Kazman (2003) e de Hofmeister, Nord e Soni (2000).

\footnotetext{
${ }^{1}$ http://aws.amazon.com/
} 


\subsubsection{Norma ISO/IEC 42010 (2007)}

A norma IEEE 1471 (2000) foi adotada como um padrão ISO em 2007 pelo comitê técnico ISO/IEC JTC, Information Technology, tornando-se o padrão ISO/IEC 42010 (2007).

Esta norma tem como propósito facilitar a expressão e comunicação de arquiteturas de software através da padronização de elementos e práticas para a descrição arquitetural. De acordo com os objetivos da norma ISO/IEC 42010 (2007), os seguintes termos e definições são aplicáveis:

- Descrição arquitetural (architectural description) - coleção de artefatos para documentar uma arquitetura;

- Arquitetura (architecture) - organização fundamental de um sistema, composta por seus componentes e relacionamentos, o ambiente e os princípios que direcionam o projeto e a evolução;

- Sistema (system) - coleção de componentes, organizados para realizar uma função específica ou um conjunto de funções;

- Participante do sistema (system stakeholder) - indivíduo, equipe ou organização com interesses relativos ao sistema;

- Visão (view) - representação do sistema como um todo, a partir da perspectiva relacionada a um conjunto de interesses;

- Ponto de vista (viewpoint) - especificação das convenções para construção e uso de uma visão. Um padrão ou template, a partir do qual se desenvolvem visões individuais através do estabelecimento de propósitos e interesses dos participantes e as técnicas para sua criação e análise.

A Figura 13 mostra o modelo conceitual da descrição arquitetural, seus elementos e relacionamentos. 


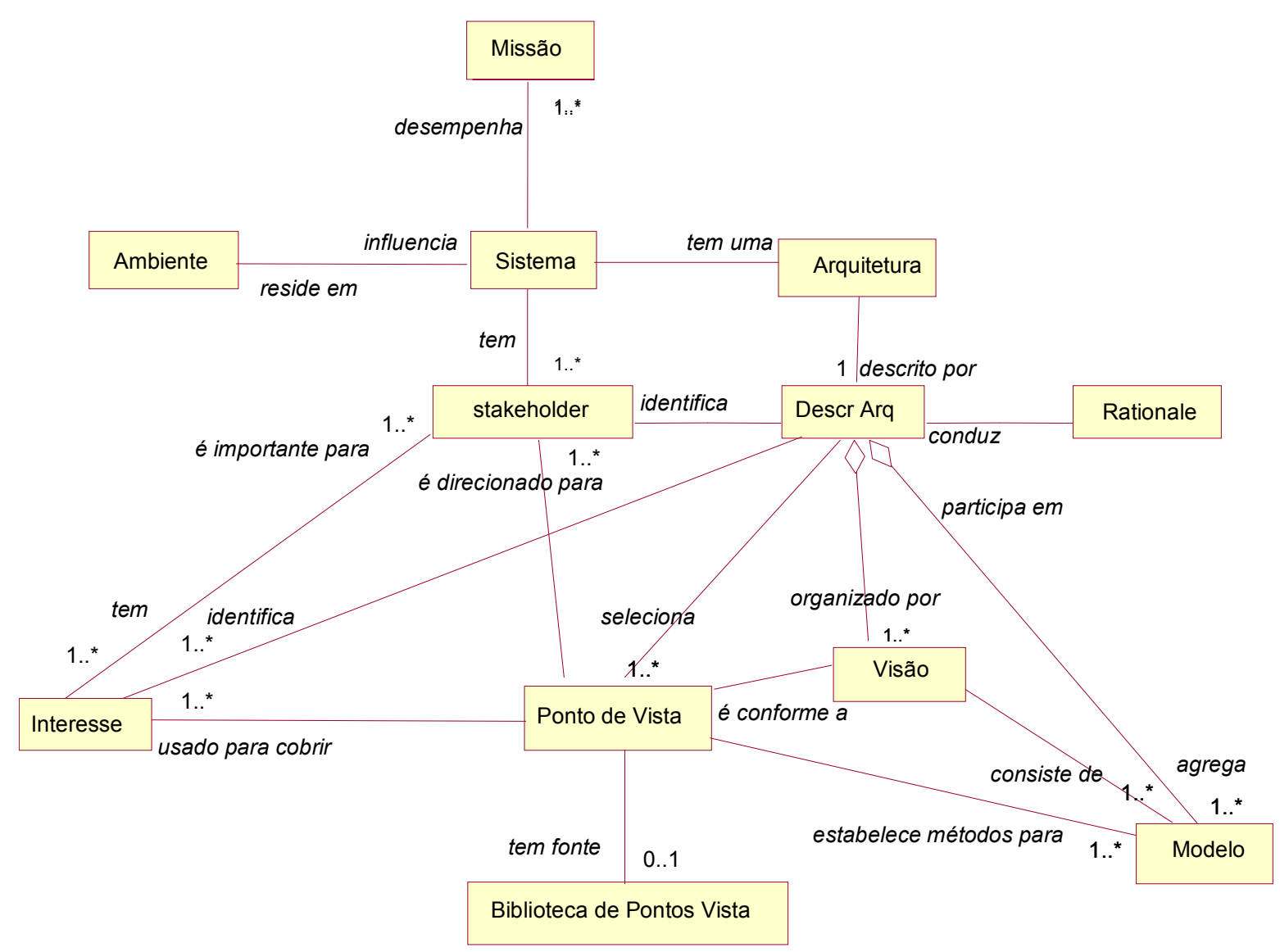

Figura 13 - Modelo conceitual da descrição de arquitetura (ISO/IEC 42010, 2007)

Uma descrição arquitetural (Descr Arq) é composta por um ou mais elementos chamados Visão. Uma visão é construída seguindo um ou mais modelos de arquitetura (Modelo) e consiste na representação do sistema como um todo a partir da perspectiva de um conjunto de interesses. O termo Visão é usado para expressar a arquitetura do sistema, em conformidade com um ponto de vista particular (Ponto de Vista). Este determina as linguagens (incluindo notações, modelos ou tipos de produto) a serem usados para descrever a Visão, e quaisquer métodos de modelagem ou técnicas de análise aplicadas nas representações arquiteturais. Um ponto de vista que for definido externamente ao sistema para reutilização é chamado Biblioteca de Pontos de Vista.

A descrição da arquitetura deve ser conduzida por um Rationale, definido como um conjunto de diretrizes para a elaboração da arquitetura e identificação dos interesses (Interesse) dos participantes (stakeholder). 


\subsection{ABORDAGENS DE VISÕES EM ARQUITETURA DE SOFTWARE}

Um dos conceitos mais importantes associados à documentação de arquitetura de software é o de Visão (view). Uma arquitetura de software é uma entidade complexa que não pode ser descrita de forma unidimensional (CLEMENTS et al., 2003). Cada Visão representa um conjunto de aspectos importantes que representam parte da descrição completa de uma arquitetura de software. Isso pode ser visto claramente na Figura 13, onde a relação de agregação mostra que a descrição arquitetural (Descr Arq) agrega as várias visões (Visão), métodos de modelagem (Modelo), além de se relacionar com Pontos de Vista e Interesses.

Nas seções a seguir, são apresentadas algumas abordagens baseadas em visões relevantes na área de arquitetura de software. As abordagens diferenciam-se umas das outras pelo conjunto de pontos de vista que cada uma propõe.

\subsubsection{Arquitetura no Processo Unificado}

A visão "4+1" desenvolvida pela Rational Corporation (KRUCHTEN, 1995) foi criada como um modelo de arquitetura genérico que podia ser utilizado por diferentes métodos orientados a objetos tais como Booch (1994), Jacobson et al. (1992) e Rumbaugh et al. (1991) apud Matos (2005). Posteriormente unificados, esses métodos constituíram o núcleo do que hoje se conhece como Processo Unificado (UP) ou RUP (Rational Unified Process). Com o advento da UML como linguagem padrão para modelagem de software - e apoio ao UP -, Booch, Rumbaugh e Jacobson (2005) propõem modelos UML para descrição de cada uma das visões. A visão "4+1" faz parte do Processo Unificado, originalmente da Rational (Rational Unified Process - RUP) e hoje na IBM, como um modelo para representação da arquitetura (KRUCHTEN, 2003). 
Para a descrição de uma arquitetura de software é utilizado um modelo composto de cinco visões principais, conforme apresentado na Figura 14.

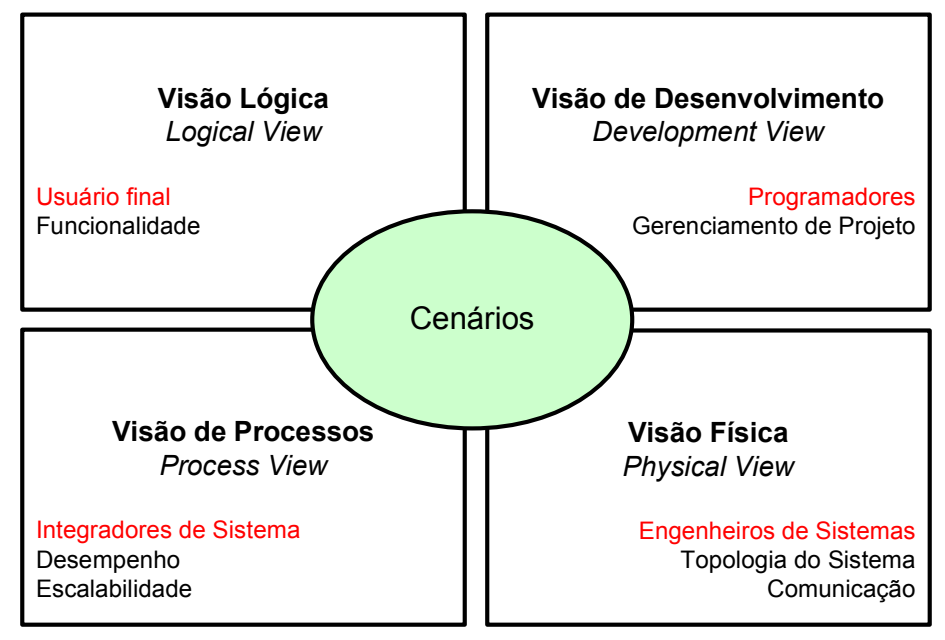

Figura 14 - Visão “4+1” (KRUCHTEN, 1995)

- Visão Lógica - visão voltada aos requisitos funcionais, ou seja, o que o sistema deve fornecer em termos de serviços aos seus usuários finais. O domínio do problema é decomposto em uma série de abstrações na forma de objetos e classes. Esta decomposição serve tanto para a análise funcional quanto para identificar mecanismos comuns e elementos de projeto ao longo das várias partes do sistema;

- Visão de Processos - visão que aborda alguns requisitos não funcionais, tais como desempenho e disponibilidade, considerando questões de concorrência, distribuição, integridade de sistema e tolerância a falhas;

- Visão de Desenvolvimento - descreve a organização estática do software código fonte, arquivos de dados, componentes, executáveis e outros artefatos que os acompanham - em seu ambiente de desenvolvimento;

- Visão Física - descreve o mapeamento do software no hardware e reflete aspectos de distribuição.

As decisões arquiteturais são descritas por estas quatro visões e organizadas em torno de um conjunto de casos de uso ou cenários, perfazendo o total de cinco visões (4+1). A visão de cenários auxilia na descoberta de elementos arquiteturais durante o projeto da arquitetura e na validação, depois que a arquitetura é completada. 
O fato das visões "4+1" precederem a norma ISO/IEC 42010 (2007), elas não estão de acordo com a definição de visão especificada pela norma. As visões "4+1" estão mais alinhadas com a definição de ponto de vista da ISO/IEC 42010 (2007) (GARLAND; ANTHONY, 2002). Visões são diferentes formas de documentar a arquitetura de um sistema específico enquanto que pontos de vista especificam as regras e convenções para a geração de visões de arquitetura.

\subsubsection{Pontos de Vista RM-ODP}

A norma RM-ODP ISO/IEC-10476 (1995) (Reference Model of Open Distributed Processing) foi um esforço conjunto dos padrões internacionais ISO e ITU-T para o desenvolvimento de um arcabouço (framework) para a padronização de processamento aberto e distribuído (Open Distributed Processing - ODP) (RAYMOND, 1995). O RM-ODP define propriedades importantes de sistemas distribuídos para que sejam abertos, integráveis, flexíveis, modulares, gerenciáveis, seguros e para fornecerem a qualidade de serviço desejável (GARLAND; ANTHONY, 2002).

Esta norma consiste de quatro partes e a terceira - ISO 10746-3 / ITU-T X.903 - é relativa à arquitetura, em que descreve um arcabouço de conceitos, estruturas, regras e funções requeridos para o processamento aberto e distribuído. A norma define um conjunto de pontos de vista, cuja definição corresponde à norma ISO/IEC 42010 (2007). Os cinco pontos de vista descritos pelo RM-ODP são:

- Ponto de Vista da Empresa - foca-se nos requisitos de negócio, escopo e restrições para o sistema; esta visão descreve o papel e as necessidades dos usuários do sistema, de forma a adequar os objetivos e políticas da organização aos requisitos do sistema;

- Ponto de Vista da Informação - foca-se na semântica e processamento da informação; modelos de informação e esquemas de banco de dados são geralmente definidos neste ponto de vista; 
- Ponto de Vista Computacional - visa permitir a distribuição dos elementos funcionais do sistema em objetos que interagem através de interfaces; uma especificação computacional define os objetos que fazem parte de um sistema ODP, as atividades definidas por estes objetos e as interações que podem ocorrer entre eles, especificadas pelas suas interfaces;

- Ponto de Vista da Engenharia - foca-se nos mecanismos e funções requeridas para suportar a interação distribuída entre objetos no sistema; por exemplo, a topologia de rede, os padrões de comunicação, diagramas de implantação para comunicação e infraestrutura de segurança são descritos neste ponto de vista;

- Ponto de Vista da Tecnologia - foca-se na escolha da tecnologia para o sistema, incluindo-se os recursos de hardware e software utilizados na implementação da aplicação.

O destaque de RM-ODP é que força os arquitetos a resolverem tanto as questões de alto nível, tais como processos e restrições, quanto questões de baixo nível que cercam as atividades de projeto, tais como: formatos de dados e objetos (EGYHAZY; MUKHERJI, 2004).

A Figura 15 mostra como os pontos de vista do RM-ODP podem ser utilizados nas diversas fases do ciclo de vida de um sistema ODP.

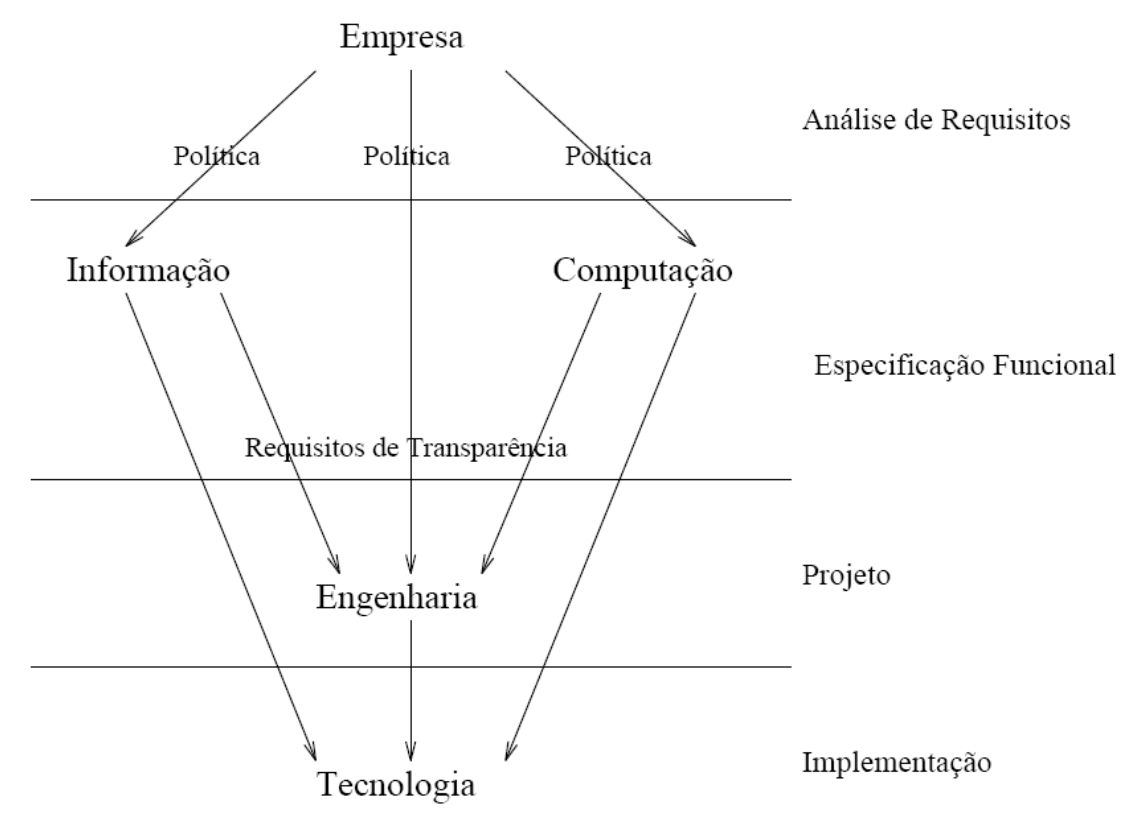

Figura 15 - Pontos de vista RM-ODP e ciclo de vida do sistema (RAYMOND, 1995) 
Por exemplo, o Ponto de Vista da Empresa leva à análise dos requisitos e políticas do sistema; os Pontos de Vista de Informação e Computacional fornecem documentos válidos para a fase de especificação funcional tais como: a especificação dos requisitos da informação, modelos de interação e construção. $O$ Ponto de Vista de Engenharia permite a especificação das funções de processamento, armazenamento e comunicação necessárias à implementação do sistema. Finalmente, através do Ponto de Vista da Tecnologia deverão ser formulados requisitos de implementação e identificadas as tecnologias a serem usadas.

\subsubsection{Outras Abordagens de Visões Arquiteturais}

As visões " $4+1$ " e os pontos de vista RM-ODP são os esquemas de visões de arquitetura mais conhecidos atualmente. Existem também outras abordagens menos difundidas, como o modelo de Bass, Clements e Kazman (2003) e a abordagem segundo Hofmeister, Nord e Soni (2000), que em alguns casos possuem similaridades com as visões apresentadas.

\subsubsection{Arquitetura de Software Segundo Bass, Clements e Kazman (2003)}

Segundo Bass, Clements e Kazman (2003), as visões arquiteturais são conceitos fundamentais para a documentação da arquitetura de software. No entanto, não se restringem a uma coleção particular de visões como em outros modelos. Os atributos de qualidade de maior interesse para os stakeholders definirão a escolha das visões.

Apesar de não se restringir a um conjunto limitado de visões, Bass, Clements e Kazman (2003) classificam as visões em três grupos: módulos, componentes e conectores e alocação. 
- Visões de Módulos - apresenta os módulos que compõem o sistema, as responsabilidades funcionais de cada um e os relacionamentos com outros módulos ou elementos de software. Neste contexto, a visão de módulos possui função similar a visão de lógica do esquema "4+1". Na visão de módulo, este é definido como uma unidade de implementação em nível de código fonte.

- Visões de Componentes e Conectores - representa os elementos como componentes em tempo de execução e seus conectores. Trata de aspectos dinâmicos do sistema, tais como paralelismo, concorrência e replicação. Esta visão corresponde à visão de processos do esquema " $4+1$ ".

- Visões de Alocação - descreve a alocação dos elementos de software nos ambientes de execução e desenvolvimento. Esta visão corresponde à visão física do esquema " $4+1$ ".

\subsubsection{Arquitetura de Software Segundo Hofmeister, Nord e Soni (2000)}

A proposta de Hofmeister, Nord e Soni (2000) utiliza quatro visões definidas como:

- Visão Conceitual - representa os principais elementos do sistema e o relacionamento entre eles.

- Visão de Módulo - apresenta os módulos do sistema particionados em camadas; esta decomposição facilita o tratamento da complexidade do sistema e permite uma melhor distribuição de trabalho entre os desenvolvedores.

- Visão de Execução - descreve como os módulos são mapeados em elementos do sistema em tempo de execução e trata de questões relacionadas à comunicação, coordenação e sincronismo entre os componentes.

- Visão de Código - descreve a organização do código fonte em código objeto, bibliotecas e arquivos binários, que depois serão agrupados segundo a versão, arquivos e diretórios. 


\subsection{CONSIDERAÇÕES FINAIS}

Neste capítulo, foram apresentados os principais conceitos envolvendo arquitetura de software. Nos últimos anos, a arquitetura de software destacou-se como uma disciplina na área de engenharia de software, mas a sua importância nem sempre é bem compreendida. O uso mais conhecido da arquitetura de software é o de representar uma abstração de alto nível do software, servindo de base para o projeto do sistema. Entretanto, conforme exposto no capítulo, a arquitetura de software serve a outros propósitos.

Os conceitos de padrões de arquitetura, modelo de referência e arquitetura de referência foram definidos para que se tornasse clara a distinção com a arquitetura de software. Estes conceitos, quando considerados isoladamente, não representam a arquitetura de um sistema. Entretanto, a partir de uma arquitetura de referência, pode-se chegar à arquitetura de software quando considerados também os atributos de qualidade do software.

A norma ISO/IEC 42010 (2007) mostra os elementos que compõem a documentação da arquitetura e os fatores que influenciam na sua composição. A norma ISO/IEC 42010 (2007) é amplamente aceita como padronização de descrição de arquitetura de software e será utilizada para a documentação da arquitetura do sistema SHASIM.

No capítulo, foram apresentados os arcabouços de arquitetura de software mais relevantes, juntamente com um conjunto de pontos de vista propostos. Como precedem a norma ISO/IEC 42010 (2007), os conceitos de visão nos modelos "4+1" (KRUCHTEN, 1995) e no modelo de Hofmeister, Nord e Soni (2000) não estão em conformidade com a definição apresentada. O termo Visão apresentado nestes modelos se aproxima da definição de Ponto de Vista na norma, pois descreve o propósito e a forma de representação da arquitetura sob um determinado aspecto. 


\section{ATRIBUTOS DE QUALIDADE DE SISTEMAS HIPERMÍDIA ADAPTATIVOS}

O objetivo deste capítulo é apresentar os principais atributos de qualidade requiridos para Sistemas Hipermídia Adaptativos. As características de qualidade discutidas neste capítulo servirão de base para a construção da arquitetura do Sistema Hipermídia Adaptativo SHASIM. A base desse estudo é a norma ISO/IEC 9126 e com base nesse modelo selecionam-se os elementos a serem usados na dissertação.

\subsection{MODELO DE QUALIDADE DE PRODUTO DA NORMA ISO/IEC-9126}

A ISO/IEC 9126 é uma norma internacional amplamente aceita para a padronização das características de qualidade de software (MATOS, 2005) e consiste de quatro partes:

- Parte 1: Modelo de Qualidade;

- Parte 2: Métricas Externas;

- Parte 3: Métricas Internas;

- Parte 4: Métricas de Qualidade em Uso.

A primeira parte da norma ISO/IEC 9126-1 (2001) descreve o Modelo de Qualidade do produto de software, enquanto que as outras partes descrevem as métricas definidas para mensurar a qualidade.

O Modelo de Qualidade é dividido em duas partes: a) qualidade interna e externa, e b) qualidade em uso. A qualidade do produto de software pode ser avaliada medindo-se os atributos internos (tipicamente as medidas estáticas dos produtos intermediários do ciclo de vida de desenvolvimento), os atributos externos (tipicamente as medidas de comportamento do software quando executado) ou os atributos de qualidade do software em uso, segundo a perspectiva do usuário. 
O modelo de qualidade para a qualidade interna e externa é categorizado em seis características e suas respectivas sub-características, conforme mostra a Figura 16.

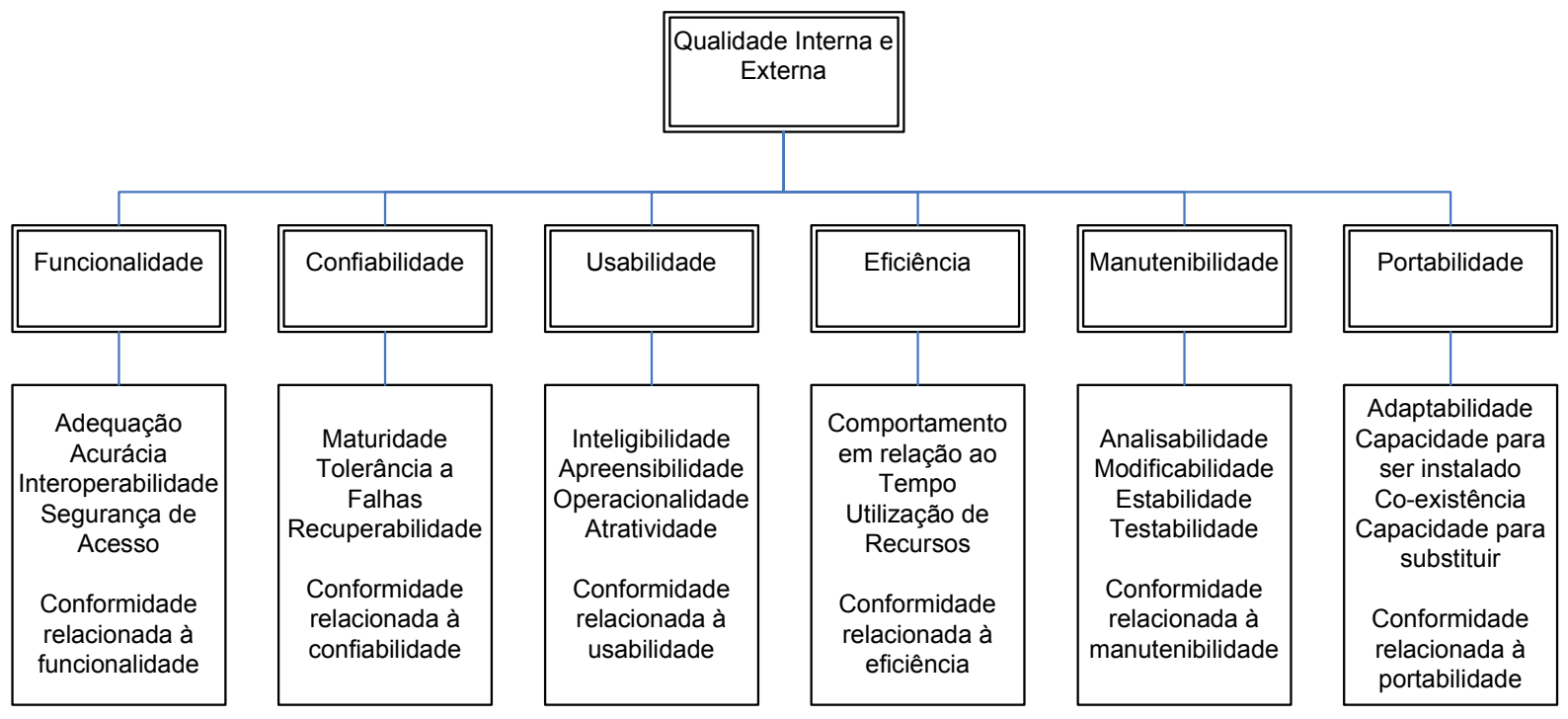

Figura 16 - Modelo de qualidade para qualidade interna e externa (ISO/IEC 9126-1, 2001)

Descrevem-se a seguir essas seis dimensões.

1. Funcionalidade (Functionality) - é a capacidade do software em fornecer funções que satisfaçam as necessidades do usuário em condições de uso específicas. Ela se caracteriza pelos seguintes aspectos:

- Adequação (suitability): evidencia a capacidade do software em fornecer um conjunto apropriado de funções capazes de realizar tarefas e objetivos específicos ao usuário;

- Acurácia (accuracy): característica do software em fornecer os resultados esperados com o grau de precisão necessário;

- Interoperabilidade (interoperability): indica a capacidade do software em interagir com um ou mais sistemas especificados;

- Segurança de acesso (security): confere ao software a capacidade de proteger os dados e informações de acessos não autorizados por parte de indivíduos ou sistemas e, também, de garantir acesso a pessoas ou sistemas autorizados;

- Conformidade relacionada à funcionalidade (compliance): atributos que evidenciam a aderência do software a padrões, convenções, leis regulatórias ou restrições similares, relacionadas à sua funcionalidade. 
2. Confiabilidade (Reliability) - evidencia a capacidade do software em manter um nível de desempenho especificado, quando usado sob condições específicas. Ela se caracteriza pelos seguintes aspectos:

- Maturidade (maturity): qualidade do software em não apresentar falhas como resultado de erros de desenvolvimento;

- Tolerância a Falhas (fault tolerance) - capacidade do software em manter um nível de desempenho especificado em casos de falhas ou infrações de suas interfaces;

- Recuperabilidade (recoverability): atributo que demonstra a capacidade do software em restabelecer um nível de desempenho especificado e de recuperar os dados diretamente afetados em caso de falha;

- Conformidade relacionada à confiabilidade (compliance) - qualidade do software em aderir aos padrões, convenções e regulamentações referentes à confiabilidade.

3. Usabilidade - é a capacidade do software em ser compreendido, aprendido, utilizado e mostrar-se atrativo para o usuário, quando usado sob condições especificadas. Ela se caracteriza pelos seguintes aspectos:

- Inteligibilidade (understandability): capacidade do software em permitir que o usuário compreenda se é adequado às suas necessidades, como pode ser usado em tarefas particulares e em que condições de uso;

- Apreensibilidade (learnability): qualidade do software em permitir que o usuário aprenda sua aplicação;

- Operacionalidade (operability): capacidade do software em permitir que o usuário o controle e o opere;

- Atratividade (attractiveness): capacidade do software de ser atrativo para o usuário;

- Conformidade relacionada à usabilidade (compliance): característica do software de ser aderente a padrões, convenções, guias de estilo e regulamentações relacionadas à usabilidade. 
4. Eficiência (Efficiency) - é a capacidade do software em fornecer o desempenho apropriado em relação à quantidade de recursos utilizados e sob condições específicas. Caracteriza-se pelos seguintes aspectos:

- Comportamento em relação ao tempo (time behaviour): qualidade do software em fornecer a resposta à uma solicitação com tempo e taxa de processamento adequados, sob condições de uso específicos;

- Utilização de Recursos (resource utilisation): capacidade do software em utilizar quantidades e tipos de recursos apropriados, quando o software executar suas funções sob condições de uso específicos;

- Conformidade relacionada à eficiência (compliance): característica do software ser aderente a padrões ou convenções relacionadas à eficiência.

5. Manutenibilidade - é a capacidade do software de ser modificado. Modificações incluem correções, melhorias ou adaptação do software a mudanças no ambiente ou em requisitos funcionais.

- Analisabilidade (analysability): qualidade que permite que o software seja diagnosticado no que diz respeito a deficiências ou causas de falhas, identificando-se que partes devem ser modificadas;

- Modificabilidade (changeability): é a capacidade do software em permitir que uma modificação seja implementada.

- Estabilidade (stability): é a capacidade do software em evitar efeitos inesperados decorrentes de modificações no software.

- Testabilidade (testability): é a capacidade do software em permitir que, após uma alteração, o software modificado seja validado;

- Conformidade relacionada à manutenibilidade (compliance): é a capacidade do software em aderir a padrões ou convenções relacionadas a manutenibilidade.

6. Portabilidade (Portability) - é a capacidade do software de ser transferido de um ambiente para outro. Ela inclui os seguintes aspectos: 
- Adaptabilidade (adaptability): é a característica do software em ser adaptado para diferentes ambientes, aplicando-se meios ou ações especificados para esse propósito;

- Capacidade para ser instalado (installability): é a capacidade do software de ser instalado em um ambiente especificado;

- Co-existência (co-existence): é a capacidade do software em co-existir com outros softwares independentes, compartilhando recursos em comum;

- Capacidade para substituir (replaceability): é a capacidade do software de ser usado em lugar de outro especificado para o mesmo propósito, no mesmo ambiente.

- Conformidade relacionada à portabilidade (compliance): é a qualidade do software em aderir a padrões ou convenções relacionadas à portabilidade.

A qualidade em uso é capacidade do produto de software de permitir que usuários especificados atinjam metas especificadas com eficácia, produtividade, segurança e satisfação em contextos de uso especificados. Os atributos de qualidade em uso são categorizados em quatro características: efetividade, produtividade, segurança e satisfação.

1. Eficácia (effectiveness): capacidade do software em permitir que os usuários alcancem os objetivos com acurácia e completude em um contexto de uso especificado.

2. Produtividade (productivity): capacidade do software em permitir que os usuários utilizem a quantidade apropriada de recursos em relação à produtividade alcançada em um contexto de uso específico.

3. Segurança (safety): capacidade do software em alcançar níveis aceitáveis de risco para pessoas, negócio, software, propriedade ou ambiente em um contexto de uso especificado.

4. Satisfação (satisfaction): capacidade do software em satisfazer os usuários em um contexto de uso especificado. 


\subsection{ATRIBUTOS DE QUALIDADE DE SISTEMAS HIPERMÍDIA ADAPTATIVOS}

Os principais representantes de sistemas adaptativos baseados na Web tais como 0 AHA (DE BRA; SMITS; STASH, 2006), o KBS-HYPERBOOK (FROHLICH; NEJDL; WOLPERS, 1998), o Interbook (BRUSILOVSKY; EKLUND; SCHWARZ, 1998) e o NetCoach (WEBER; KUHL; WEIBELZAHL, 2002), são empregados em sistemas educacionais e para informação. Entretanto, estes sistemas Web adaptativos citados ainda representam iniciativas de pesquisa, sem a preocupação de atingir todos os atributos de qualidade de uma aplicação Web comercial (BRUSILOVSKY; MAYBURY, 2002).

Idealmente, um sistema deveria possuir todos os atributos de qualidade descritos na norma ISO/IEC 9126, mas sabe-se que existem conflitos entre atributos, os quais devem ser negociados. Por exemplo, quando se introduz mecanismos de segurança em um sistema, aumenta-se a quantidade de verificações que devem ser efetuadas, o que degrada o seu desempenho.

Neste trabalho serão considerados os atributos Confiabilidade, Segurança de acesso (subcaracterística de funcionalidade), Usabilidade e Manutenibilidade na elaboração da arquitetura. Atributos fortemente ligados as condições de uso específicas de cada ambiente como Eficiência e Portabilidade, apesar de importantes, não serão foco neste trabalho, pois para isso seria necessário um projeto real de implementação do sistema, destinado ao levantamento de fatores limitantes adicionais.

A arquitetura de software é um fator chave para a realização dos atributos de qualidade de um sistema e estas qualidades devem ser projetadas e avaliadas no nível arquitetural. Para se alcançar os requisitos de qualidade desejados, devem ser considerados também ao longo das atividades de arquitetura, projeto e implementação do sistema (BASS; CLEMENTS; KAZMAN, 2003).

O sucesso comercial de muitos negócios na Web depende do sistema funcionar de forma confiável, ou seja, a característica de Confiabilidade descrita na norma ISO/IEC 9126-1 (2001) deve estar presente em sistemas desta natureza. Para se compreender a qualidade de confiabilidade, é necessário esclarecer as diferenças 
entre falhas, erros e disfunção. Quando o comportamento de um sistema se desvia daquele especificado, tem-se a ocorrência de um mau funcionamento ou disfunção, que se refere ao comportamento externo inadequado do sistema, comportamento esse resultante de problemas internos. Tais problemas internos são chamados de erros e são, por sua vez, causados por componentes ou módulos com falhas. A falha de um componente ou módulo é causada por problemas no software (ALMEIDA JR., 2003).

A qualidade de Confiabilidade, de acordo com a norma ISO/IEC 9126-1 (2001), é composta pelas dimensões Maturidade, Tolerância a Falhas e Recuperabilidade. A Maturidade indica a freqüência com que as disfunções se manifestam num intervalo de tempo e está diretamente relacionada à quantidade de defeitos no software ou à ausência de tratamento de situações de exceção. A característica de Maturidade de um software é objeto de interesse de desenvolvedores, testadores, mantenedores e usuários (ISO/IEC 9126-2, 2003), ou seja, é influenciada pela qualidade do projeto, implementação e testes do sistema. Para que um software seja tolerante a falhas, é necessário que este consiga detectar e contornar as situações de erros e exceções. Além disso, mesmo que ocorra uma disfunção, o sistema deve ser capaz de retomar a operação normal a partir de um estado confiável. A subcaracterística Recuperabilidade é necessária para que o sistema volte a operar normalmente, mesmo após a ocorrência de uma disfunção.

Disponibilidade é a capacidade do software em permanecer em um estado que permita realizar uma função requerida num determinado momento, sob condições específicas de uso. Externamente, a disponibilidade pode ser avaliada pela proporção do tempo total em que o software está em um estado operacional. Disponibilidade é uma combinação de Maturidade (freqüência de disfunções), Tolerância a falhas e Recuperabilidade (intervalo de tempo de indisponibilidade do sistema após cada disfunção) e, por este motivo, não é considerada como uma subcaracterística separada para Confiabilidade.

De acordo com a norma ISO/IEC 9126-1 (2001), Usabilidade é a capacidade do software de ser compreendido, aprendido, usado e de ser atrativo ao usuário quando usado sob condições específicas. Apesar do progresso alcançado na área de Usabilidade de websites, muitos ainda não conseguem satisfazer as expectativas de Usabilidade dos usuários, o que pode provocar a migração de usuários para sites 
que apresentem esta característica (OFFUT, 2002). A qualidade de Usabilidade envolve tanto aspectos arquiteturais quanto não arquiteturais. Os fatores que tornam a interface inteligível, apreensível e atrativa são questões de design visual, ou seja, são aspectos não arquiteturais, enquanto que fatores relacionados à operacionalidade do software têm relação com a arquitetura (BASS; CLEMENTS; KAZMAN, 2003). No caso específico de sistemas Web, os principais aspectos que afetam a percepção de Usabilidade de um site na Web são o layout da página, a navegação, a consistência de design visual, o conteúdo da informação, o desempenho, serviços ao cliente, confiabilidade e segurança (security) (BECKER; MOTTAY, 2001). Destes fatores, apenas desempenho, confiabilidade e segurança são atributos influenciados pela arquitetura.

Atualmente, muitas aplicações na Web manipulam dados sigilosos de seus usuários e devem ser tratados com o máximo de segurança possível. Uma falha de segurança de um website de uma empresa pode significar prejuízos financeiros, provocar conseqüências de cunho legais e perda de credibilidade por parte de seus clientes. O atributo de qualidade Segurança estabelece a capacidade do software em proteger informação e dados, de forma a que somente pessoas ou sistema autorizados os possam ler ou modificar (ISO/IEC 9126-1, 2001). Para Ramachandran (2002), os seguintes princípios de segurança que se seguem são, geralmente, aceitos como os necessários para uma boa solução de segurança:

- Autenticação - o processo de estabelecer a validade da identidade de um indivíduo. A origem da requisição de acesso a um componente ou o iniciador de uma sessão ou transação, que deve ser realizada de forma segura, devem fornecer credenciais que provem as suas identidades;

- Autorização - é o processo de determinar se uma entidade validada tem permissão de acesso a um recurso seguro, baseando-se em atributos, predicados ou contexto.

- Integridade - a prevenção de modificação ou destruição de informação por uma entidade não autorizada.

- Disponibilidade - segundo o ponto de vista da segurança, é a proteção de recursos contra ameaças de negação de serviço, que podem impactar na disponibilidade do sistema. 
- Confidencialidade - é a propriedade do sistema de não revelar informações para usuários, entidades ou processo não autorizados.

- Auditoria - a propriedade de efetuar log de todas as atividades do sistema em níveis suficientes para a reconstrução de eventos.

- Não-repúdio - é a propriedade que uma transação - acesso ou modificação de dados ou serviços - não poder ser negada por nenhum dos participantes. Por exemplo, um indivíduo não consegue negar que realizou um pedido em uma loja pela Internet se, de fato, ele o fez.

A norma ISO/IEC 9126-1 (2001) trata a manutenibilidade como a capacidade do software em ser modificado. Modificações podem incluir correções, melhorias ou adaptações do software devido a mudanças no ambiente ou nos requisitos funcionais. Um aspecto importante de software desenvolvido para a Web é a freqüência com que novas versões do sistema são disponibilizadas. Ao contrário de softwares tradicionais que, normalmente, apresentam novas versões em intervalos de meses ou anos, os sites na Web podem ter ciclos de manutenção de dias ou mesmo horas, o que impacta fortemente esse requisito (OFFUT, 2002).

Um site na Web pode virtualmente receber um número ilimitado de visitas de usuários. $O$ projeto e construção de um software para a Web que possua boa escalabilidade representam um dos desafios mais importantes no desenvolvimento do sistema (OFFUT, 2002). Um sistema escalável permite um crescente aumento no uso e no volume de dados processados sem perda de desempenho (HENDERSON, 2006). Desempenho e escalabilidade não necessariamente são dependentes. Podese construir um sistema com alto desempenho que não é escalável, enquanto que o contrário geralmente é verdadeiro, ou seja, pode-se aumentar o desempenho aumentando-se a escalabilidade do sistema. Embora não seja explicitamente descrita na norma ISO/IEC 9126-1 (2001), a escalabilidade tem relação direta com o atributo de qualidade Manutenibilidade, pois para que um sistema seja escalável é necessário que ele permita a inclusão de redundância de componentes sem interferir em outras partes do sistema. 


\subsection{CONSIDERAÇÕES FINAIS}

Neste capítulo foram apresentados aspectos da norma ISO/IEC 9126-1 (2001) relativos a um modelo de qualidade de software. Por se tratar de uma norma internacional amplamente aceita, a ISO/IEC 9126-1 (2001) foi utilizada na classificação dos atributos de qualidade para a arquitetura do sistema hipermídia adaptativos.

Os atributos de qualidade que serão utilizados como direcionadores da arquitetura proposta são Confiabilidade, Segurança de acesso, Usabilidade e Manutenibilidade. A característica Usabilidade envolve tanto atributos relacionados à arquitetura quanto atributos sem relação alguma com ela. Atratividade do sistema, facilidade de uso e de entendimento não são atributos influenciados pela arquitetura do sistema. O atributo Operacionalidade, que é uma subcaracterística de Usabilidade, pode ser considerada um atributo relacionado à Arquitetura, pois um sistema que não apresenta o desempenho ou disponibilidade adequados oferece uma baixa operacionalidade ao usuário. 


\section{ARQUITETURA DE SISTEMAS HIPERMÍDIA ADAPTATIVOS}

O objetivo deste capítulo é propor uma arquitetura de referência para sistemas adaptativos baseados na Web, a partir do modelo Munich e das táticas e padrões arquiteturais selecionados para realizar os atributos de qualidade definidos no capítulo 4. O modelo Munich foi selecionado como modelo de referência por ser um modelo amplamente conhecido na área de Sistemas Hipermídias Adaptativos, sendo o modelo utilizado como base para o SHASIM. O Modelo Munich constitui o resultado da evolução dos modelos anteriores, que se basearam no Modelo Dexter, mas foi concebido com uma abordagem orientada a objetos, que foi a técnica utilizada no desenvolvimento da arquitetura de software do SHASIM.

O Modelo de Referência Munich foi definido formalmente em linguagem OCL. O modelo não utilizou nenhum padrão arquitetônico, mas seus componentes foram distribuídos, pela autora, em três camadas (layers): a Camada de Execução através da qual o usuário interage com o sistema -, a Camada de Armazenamento onde se localizam os modelos de usuário, negócios e adaptação - e a Camada Interna de Componentes, dependente do domínio da aplicação e de sua modelagem. Essa última camada, numa aplicação educacional, seria composta por módulos educacionais e/ou objetos de aprendizagem. Os mecanismos adaptativos se situam na Camada de Armazenamento (modelo de adaptação) e essa camada é que constitui o foco de todos os estudos sobre Sistema de Hipermídia Adaptativa. Os demais Sistemas de Hipermídia Adaptativa mencionados nesse trabalho também não se detiveram nas Camadas de Execução ou de Componentes; a Camada de Execução foi sempre implementada segundo um projeto pré-fixado.

Essa divisão do modelo em camadas guarda um certo relacionamento com o Padrão Arquitetônico Layers descrito por Larman (2002), entretanto ela não apresenta uma camada de serviços explicitamente apresentada. A Camada Interna de Componentes poderia ser melhor imaginada como uma subdivisão da Camada de Negócios do Padrão Arquitetônico Layers, mas que não trata do mecanismo de adaptação. 


\subsection{DETALHAMENTO ARQUITETURAL DO MODELO MUNICH}

O Modelo Munich foi introduzido no capítulo 2, onde foram descritos seus principais módulos funcionais. Nesta seção, seus modelos e mecanismos adaptativos serão detalhados, já que seu conhecimento em detalhe permite entender melhor a proposta de arquitetura.

Os quatro principais modelos do Munich - Execução, Adaptação, Domínio e Usuário - e suas classes principais estão representados na Figura 17. 


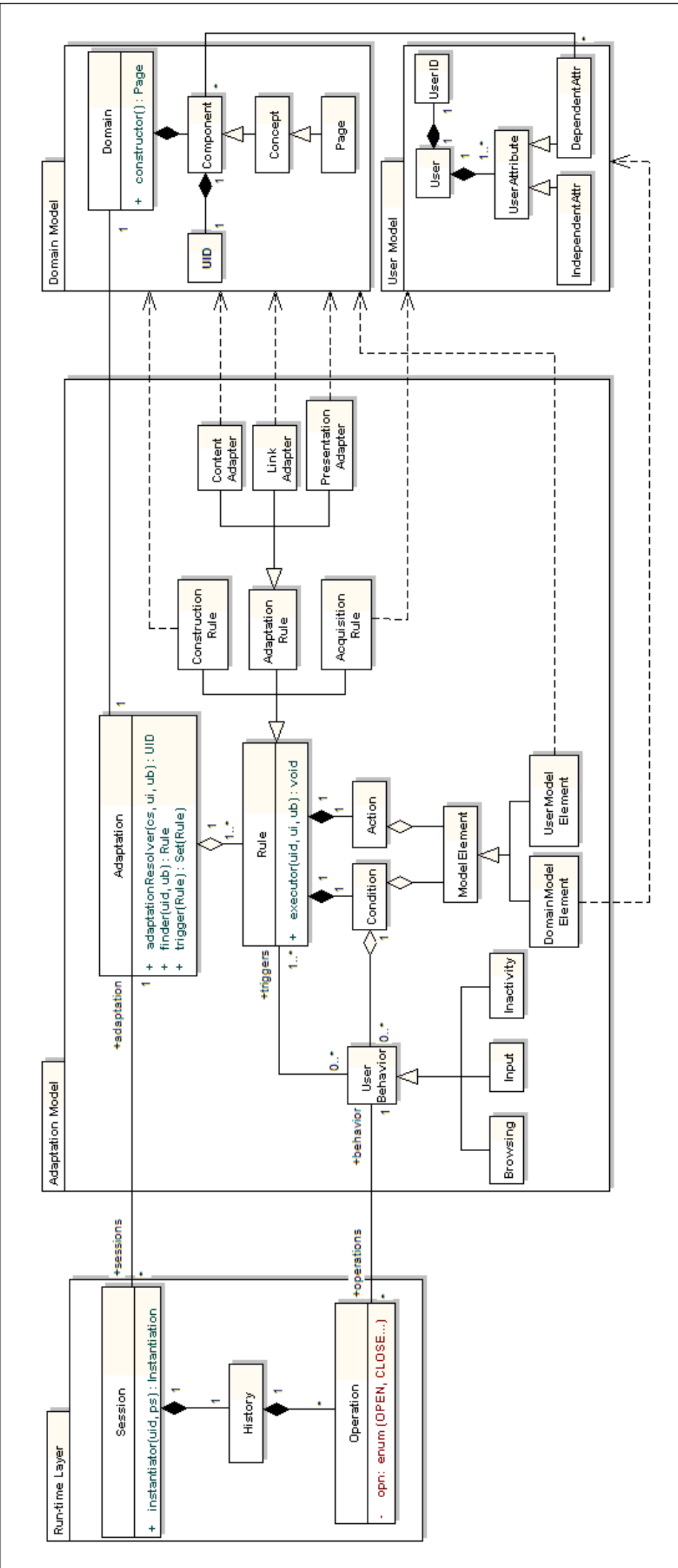

Figura 17 - Camadas de Execução, Adaptação, Domínio e Usuário do Modelo Munich (Adaptado de: Koch (2000)) 
A Camada de Execução (Run-Time Layer) é a camada que suporta a interação do usuário com o sistema hipermídia adaptativo. Os principais conceitos relacionados a esta camada são a sessão do usuário e a instanciação de componentes. A sessão (classe Session) é estabelecida toda vez que um usuário inicia uma interação com o sistema. A sessão contém a história de todas as atividades realizadas pelo usuário, registradas na classe History. Uma instância (obtida pelo método instantiator da classe Session da camada de execução) é uma apresentação do componente ao usuário. Ela pode ser considerada como um tipo de cópia do componente visível e editável pelo usuário. Assim, mais de uma instância de um componente podem coexistir. O principal método do modelo de execução é instantiator. Dado o identificador de um componente (uid) e a especificação de apresentação (ps - Presentation Specification), a função retorna uma instância do componente que é parte da sessão. A especificação de apresentação é uma primitiva no modelo que contém informação sobre como o componente deve ser apresentado pelo sistema durante a instanciação.

O Modelo de Referência Dexter inclui sete tipos diferentes de operações que o usuário pode realizar durante uma sessão. Estas operações representadas pela classe Operation são: abrir e fechar uma sessão, apresentar e esconder uma instância de um componente, criar uma instância do componente durante a sessão, editar, salvar ou remover uma instância. O Modelo de Referência Munich extende esta lista para incluir uma operação adicional, que é a inatividade do usuário por um período de tempo. O objetivo é modelar a inatividade do usuário por longos períodos de tempo. A lista de nove operações pode ser agrupada em navegação (browsing), entrada (input) e inatividade (inactivity), conforme mostrado abaixo. Estes são os diferentes comportamentos de usuário modelados na camada de adaptação e utilizados em condições de regras de adaptação. Estes comportamentos são representados pela classe UserBehavior, que se encontra no Adaptation Model, conforme:

- Navegação: abrir, fechar, apresentar, esconder

- Entrada: criar, editar, salvar, remover

- Inatividade: timeout 
Em aplicações Web atuais, as páginas ou componentes apresentam um tempo de vida curto, apenas durante a resposta a uma requisição. Deste modo, nenhuma instância de componente apresentado ao usuário é armazenado em sua sessão e, portanto, não requerem operações para criar, editar, salvar e remover uma instância de componente. No modelo SHASIM, o comportamento de entrada possui uma operação adicional que é a entrada de dados referente a atributos de um conceito do domínio.

O comportamento do usuário (classe UserBehavior) é o elemento "disparador" da execução das regras adaptativas. O modelo de adaptação (Adaptation Model) consiste de um conjunto de regras e de um conjunto de funções para realização da adaptação. As regras determinam como as páginas serão construídas e como serão apresentadas ao usuário. O modelo Munich estabelece como a adaptação de conteúdo, a adaptação de link e a adaptação de apresentação serão realizadas e como os valores de atributos de usuário são atualizados, isto é, como o Modelo de Usuário é atualizado.

As principais funções presentes no modelo de adaptação são adaptationResolver, finder, trigger e executor. A função adaptationResolver retorna o identificador de um componente (uid) baseado na sua referência (cs - component specification), na identificação do usuário (ui - user identification) e no seu comportamento (ub - user behavior). A regra inicial disparada por alguma ação do usuário (parâmetro ub) sobre um componente (parâmetro uid) é encontrada pela função finder. Iniciando-se por esta regra, as outras regras a serem aplicadas são determinadas pela função trigger. A execução de cada regra é realizada pela função executor (da classe Rule), que permite a execução das regras para seleção dos conceitos selecionados e adaptação do conteúdo, apresentação e links, bem como para o processo de atualização do Modelo do Usuário.

Uma regra é modelada pela classe Rule, que consiste de uma condição (Condition) e uma ação (Action). Condições e ações são expressões contendo elementos do modelo (ModelElement) e operadores. Dois tipos de regras podem existir, dependendo se a regra é aplicável a todas as instâncias de uma classe de 
domínio (DomainModelElement) ou a apenas uma instância específica de usuário (UserModelElement).

As regras também podem ser classificadas de acordo com seus objetivos, como regras de construção (ConstructionRule), regras de aquisição (AcquisitionRule) e regras de adaptação (AdaptationRule).

- O objetivo da regra de construção é encontrar um conceito com base em relacionamentos como, por exemplo, do tipo pré-requisito, bem como nas informações fornecidas pelo Modelo do Usuário. A regra de construção retorna o UID (identificador único) do conceito.

- O objetivo da regra de aquisição é obter as informações sobre o usuário a fim de construir o Modelo do Usuário. A execução da regra retorna uma lista de atributos atualizados do usuário.

- A regra de adaptação é definida para adaptar as páginas, baseando-se no estado do Modelo do Usuário. De acordo com os tipos de adaptação, três tipos de regras de adaptação são definidos:

- ContentAdapter para a seleção dos fragmentos para a construção da página.

- LinkAdapter para a aplicação de diferentes técnicas de navegação adaptativa, tais como anotação de link, remoção de link, ordenação de link, orientação direta etc.

- PresentationAdapter para o ajuste da forma de apresentação da página tais como estilo, fontes e tamanhos.

O Modelo do Domínio é representado pelo elemento principal Domain. O domínio é formado por um conjunto de componentes (Component), que podem representar conceitos (Concept) e páginas (Page). Aplicações hipermídia adaptativas são aplicações dinâmicas, isto é, lidam com a geração dinâmica de páginas. Para realizar esta geração, a função constructor (da classe Domain) é adicionada ao modelo, com a finalidade de montar uma página a partir de itens de informação, também chamados de fragmentos. 
O Modelo do Usuário (User Model) descreve a estrutura dos modelos individuais de cada usuário e como estes modelos são administrados. Usuários (User) de um sistema hipermídia adaptativo são modelados pelo ID do usuário (UserID) que o identifica unicamente, e por um conjunto de atributos de usuário (UserAttribute). Existem dois grupos de atributos no Modelo de Usuário: atributos relacionados ao conhecimento do usuário sobre os componentes do domínio e características genéricas do usuário. O primeiro grupo inclui os atributos dependentes de domínio (DependentAttr), enquanto os atributos do segundo grupo são independentes do domínio (IndependentAttr), ou seja, incluem informações não relacionadas aos componentes. 


\subsection{ARQUITETURA DE REFERÊNCIA PARA SISTEMAS ADAPTATIVOS BASEADOS NA WEB}

Os modelos de referência de Sistemas Hipermídia Adaptativos descrevem as principais funcionalidades requeridas por estes sistemas. Entretanto, para o desenvolvimento de uma arquitetura é necessário considerar todos os aspectos importantes para os participantes (stakeholders) do sistema, conforme o exposto pela norma ISO/IEC 42010 (2007), que descreve um padrão para descrição arquitetural de sistemas de software.

Para se alcançar as qualidades exigidas por um sistema, o arquiteto deve tomar uma série de decisões de projeto chamadas de táticas (BASS; CLEMENTS; KAZMAN, 2003). A introdução de redundância de módulos é um exemplo de tática arquitetural utilizada para aumentar a disponibilidade do sistema. Segundo Bass, Clements e Kazman (2003), o arquiteto normalmente escolhe um padrão ou uma coleção de padrões arquiteturais para realizar uma ou mais táticas.

Um padrão arquitetural em software, também conhecido como estilo arquitetural, é análogo a um estilo arquitetural na construção civil. Ele consiste de algumas características chaves e de regras para combiná-las, de forma que a integridade arquitetural seja preservada. Um padrão arquitetural é determinado por:

- Um conjunto de tipos de elementos (tais como repositório de dados ou um componente que realiza um cálculo matemático);

- Um leiaute topológico dos elementos, indicando seus relacionamentos;

- Um conjunto de restrições semânticas;

- Um conjunto de mecanismos de interação, que determinam como os elementos se coordenam na topologia permitida.

O padrão arquitetural de camadas é uma das técnicas mais utilizadas pelos projetistas para estruturar um sistema de software complexo (FOWLER, 2002). Quando se pensa em um sistema em termos de camadas, imaginam-se os módulos principais do software dispostos em camadas, onde cada camada reside sobre a inferior. Neste esquema, a camada superior usa os serviços definidos pela inferior, 
mas a inferior não é ciente da superior. Além disso, cada camada normalmente esconde suas camadas inferiores das superiores. Assim, em um sistema de três camadas, o mais conhecido desses padrões, a camada três, que utiliza os serviços da camada dois, não está ciente dos serviços oferecidos pela camada um. O padrão de camadas apresenta os seguintes benefícios (BUSCHMANN et al., 1996):

- Elementos com responsabilidades similares estão agrupados, facilitando a compreensibilidade e manutenibilidade do sistema;

- Facilita a modularização do sistema, permitindo que componentes possam ser substituídos por implementações alternativas, sem afetar o resto do sistema;

- Uma camada inferior pode fornecer serviços para mais de uma camada superior; isso pode favorecer, em um momento posterior, o reuso;

- Subdivide o sistema através de limites definidos, auxiliando na divisão de trabalho entre equipes de programadores com especialidades distintas.

A arquitetura proposta está centrada em três camadas principais (FOWLER, 2002):

- Apresentação (Presentation) - camada responsável pela interação entre o usuário e o software. A responsabilidade principal é a exibição da informação para o usuário e a transformação dos comandos do usuário em ações sobre a aplicação. As funções que envolvem a montagem da interface Web, tais como a adaptação da navegação e a apresentação de conteúdo, residirão nesta camada. A camada de apresentação é funcionalmente equivalente à camada de execução do Modelo de Referência Munich. Os objetos desta camada são implantados em um servidor Web. Um servidor Web é um software capaz de receber requisições do cliente (navegador Web) através do protocolo HTTP (Hyper Text Transfer Protocol), interpretá-las e retornar a resposta ao cliente com a página requisitada. Existem duas classes de servidores Web, os de conteúdo estático, que retornam páginas fixas para cada URL independentemente do usuário, e os de conteúdo dinâmico, que criam as páginas dinamicamente para cada tipo de requisição. Estes últimos são os utilizados no contexto desta arquitetura. Exemplos de servidores Web dinâmicos são o Apache Tomcat ${ }^{2}$ e o Microsoft IIS ${ }^{3}$.

\footnotetext{
${ }^{2} \mathrm{http}: / /$ tomcat.apache.org/

3 http://www.iis.net/
} 
- Lógica (Domain) - é a camada que fornecerá os serviços para a camada de apresentação. Esta camada abrigará as funções ligadas às regras de adaptação, domínio, usuário e segurança e deve ser implantada em um servidor de aplicações. A camada lógica é funcionalmente equivalente à camada de armazenamento do Modelo de Referência Munich. Um servidor de aplicação é um software tipicamente usado para aplicações baseadas em transações complexas, com suporte a mecanismos de redundância, monitores para verificação de disponibilidade e desempenho, serviços de aplicações distribuídas e suporte a acessos complexos a bancos de dados. Exemplos de servidores de aplicação são o IBM WebSphere ${ }^{4}$ e o Oracle WebLogic ${ }^{5}$.

- Acesso a Dados (Data Source) - camada responsável pela comunicação com outros sistemas que realizam funções para a aplicação, tais como: monitores de transação, sistemas de mensagens, bancos de dados e outros. Assim como a camada de domínio, a camada de acesso a dados também reside no Servidor de Aplicações.

As camadas de Fowler (2002) podem ser mapeadas no modelo 5-tier de Alur, Crupi e Malks (2003), conforme mostra o quadro abaixo:

Quadro2 - Correspondência entre layers de Fowler e tiers de Alur, Crupi e Malks

\begin{tabular}{|c|c|}
\hline Fowler & Alur, Crupi, Malks \\
\hline \multirow{2}{*}{ Presentation } & Client Tier \\
\cline { 2 - 2 } & Presentation Tier \\
\hline Domain & Business Tier \\
\hline Data Source & Integration Tier \\
\hline- & Resource Tier \\
\hline
\end{tabular}

As camadas Domain e Data Source de Fowler correspondem respectivamente às camadas Business Tier e Integration Tier de Alur, Crupi e Malks. A camada Presentation de Fowler acumula as funções das camadas Client Tier - responsável pela interação com usuário e apresentação da interface - e Presentation Tier -

\footnotetext{
${ }^{4} \mathrm{http}: / / \mathrm{www}-01 . \mathrm{ibm} . \mathrm{com} / \mathrm{software} / \mathrm{Webservers/appserv/was/}$

5 http://www.oracle.com/technology/products/Weblogic/index.html
} 
responsável pelo gerenciamento de sessão, criação de conteúdo da interface e comunicação com o cliente (browser). Neste trabalho, o foco será dado à Presentation Tier, pois considera-se que as funções da Client Tier serão fornecidas pelo navegador (browser). A Resource Tier é formada por repositórios de dados e fontes externas de informação e não possuem correspondência com nenhuma camada de Fowler. Nesta dissertação, é representada pelo banco de dados onde serão armazenadas as informações de usuário e domínio da aplicação. Em uma aplicação educacional, os módulos educacionais e/ou objetos de aprendizagem poderiam também fazer parte da Resource Tier, pois trata-se de um repositório ou sistema externo para armazenamento de objetos educacionais.

A cada acesso à aplicação, a requisição do cliente deve ser verificada, se é proveniente de um usuário já autenticado, se a sessão ainda é válida, se o usuário tem acesso ao recurso solicitado, qual o tipo de comportamento esperado navegação ou entrada de dados - e qual o conceito acessado. Para evitar que este tipo de comportamento seja duplicado entre os módulos da camada de apresentação, recomenda-se a utilização do padrão Front Controller (FOWLER, 2002), que consolida todas as requisições, canalizando-as para um único objeto de tratamento das requisições. Este padrão está representado pela classe FrontController na Figura 18. Dependendo do tipo de interação do usuário com o sistema, o método doGet (navegação) ou doPost (entrada de dados) é executado. 


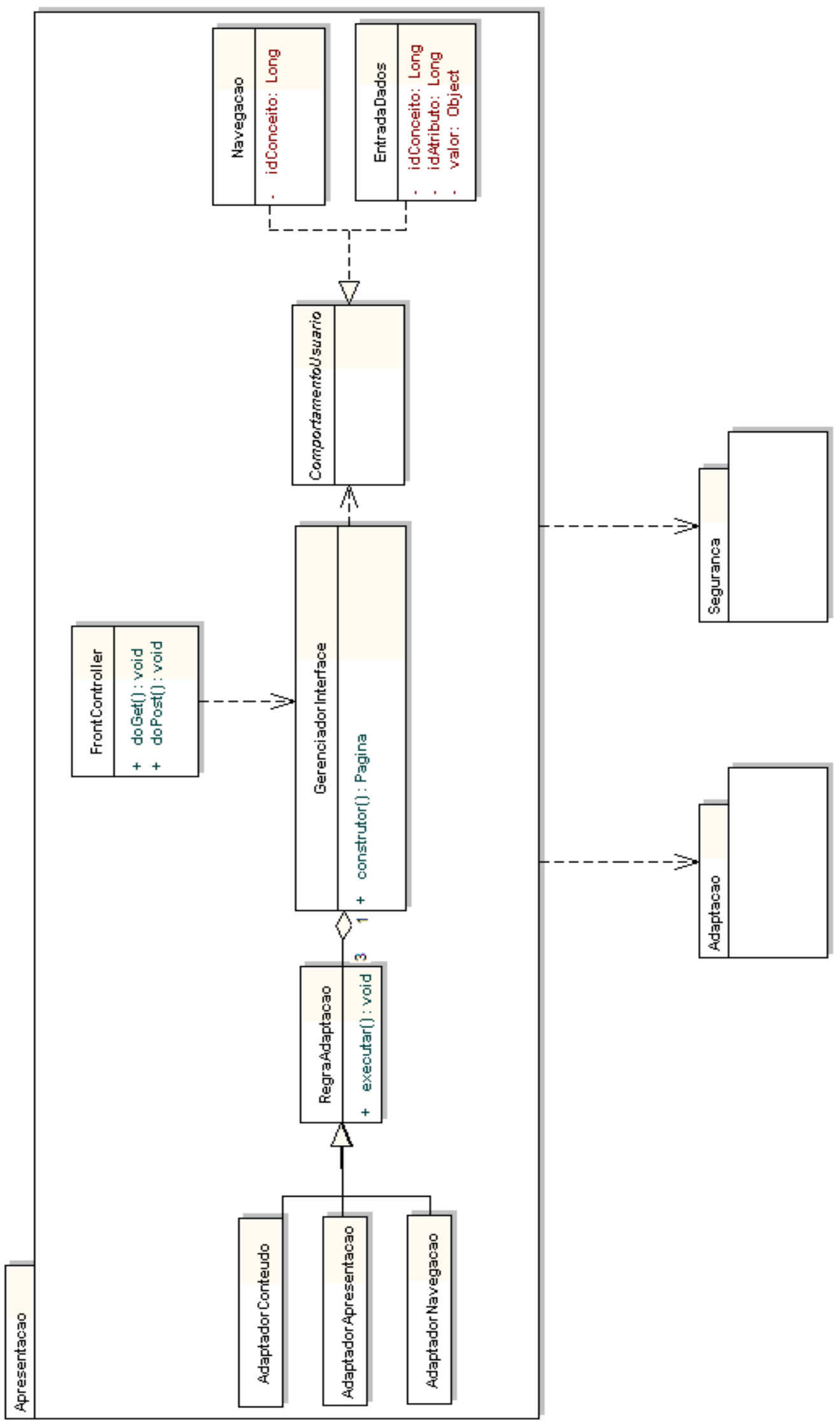

Figura 18 - Camada de Apresentação da arquitetura de referência 
O Modelo Munich $(\mathrm{KOCH}, 2002)$ prevê, no Modelo de Adaptação, três tipos de regras de adaptação: Content Adapter, Link Adapter e Presentation Adapter, que correspondem à classificação de adaptação apresentada por Paterno e Mancini (1999). No Modelo Munich, estas funções estão localizadas no Modelo de Adaptação. Na arquitetura proposta, de acordo com a divisão do sistema em camadas, estas funções foram alocadas na camada de apresentação nas classes AdaptadorConteudo, AdaptadorApresentacao e AdaptadorNavegacao mostradas na Figura 18, pois estão relacionadas à montagem da interface de usuário. O método constructor pertencente ao Modelo de Domínio do Modelo Munich, responsável pela montagem da página a partir de seus fragmentos atômicos, foi alocado também na camada de apresentação, na classe GerenciadorInterface. Caso a interface possua vários frames, este método deve ser capaz de agregá-los, recorrendo às classes de adaptação para adaptar o conteúdo (AdaptadorConteudo), apresentação (AdaptadorApresentacao) e navegação (AdaptadorNavegacao) conforme o estado do Modelo do Usuário.

Para a montagem da interface Web, não é recomendável que a página HTML seja construída manipulando-se caracteres em programação, na Camada de Apresentação. Esta estratégia, além de não ser produtiva, pode trazer problemas de manutenibilidade futuras. Uma forma de resolver este problema é o uso do padrão Template View (FOWLER, 2002). A idéia básica deste padrão é inserir marcadores em uma página HTML. Quando o usuário requisita um conceito, os marcadores na página associada são substituídos pelo resultado da adaptação. Esta abordagem é a mesma utilizada pelo AHA (DE BRA; SMITS; STASH, 2006) e pelo Interbook (BRUSILOVSKY; EKLUND; SCHWARZ, 1998) e traz como benefícios a facilidade de construção e manutenção das páginas, caso seja utilizada uma linguagem de marcação como o XML ou XHTML. A utilização deste padrão antecipa a construção da página a partir de seus fragmentos atômicos, o que é previsto pela função constructor do Modelo Munich. O método construtor da classe GerenciadorInterface possui outras atribuições como, por exemplo, montar a estrutura de frames da interface gráfica, além de controlar as chamadas às classes de adaptação. 
Um Sistema Hipermídia Adaptativo modifica os atributos do Modelo do Usuário a cada interação com o sistema. Um simples acesso a uma página pode provocar o disparo de uma série de regras de adaptação, cada uma acessando e alterando um ou mais atributos do usuário. Para manter a consistência do Modelo do Usuário e de atributos globais, é necessário que as regras de adaptação sejam executadas dentro de uma mesma transação, garantindo-se assim que todas as alterações realizadas possam ser desfeitas caso ocorra algum erro entre a execução das regras. Erros a serem considerados incluem: indisponibilidade do banco de dados, problemas na rede etc. As funções do Modelo de Adaptação, do Modelo de Usuário e do Modelo de Domínio devem residir no Servidor de Aplicações, pois assim elimina-se a necessidade do controle de transações por parte da aplicação (ROMAN; AMBLER; MARINESCU, 2001).

Os Sistemas Hipermídia Adaptativos mais conhecidos, citados anteriormente, não são implementados em servidores de aplicação. O AHA (DE BRA; SMITS; STASH, 2006) e o KBS-HYPERBOOK (FROHLICH; NEJDL; WOLPERS, 1998) são implementados em componentes Servlets Java da Camada de Apresentação, que são executados em um servidor Web. Servlets são objetos programados com a linguagem Java e que executam em servidores Web específicos para esta linguagem. A função destes objetos é a de interpretar a requisição e os dados enviados pelo cliente, chamar as funções da aplicação necessárias em objetos remotos da camada de aplicação e, a partir da resposta desta execução, gerar dinamicamente a interface Web adaptada para o cliente. Assim, devido à falta de alguns recursos, encontrados somente em servidores de Aplicação como um gerenciador de transações e serviços para aplicações distribuídas, os servidores Web não são indicados para executar as funções que envolvem a manipulação de dados e regras de aplicação. Outros exemplos de Sistemas Hipermídia Adaptativos como o Interbook (BRUSILOVSKY; EKLUND; SCHWARZ, 1998) e o NetCoach (WEBER; KUHL; WEIBELZAHL, 2002) utilizam o Servidor Web CL-HTTP. Este é um servidor Web capaz de retornar páginas geradas a partir de conteúdo estático e dinâmico, mas como não suporta o gerenciamento de transações e não possui características para clusterização, não atende aos atributos de qualidade de alta disponibilidade e escalabilidade. 
Na Figura 19 está representado o Módulo de Adaptação, cujas funções baseiam-se no modelo Munich (KOCH, 2002).

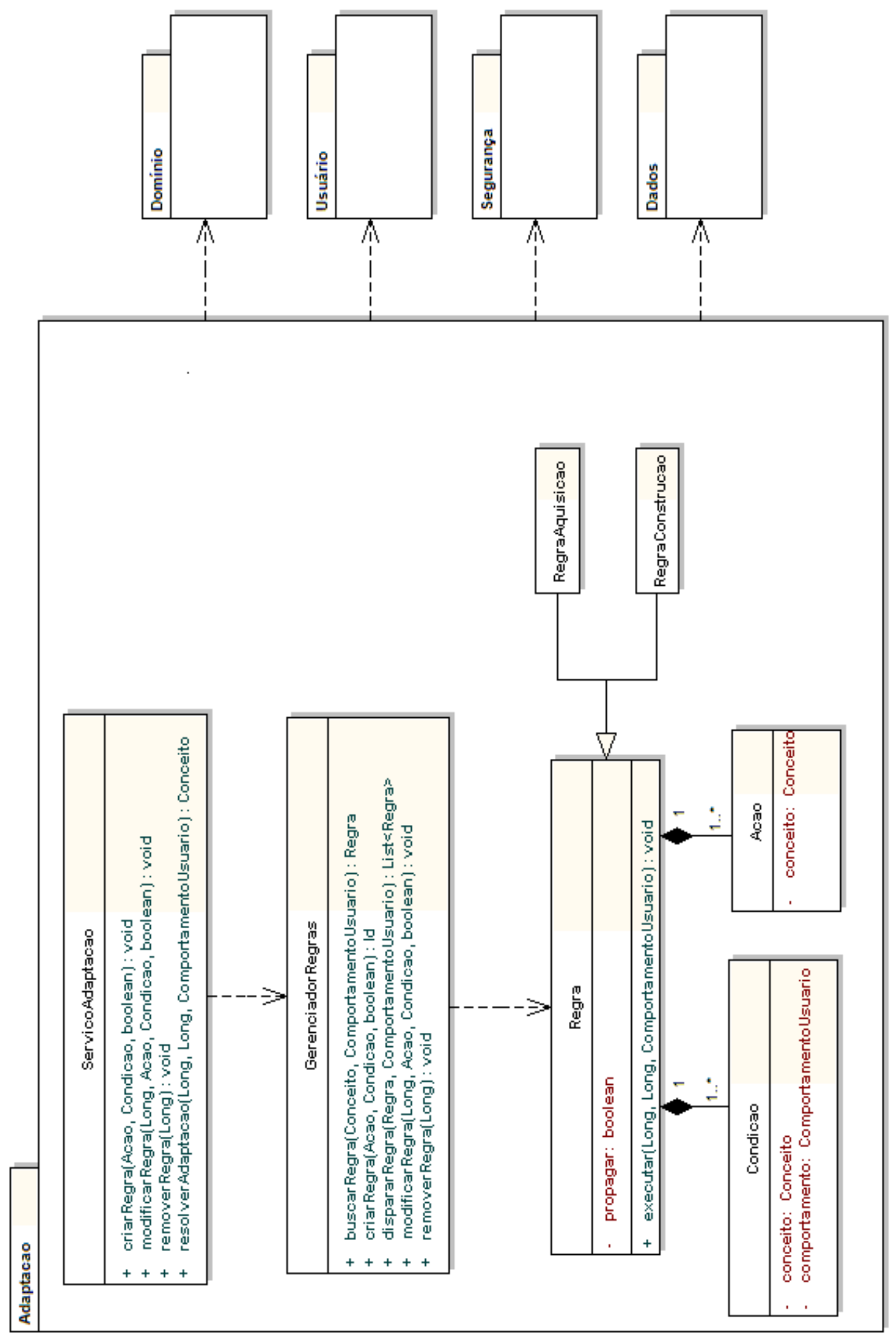

Figura 19 - Camada de Adaptação da arquitetura de referência 
O módulo de adaptação da Figura 19 corresponde ao modelo de adaptação do Modelo Munich, com os métodos especificados pelo modelo: resolverAdaptacao (adaptationResolver do Munich), buscarRegra(finder do Munich), dispararRegra (trigger do Munich), executar (executor do Munich), além das funções de autoria criarRegra (createRule do Munich), removerRegra (deleteRule do Munich) e modificarRegra (modifyRule do Munich). Conforme mencionado, por estarem relacionadas à adaptação da interface, as regras de adaptação do Modelo Munich foram alocadas na camada de apresentação. Na camada de adaptação, permaneceram as regras de aquisição (RegraAquisicao), responsáveis pela consulta e atualização dos valores armazenados no Modelo do Usuário, e as regras de construção, responsáveis pela consulta à estrutura do Modelo de Domínio da aplicação. O módulo de adaptação relaciona-se com o módulo de domínio, para execução das regras de construção, com o módulo de usuário, para execução das regras de aquisição, com o módulo de segurança, para verificar a permissão do cliente do serviço, e com o módulo de dados, para acesso às regras armazenadas em banco de dados.

A dinâmica de chamada da função resolverAdaptacao está representada no Diagrama de Seqüência da Figura 20. Ao ser chamada, a função resolverAdaptacao executa a função buscarRegra para encontrar a regra associada ao conceito requisitado pelo usuário e em seguida a função dispararRegra para buscar outras regras acionadas pela execução da primeira. Uma regra pode causar o disparo de outras regras, de acordo com a função dispararRegra, o que poderia causar um laço infinito. Este problema pode ser contornado definindo-se um limite arbitrário no número de vezes que cada regra pode ser executada, conforme proposto por WU (2002). 


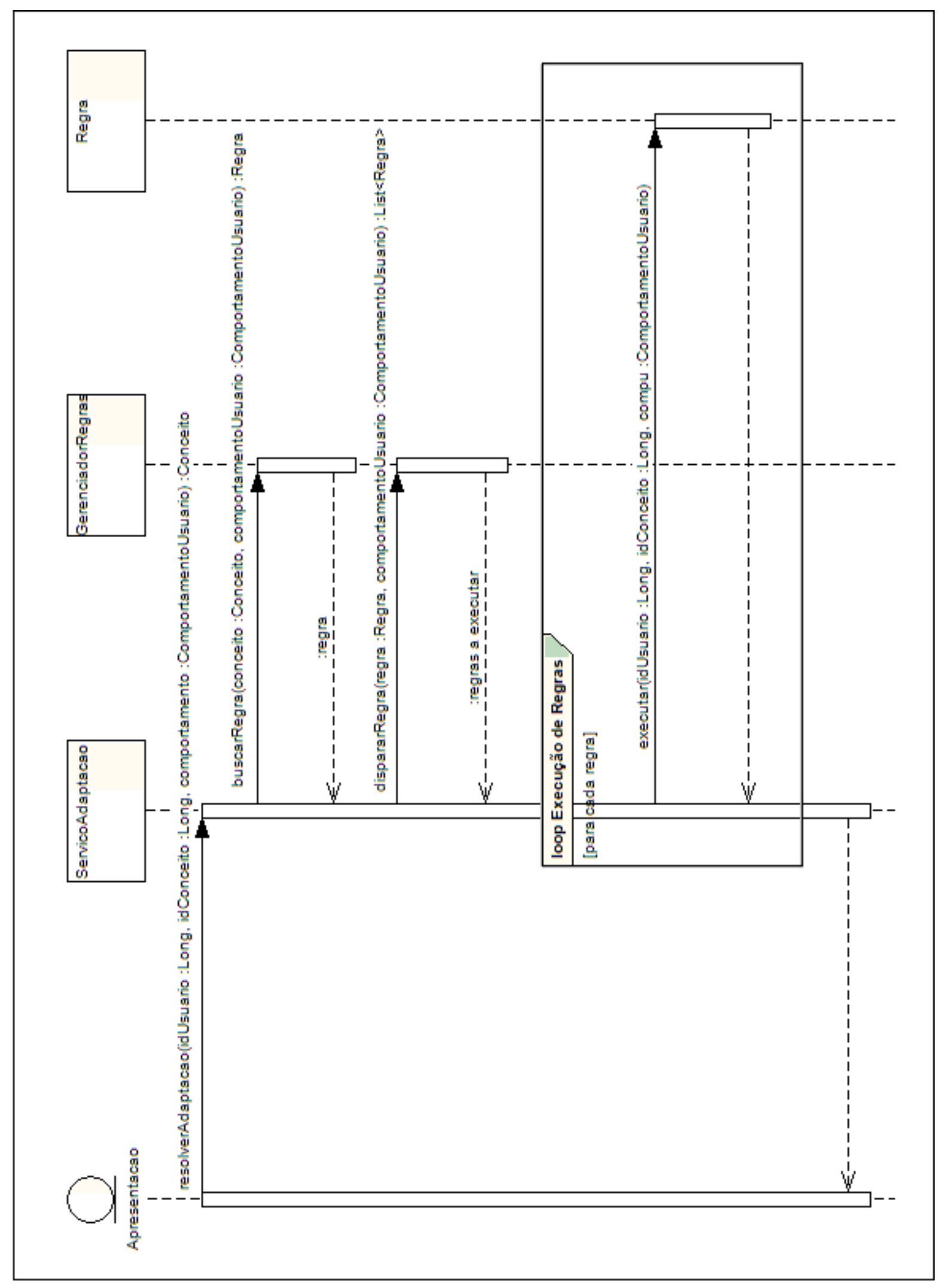

Figura 20 - Diagrama de seqüência do Modelo de Adaptação 
Ao invés da camada de apresentação coordenar várias chamadas de granularidade fina à camada lógica a fim de executar um serviço, esta tarefa é delegada a uma interface com um conjunto de serviços disponíveis às camadas clientes adjacentes. Este padrão é chamado de Service Layer (FOWLER, 2002) e é utilizado para expor os serviços da camada lógica disponíveis à camada de apresentação. No módulo de adaptação representado na Figura 19, este padrão é representado pela classe ServicoAdaptacao. De acordo com este padrão, somente o método de adaptação resolverAdaptacao precisa ser exposta para a camada de apresentação. A execução dos outros métodos envolvidos na adaptação (buscarRegra, dispararRegra e executar) são coordenados pelo método resolverAdaptacao e não precisam ser visíveis às demais camadas. A utilização do padrão Service Layer apresenta as seguintes vantagens:

- Fornece uma interface de acesso à camada lógica, encarregando-se de coordenar as chamadas a outros métodos e a definição de limites transacionais para a realização do serviço requisitado.

- Facilita a invocação remota dos serviços oferecidos pela camada lógica, bastando tornar as classes de serviços em objetos remotos. A invocação remota destes serviços é importante, pois as camadas de apresentação e lógica podem não residir no mesmo servidor físico.

A exposição remota dos serviços da camada de aplicação pode criar uma "brecha" de segurança, uma vez que qualquer cliente com acesso ao servidor de aplicações poderá invocar um serviço. Para resolver este problema foi criado o Módulo de Segurança (Figura 21), onde é feita a verificação da autenticidade do cliente e a verificação do tipo de acesso requerido, antes de permitir a execução do serviço propriamente dito. Além de controlar o acesso à camada lógica, o módulo de segurança deve ser utilizado, também, pela Camada de Apresentação, permitindo a autenticação do usuário e o controle de acesso às opções da interface do usuário, exibindo ou escondendo os elementos de interface de acordo com as permissões do usuário. 


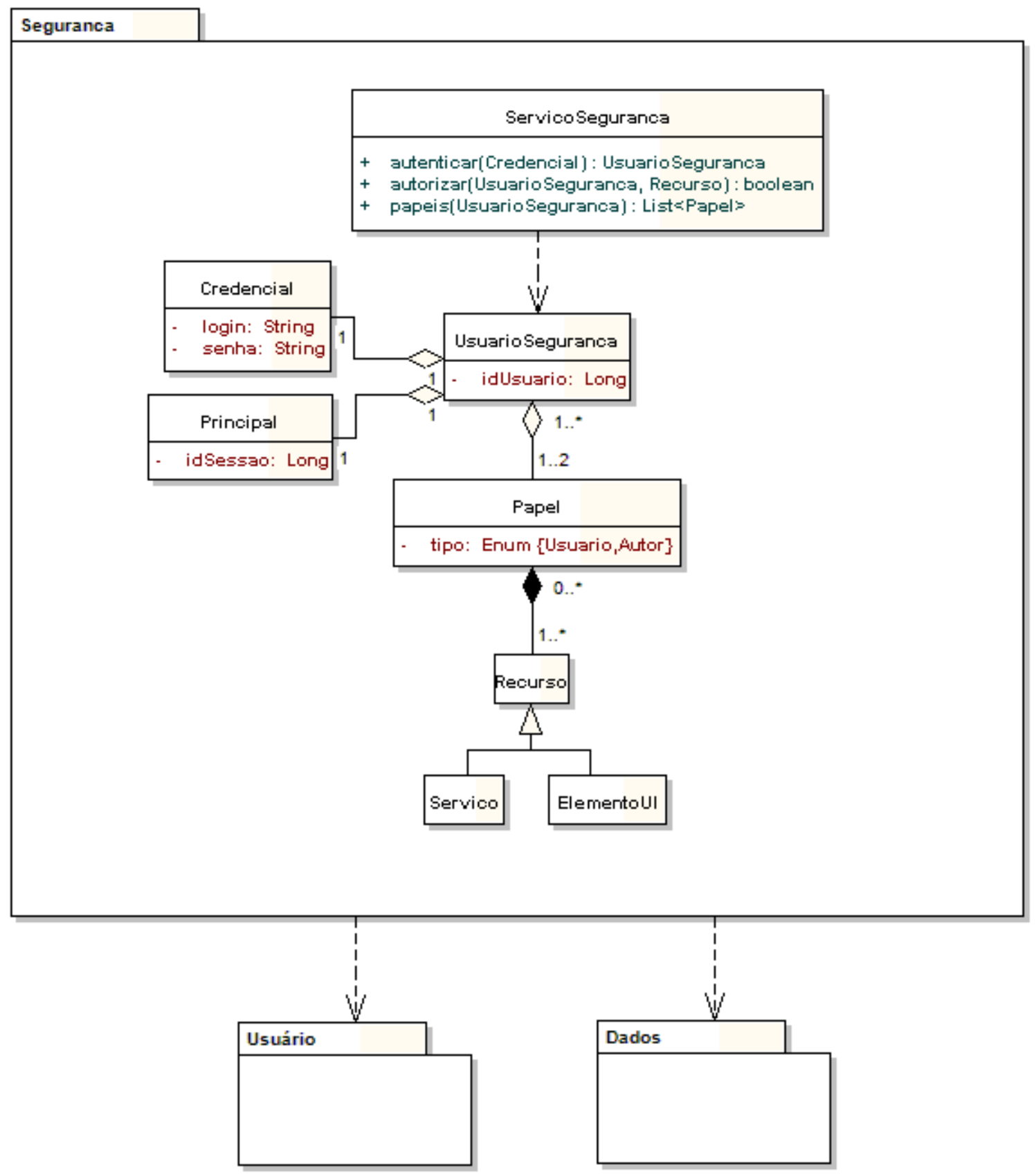

Figura 21 - Módulo de Segurança da arquitetura de referência

Devido ao grande número de usuários e recursos que a aplicação deve controlar, o controle de acesso baseado em papéis (Role-Based Access Control) é utilizado (SCHUMACHER et al., 2006). O controle de acesso baseado em papéis simplifica a criação de novos usuários, pois o usuário é associado a um dos perfis de acesso previamente definidos para o domínio. Para a arquitetura proposta, são necessários o perfil de usuário da aplicação hipermídia, com permissão de navegação pela aplicação, e o perfil de autor, com permissão de execução das funções de autoria. 
Pela Figura 21, um papel está associado a um ou mais recursos protegidos do sistema e o tipo de acesso permitido ao recurso.

A arquitetura não especifica os mecanismos de autenticação, como autenticação por usuário e senha ou certificado digital, pois esta decisão depende de cada ambiente de implementação e dos níveis de segurança exigidos para a aplicação. Entretanto, a arquitetura prevê um serviço de autenticação em que o usuário fornece as credenciais de acesso com as informações de autenticação, retornando o "principal autenticado" em caso de sucesso. Principal é qualquer entidade dentro de uma aplicação que precisa ser autenticada de alguma forma (RAMACHANDRAN, 2002). Uma vez que o cliente é autenticado, ele recebe um token ou ticket, que é uma informação de contexto fornecida a um principal previamente autenticado, representado na Figura 21 pelo identificador de sessão do usuário. Através do token, a aplicação é capaz de verificar se um principal foi previamente autenticado (RAMACHANDRAN, 2002). Logo após a autenticação, o token deve ser armazenado na camada de apresentação e ser fornecido a cada chamada de serviço para verificação de permissão de acesso.

Na Figura 22 está representa a visão lógica geral dos componentes da arquitetura, onde é possível entender como os elementos entre módulos se relacionam. 


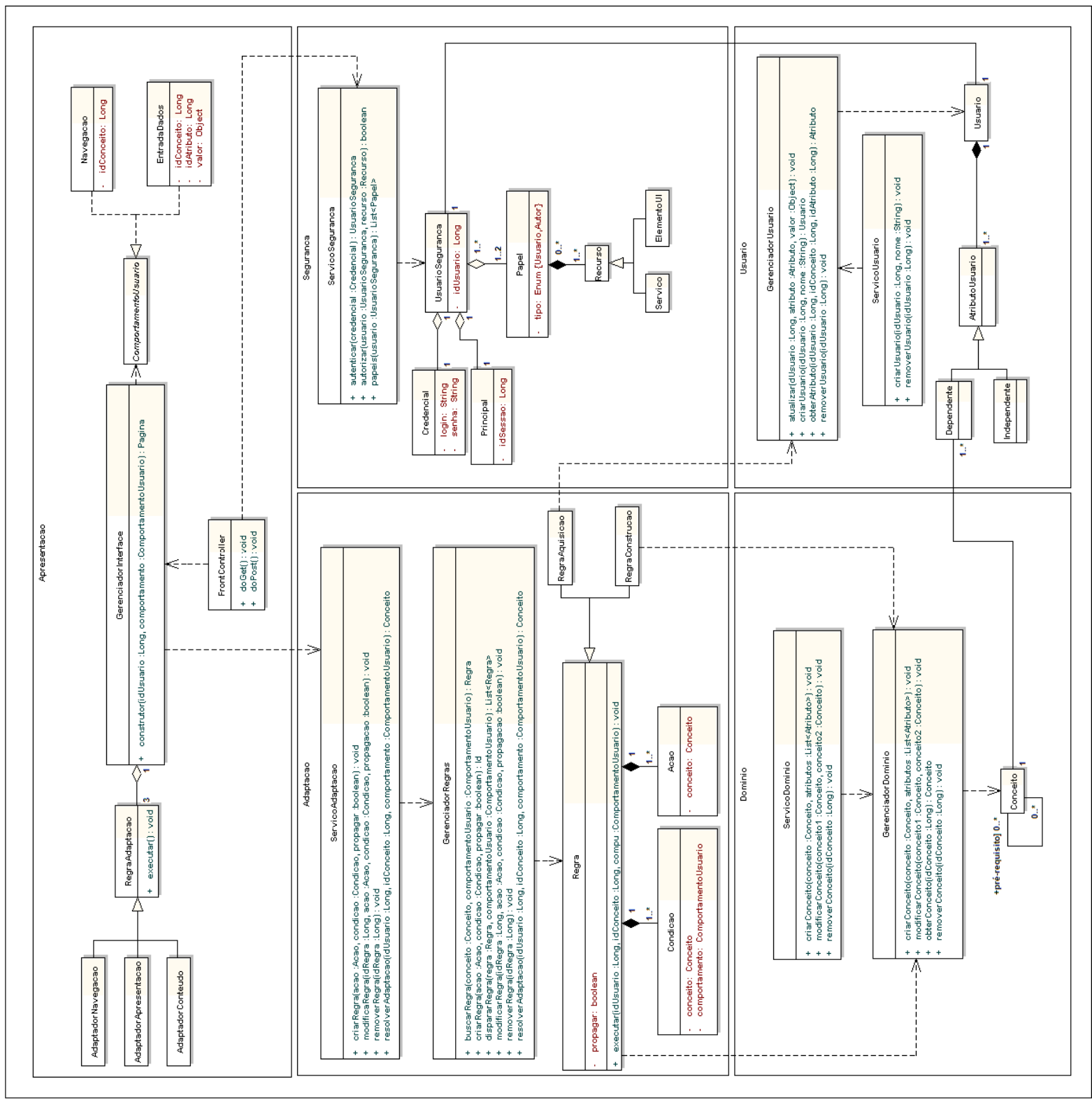

Figura 22 - Visão geral da arquitetura de referência proposta para o Modelo Munich 
A classe FrontController é o ponto de entrada para todas as requisições originadas pelo usuário, com o papel de validar o usuário através do módulo de segurança e identificar o tipo de interação (navegação ou entrada de dados). A classe GerenciadorInterface, através do método construtor, tem a responsabilidade de montar a interface adaptada de usuário e para isso, deve interagir com o módulo de adaptação da camada de aplicação e com as classes de adaptação (AdaptadorNavegacao, AdaptadorApresentacao e AdaptadorConteudo).

Para a execução das regras da camada de adaptação, é preciso invocar o serviço resolverAdaptacao. Dois tipos de regras podem ser executadas na camada de adaptação, as regras de aquisição e as regras de construção. A atualização do estado do Modelo do Usuário, de acordo com seu comportamento, exige a execução das regras de aquisição. Quando as regras de aquisição são executadas, o retorno do serviço resolverAdaptacao é um objeto de conceito atualizado, com a informação de localização da página "modelo" do padrão Template View (FOWLER, 2002). As regras do tipo construção são executadas opcionalmente, quando a camada de apresentação precisa das informações de composição do modelo do domínio, por exemplo, para recuperar um conceito com base em relações de pré-requisitos.

Com o modelo do usuário atualizado, prossegue-se com a fase de adaptação da interface de usuário. Na página modelo podem existir links e referências a outros conceitos. A resolução dos links é realizada pelas regras de adaptação de navegação (AdaptadorNavegacao) e das referências a conceitos pelas regras de adaptação de conteúdo (AdaptadorConteudo). Para as adaptações de navegação e conteúdo, são necessários os atributos do Modelo do Usuário atualizado, enquanto que para a adaptação de apresentação, são precisos alguns atributos independentes de domínio. A camada de apresentação obtém os atributos do Modelo do Usuário através do serviço obterAtributo do módulo de usuário.

Um cluster é um agrupamento de computadores que trabalham em conjunto de forma que para seus usuários, é visto como uma entidade única. Uma aplicação em cluster permite o aumento da escalabilidade, disponibilidade, desempenho e tolerância a falhas (RAJARAVIVARMA; BELLARMINE, 2007). A capacidade de uma 
aplicação implantada em um cluster pode ser aumentada dinamicamente, adicionando-se novas instâncias de servidores ao cluster, sem a necessidade de interrupção do serviço e impacto para os clientes. Esta característica permite o aumento do desempenho da aplicação sem afetar a sua disponibilidade. $O$ balanceamento de carga entre as instâncias do cluster contribui para o aumento da disponibilidade, pois caso um nó torne-se indisponível, as requisições são direcionadas pelo balanceador para outra instância apta a executar a requisição. Um cluster apresenta também características de tolerância a falhas e recuperabilidade (failover). Quando um componente, realizando uma tarefa particular, torna-se indisponível por algum motivo, uma cópia do mesmo objeto em outro nó do cluster pode terminar a tarefa, sem impacto para o cliente. Na arquitetura proposta, tanto os servidores Web quanto os servidores de aplicação estão configurados em cluster, conforme mostra a Figura $23 \mathrm{com}$ a representação da arquitetura física. Nesta visão arquitetural, os componentes estão representados em Java (extensão . jar) apenas como uma necessidade de representar componentes físicos. No entanto, esta arquitetura não é específica de tecnologia e poderia ser descrita por componentes de outra tecnologia (por exemplo, Microsoft .Net). 


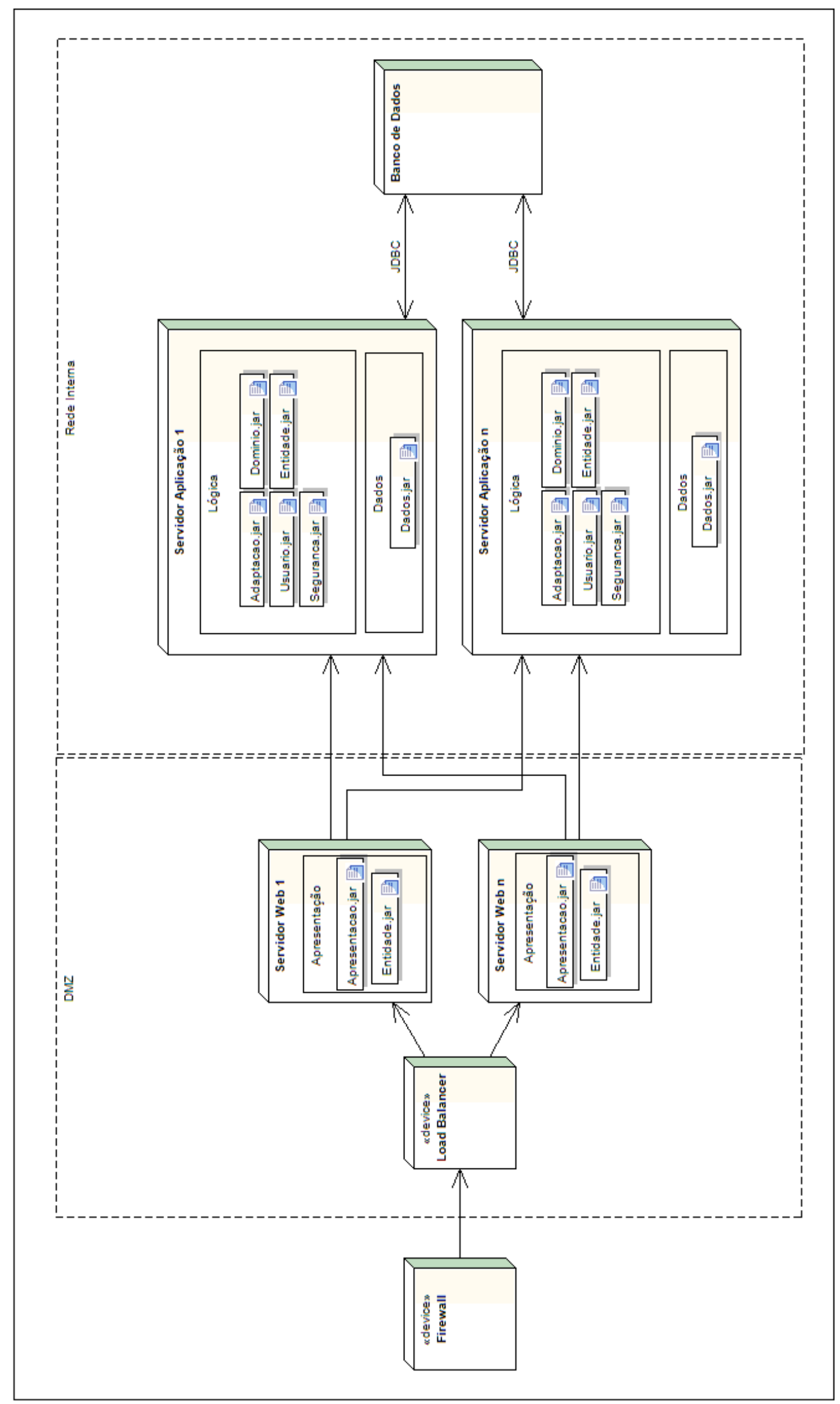

Figura 23 - Arquitetura física do sistema adaptativo baseado na Web 
Enquanto a camada lógica utiliza a abordagem orientada a objetos, os bancos de dados atuais em sua maioria são relacionais. Para interligar duas entidades que utilizam princípios diferentes, é introduzida uma camada intermediário de acesso aos dados, de acordo com o padrão "Database Access Layer" (BUSCHMANN; HENNEY; SCHMIDT, 2007), representada na Figura 23 pelo componente Dados.jar. O padrão Database Access Layer desacopla uma aplicação orientada a objetos dos detalhes do banco de dados. Todos os mapeamentos concretos de objetos para tabelas são encapsulados nesta camada. Assim, a camada lógica apenas manipula objetos, sem precisar se preocupar com a tecnologia de persistência utilizada.

Na Figura 23, o mesmo componente Entidade.jar está representado tanto na Camada de Apresentação, quanto na Camada Lógica. Neste componente estão contidos somente objetos de dados que podem trafegar entre as camadas de apresentação e lógica (classes Conceito, Usuario, AtributoUsuario, ComportamentoUsuario), conforme o padrão Data Transfer object (BUSCHMANN; HENNEY; SCHMIDT, 2007). O uso deste padrão evita que muitas chamadas remotas para consulta ou atualização de atributos simples sejam feitas entre camadas separadas fisicamente, o que pode comprometer o desempenho do sistema. O componente Apresentacao.jar é formado pelas classes da Camada de Apresentação (GerenciadorInterface, AdaptadorConteudo, AdaptadorNavegacao, AdaptadorApresentacao e FrontController) e é implantado no servidor Web. Os componentes Adaptacao.jar (formado pelas classes ServicoAdaptacao, GerenciadorRegras, Regra, RegraAquisicao, e RegraConstrucao), Dominio.jar (classes ServicoDominio e GerenciadorDominio), Usuario.jar (classes GerenciadorUsuario e Servicousuario) e Seguranca.jar (classe ServicoSeguranca) pertencem à Camada de Aplicação e são implantados nos servidores de aplicação do sistema.

Qualquer forma de Website é um alvo em potencial para ataques, especialmente aqueles na Internet. Por isso, na arquitetura física representada na Figura 23, é utilizada uma zona delimitarizada (Delimitarized Zone - DMZ) para proteger os recursos de negócio, tais como os servidores de aplicação e o banco de dados, de 
ataques provenientes da Internet (SCHUMACHER et al., 2006). Na arquitetura, o firewall é configurado para permitir somente a entrada de tráfego para acesso ao servidor Web e um roteador interno é configurado para permitir que somente o tráfego dos servidores Web passe para a rede interna, onde residem os servidores de aplicação e os bancos de dados, que são recursos computacionais com informações estratégicas e confidenciais para a empresa ou instituição.

\subsection{CONSIDERAÇÕES FINAIS}

Neste capítulo, foi apresentada uma proposta de arquitetura de referência para o Modelo Munich. Esta arquitetura foi desenvolvida com base no mapeamento dos elementos funcionais propostos no Modelo Munich, em elementos de software da arquitetura, baseando-se em atributos de qualidade como drivers deste mapeamento. Uma arquitetura de referência estabelece a base para o desenvolvimento da arquitetura final do sistema, que poderá ser finalizada considerando-se outros fatores de influência tais como políticas, regras e restrições de ambiente.

O Modelo Munich foi utilizado como o modelo de referência para sistemas hipermídia adaptativos por duas razões. Primeiramente, por ser um modelo definido formalmente com a abordagem orientada a objetos, que é uma premissa para a arquitetura proposta. Além disso, o Modelo Munich é um modelo amplamente aceito e serviu de base para o Modelo SHASIM, cuja redefinição arquitetural é um dos objetivos deste trabalho. 


\section{ARQUITETURA DO SISTEMA SHASIM}

O objetivo deste capítulo é apresentar a aplicação da arquitetura proposta, para a redefinição da arquitetura do sistema SHASIM. O SHASIM é baseado no modelo Munich, que também serviu de base para a arquitetura apresentada. Entretanto, o SHASIM define alguns requisitos adicionais como a definição das inteligências múltiplas e do estilo cognitivo do usuário para a seleção dos signos da interface gráfica.

Neste capítulo será adotada o modelo "4+1" (KRUCHTEN, 2003) devido à sua abrangência em atender vários tipos de stakeholders e por ser um modelo de visões amplamente reconhecida. Além disso, por ser o único dentre os modelos arquiteturais a apresentar uma visão de casos de uso e devido ao SHASIM já possuir uma especificação funcional baseada em casos de uso, optou-se por sua utilização para a descrição arquitetural.

\subsection{VISÃO DE CASOS DE USO}

A visão de caso de uso desempenha um papel especial na arquitetura do software. Ela contém alguns cenários chaves e casos de uso que direcionarão a implementação da arquitetura e posteriormente a validação das outras visões (KRUCHTEN, 2003).

Os atores que interagem com o SHASIM são o Aluno, o Professor, o Designer de Signos e o Administrador (PUGA, 2008).

- Aluno é o usuário que interagirá com o conteúdo programático dos cursos.

- Professor é o ator responsável pela manutenção dos conteúdos instrucionais e acompanhamento da evolução dos estudos do Aluno.

- Designer de Signos é o responsável pela manutenção dos signos instrucionais e de interação.

- Administrador é o responsável pelas tarefas de manutenção do sistema como manutenção de logins de usuários, disciplinas e cursos. 
O diagrama de casos de uso da Figura 24 foi extraído integralmente do trabalho de Puga (2008) e fornece uma visão geral das funcionalidades do SHASIM.

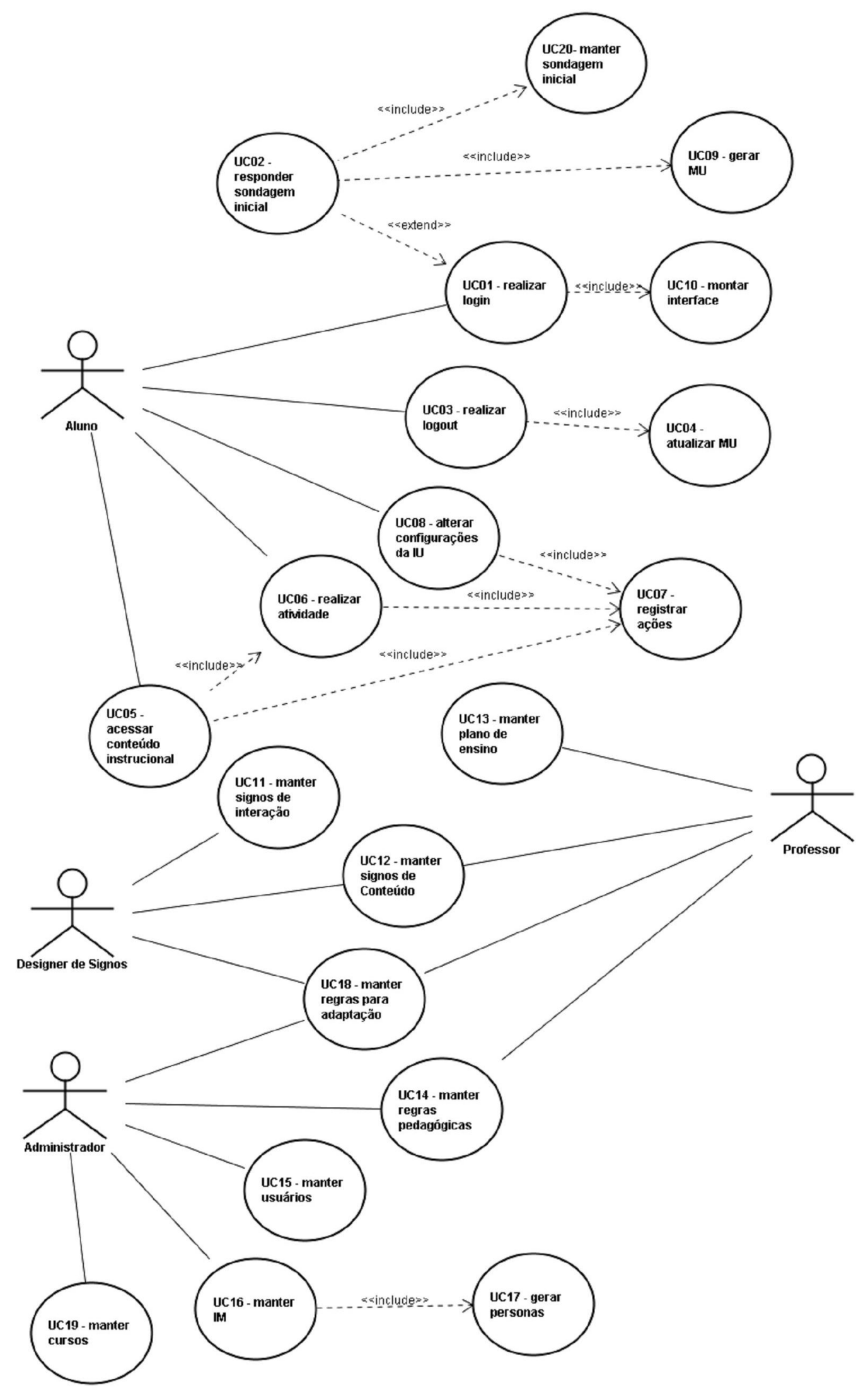

Figura 24 - Diagrama de casos de uso do SHASIM - extraído de Puga (2008, p. 108) 
Os casos de uso da Figura 24 são descritos sucintamente no quadro 2. Os casos de uso foram transcritos sem modificações do trabalho original para destacar as alterações propostas neste trabalho.

Quadro 3 - Descrição Sintética dos Casos de Uso do SHASIM - Extraído de Puga (2008, p. 107)

\begin{tabular}{|c|c|c|}
\hline ID & Nome & Descrição \\
\hline UC01 & Realizar login & $\begin{array}{l}\text { O Aluno solicita admissão no sistema, através do processo de login (por } \\
\text { exemplo, através de user e senha), informado previamente pelo } \\
\text { Administrador. Os dados são verificados na base de dados; se forem } \\
\text { válidos, verifica-se se o Aluno possui um MU; se não possuir, aciona-se } \\
\text { UC02 (realiza a sondagem inicial); se possuir um MU, aciona-se UC10. } \\
\text { Se os dados de login não estiverem corretos, emite-se uma mensagem } \\
\text { de erro ao Aluno. }\end{array}$ \\
\hline UC02 & $\begin{array}{l}\text { Responder } \\
\text { Sondagem } \\
\text { inicial }\end{array}$ & $\begin{array}{l}\text { O Aluno recebe o formulário para preenchimento de dados que serão } \\
\text { utilizados na investigação das IM, das suas preferências e de sua } \\
\text { expertise em interação humano-computador. Mesmo que ele interrompa } \\
\text { o preenchimento do questionário, suas respostas são armazenadas e no } \\
\text { próximo acesso ao sistema, o questionário parcialmente preenchido lhe } \\
\text { será apresentado para que complete o preenchimento. Somente quando } \\
\text { ele terminar esse preenchimento, ele poderá evoluir no sistema. Então, o } \\
\text { caso de uso UC09 é acionado, gerando MU. }\end{array}$ \\
\hline UC03 & Realizar logout & $\begin{array}{l}\text { O Aluno sai do sistema e sua sessão é encerrada. Os dados coletados } \\
\text { ao longo dessa sessão devem atualizar o MU. Para isso, solicita-se a } \\
\text { execução de UC04, que irá atualizar o MU. }\end{array}$ \\
\hline UC04 & Atualizar MU & $\begin{array}{l}\text { Esse caso de uso recupera os dados relativos à evolução do Aluno } \\
\text { durante a última sessão realizada, o conteúdo estudado, as atividades } \\
\text { realizadas, as interações realizadas na interface e as personalizações } \\
\text { feitas pelo Aluno; atualizam-se, então, as bases de dados MU. A } \\
\text { evolução do Aluno diz respeito ao ponto do conteúdo que o Aluno está } \\
\text { estudando, isto é, a evolução do Aluno quanto ao planejamento dos } \\
\text { estudos. }\end{array}$ \\
\hline UC05 & $\begin{array}{l}\text { Acessar } \\
\text { conteúdo } \\
\text { instrucional }\end{array}$ & $\begin{array}{l}\text { O Aluno acessa o conteúdo instrucional associado ao curso e } \\
\text { selecionado de acordo com o plano de estudos e o seu modelo de } \\
\text { usuário. Nesse momento, deve-se iniciar o registro das suas interações } \\
\text { com o conteúdo instrucional e para isso, executa-se UC07, para registrar } \\
\text { as suas ações. Para realizar alguma atividade, acessa-se UC06. }\end{array}$ \\
\hline UC06 & $\begin{array}{l}\text { Realizar } \\
\text { atividades }\end{array}$ & $\begin{array}{l}\text { O Aluno inicia a realização das atividades programadas para o curso; o } \\
\text { sistema deve apresentar-lhe atividades selecionadas de acordo com o } \\
\text { plano de estudos e com o seu modelo de usuário; nesse momento, deve- } \\
\text { se iniciar o registro das suas interações com o conteúdo; para isso, } \\
\text { executa-se UC07. }\end{array}$ \\
\hline UC07 & Registrar ações & $\begin{array}{l}\text { Este caso de uso atualiza a base de dados com os dados sobre a } \\
\text { navegação realizada pelo Aluno, numa sessão, sua evolução, o conteúdo } \\
\text { estudado, as atividades e personalizações realizadas e o tempo de } \\
\text { permanência num determinado módulo educacional (unidade de } \\
\text { aprendizagem). }\end{array}$ \\
\hline UC08 & $\begin{array}{l}\text { Alterar } \\
\text { Configurações } \\
\text { da IU }\end{array}$ & $\begin{array}{l}\text { Este caso de uso é acionado quando o Aluno altera alguma característica } \\
\text { da interface de usuário (IU); nesse momento, inicia-se UC07, e atualiza- } \\
\text { se a base de dados relacionada às preferências do Aluno. As } \\
\text { preferências do Aluno aqui consideradas são, por exemplo: cor do tema } \\
\text { da interface e tamanho da fonte. }\end{array}$ \\
\hline UC09 & Gerar MU & $\begin{array}{l}\text { Este caso de uso é acionado quando o preenchimento da sondagem } \\
\text { inicial está completo; ele é responsável pelo cálculo dos indicadores } \\
\text { necessários à geração do Modelo do Usuário e pela seleção da persona } \\
\text { apropriada ao estilo } \\
\text { cognitivo do Aluno. }\end{array}$ \\
\hline UC10 & Montar interface & Este caso de uso é acionado quando o Aluno realiza o login (caso de uso \\
\hline
\end{tabular}




\begin{tabular}{|c|c|c|}
\hline & & $\begin{array}{l}\text { UC01), já possuindo um MU. Ele responsável pela seleção de signos de } \\
\text { interação e signos instrucionais apropriados para o Aluno. Para isso, } \\
\text { consulta o plano de } \\
\text { estudos, o Modelo do Usuário e as regras para adaptação. }\end{array}$ \\
\hline UC11 & $\begin{array}{l}\text { Manter signos } \\
\text { de interação }\end{array}$ & $\begin{array}{l}\text { Este caso de uso é iniciado pelo Designer e consiste na inclusão, } \\
\text { consulta, exclusão e alteração de signos de interação. Um signo de } \\
\text { interação é composto por aspectos perceptuais e aspectos } \\
\text { funcionais/operacionais. Quando um signo de interação é adicionado, o } \\
\text { sistema deve relacionar seu aspecto perceptual às IM. }\end{array}$ \\
\hline UC12 & $\begin{array}{l}\text { Manter } \\
\text { de con }\end{array}$ & $\begin{array}{l}\text { Este caso de uso pode ser iniciado pelo Professor ou pelo Designer de } \\
\text { signos. Consiste na inclusão, consulta, exclusão e alteração de signos de } \\
\text { conteúdo. Quando um signo de conteúdo é incluído, o sistema deve } \\
\text { associá-lo às IM correspondentes. }\end{array}$ \\
\hline UC13 & & $\begin{array}{l}\text { Este caso de uso é acionado pelo Professor e consiste na inclusão, } \\
\text { exclusão, consulta e alteração de planos de ensino. }\end{array}$ \\
\hline UC14 & $\begin{array}{l}\text { Manter regras } \\
\text { pedagógicas }\end{array}$ & $\begin{array}{l}\text { nnutenção (inclusão, consulta, } \\
\text { icas. Pode ser acionado pelo }\end{array}$ \\
\hline UC15 & Manter & $\begin{array}{l}\text { pelo Administrador e consiste na inclusão, } \\
\text { são de usuários, definição de privilégios de } \\
\text { stema. }\end{array}$ \\
\hline UC16 & $\begin{array}{l}\text { Manter } \\
\text { Inteligências } \\
\text { Múltiplas }\end{array}$ & $\begin{array}{l}\text { Este caso de uso é iniciado pelo Administrador e consiste na manutenção } \\
\text { das IM (inclusão, consulta, alteração e exclusão). Quando ocorre uma } \\
\text { inclusão, alteração ou exclusão de alguma IM, aciona-se o UC17 para } \\
\text { geração de novas personas. }\end{array}$ \\
\hline UC17 & is & $\begin{array}{l}\text { Este caso de uso é acionado quando uma IM é adicionada, excluída ou } \\
\text { alterada na base de dados. }\end{array}$ \\
\hline UC18 & $\begin{array}{l}\text { Mant } \\
\text { para }\end{array}$ & $\begin{array}{l}\text { Este caso de uso é acionado pelo Administrador, Professor e Designer e } \\
\text { consiste na manutenção das regras para adaptação (inclusão, consulta, } \\
\text { alteração e exclusão). As regras para adaptação são consultadas na } \\
\text { configuração da IU. }\end{array}$ \\
\hline UC19 & Mant & $\begin{array}{l}\text { Este caso de uso é acionado pelo Administrador e consiste na } \\
\text { manutenção de cursos e disciplinas, isto é, na inclusão, consulta, } \\
\text { alteração e exclusão de cursos ou disciplinas. }\end{array}$ \\
\hline UC20 & $\begin{array}{l}\text { Manter } \\
\text { sondagem } \\
\text { Inicial }\end{array}$ & $\begin{array}{l}\text { Este caso de uso é responsável pelo registro das respostas do aluno ao } \\
\text { questionário de sondagem inicial e à recuperação do ponto de parada, } \\
\text { quando o aluno não conclui o processo. }\end{array}$ \\
\hline
\end{tabular}

A Figura 25 mostra o layout da interface de usuário do sistema SHASIM, dividida em três frames principais.

1) Frame para Interação - contém os itens para interação do usuário, composto por uma lista para a escolha do curso e uma área com o roteiro de estudos de acordo com o curso selecionado, onde a exibição dos itens correspondentes ao conteúdo instrucional é adaptada dinamicamente com a navegação do usuário. A arquitetura original propõe ainda uma área de configuração da interface sempre visível, onde o usuário pudesse escolher a cor da interface, tamanho de fonte e outras configurações customizáveis. Como esta personalização não deve ser uma tarefa frequente a cada navegação e com o intuito de diminuir a carga visual da interface, é preferível que esta área de personalização seja visível apenas quando requisitada, trocando-se os itens de configuração por um link que aponte para uma página de 
personalização da interface. Este padrão de design é a forma mais comum encontrada em Websites populares como o Google e o Yahoo.

2) Frame Instrucional - é a área onde são apresentados os conteúdos instrucionais para o aluno da unidade de estudo selecionada. Os signos instrucionais são selecionados de acordo com as regras de adaptação e da persona que representa o aluno.

3) Frame Geral - área destinada a exibição de informações do aluno, mensagens do sistema e funções complementares como um link para o aluno efetuar o logoff.

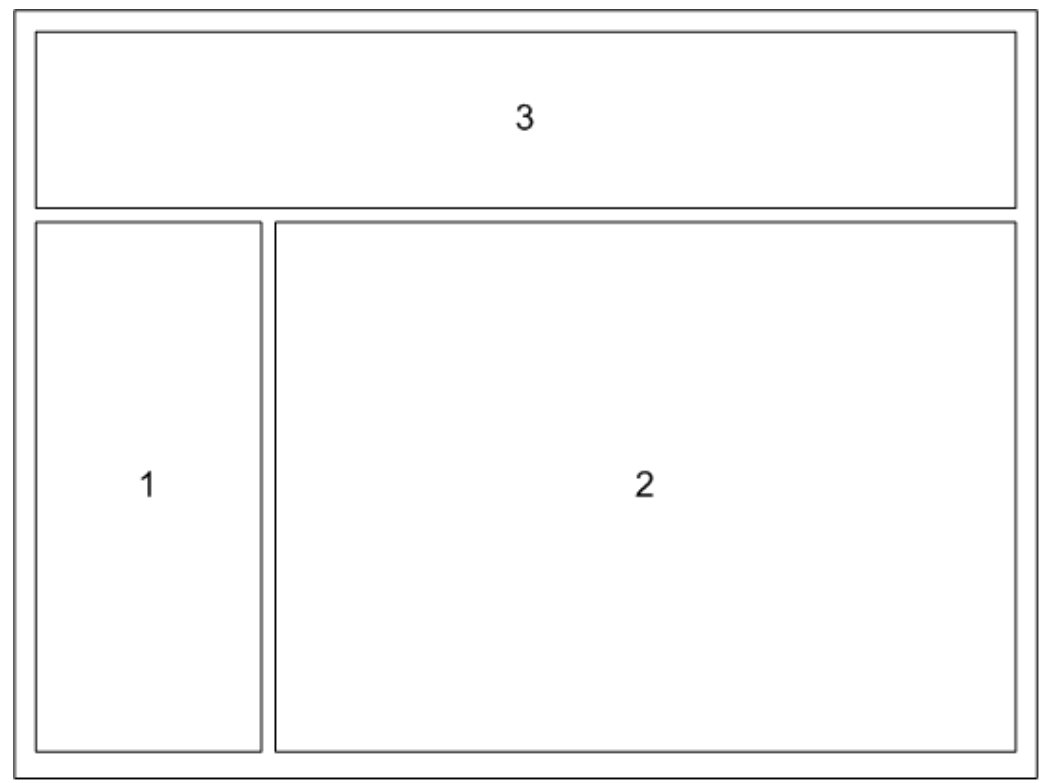

Figura 25 - Layout da interface de usuário

\subsubsection{Requisitos Adicionais}

A fim de garantir que os atributos de qualidade Confiabilidade, Segurança, Usabilidade e Manutenibilidade sejam realizados é necessário que alguns requisitos da arquitetura original sejam revistos e que outros sejam definidos.

- Confiabilidade: o sistema deve ser capaz de contornar situações de erro de forma transparente ao usuário ou, se não for possível, deve causar o mínimo de impacto ao usuário. A introdução de redundância no sistema, como a clusterização das camadas de apresentação e aplicação proposta na arquitetura de referência no capítulo 5, torna o sistema mais tolerante a falhas. $O$ 
transacionamento das atualizações da base de dados é outra premissa importante para que as informações armazenadas não sejam perdidas ou permaneçam em um estado consistente, mesmo na ocorrência de um erro durante uma operação de banco de dados. Na proposta original do SHASIM, a atualização do Modelo do Usuário (UC04 - Atualizar MU) ocorreria somente na execução do logoff pelo usuário (UC03 - Realizar logout), o que implicaria que as atualizações no Modelo do Usuário devam ser registradas na sessão do usuário. Esta abordagem apresenta desvantagens para a confiabilidade do sistema. A sessão do usuário, em servidores Web, está associada à instância do navegador Web do usuário. Assim, caso ocorra algum problema do lado do cliente e este seja obrigado a fechar a janela atual ou abrir uma nova janela do navegador, a sua sessão será perdida e, consequentemente, com isso, todas as informações previamente registradas. Além disso, a própria ação de logoff pode não ser executada pelo usuário, o que incorreria em perda de informações do Modelo do Usuário na sessão do usuário. Desta forma, ao invés de estar associado ao caso de uso "UC03 - Realizar logout", o caso de uso "UC04 - Atualizar MU” deve estar associado ao "UC07 - Registrar Ações" através de uma relação de inclusão (include) e acionado a cada ação do aluno que possa provocar a atualização de seu modelo de usuário. Assim, na sessão do usuário somente devem ser armazenados dados estáticos (por exemplo, informações de cadastro do usuário) ou quase estáticos (por exemplo, perfis de permissões de acessos às opções de interface).

- Segurança: toda a informação que trafega entre o usuário e o servidor deve ser criptografada, o que exige o uso de certificados digitais no servidor Web. $O$ SHASIM suporta quatro tipos de usuários com restrições de acessos diferentes ao sistema: aluno, professor, designer de signos e administrador. Por isso, é mandatória a autenticação de todos os usuários que acessem o sistema e a checagem de permissões para cada tipo de usuário, tanto em nível de interface gráfica, habilitando e desabilitando as opções de interface conforme o tipo de usuário, quanto em nível de serviço da camada de aplicação.

- Usabilidade: O SHASIM já prevê mecanismos visando a usabilidade do sistema, tais como opções de personalização da interface e controles de interação que facilitem a navegação pela estrutura hierárquica dos conteúdos dos cursos. 
- Manutenibilidade: O protótipo do SHASIM foi desenvolvido utilizando tecnologias proprietárias como Microsoft C\# para as interfaces e a linguagem PL/SQL do banco de dados Oracle para as funções adaptativas, escolha que pode ocasionar problemas de desempenho, manutenibilidade e portabilidade ao sistema. A inclusão de lógica de aplicação na camada de banco de dados pode sobrecarregá-la, ocasionando perda de desempenho na consulta e atualização de dados. O uso de uma linguagem de banco de dados na implementação das funções do sistema implica em redução de manutenibilidade do sistema, decorrente das limitações da própria linguagem frente a outras linguagens orientadas a objetos. A portabilidade do sistema também fica comprometida, pois o PL/SQL é uma linguagem proprietária específica do banco de dados da Oracle.

- Tecnologia: Como o SHASIM é voltado para a educação, é recomendado que sejam utilizadas tecnologias de código aberto em sua arquitetura, eliminando-se desta forma qualquer restrição de implantação por causa de custos de licenças de software. A tecnologia Java satisfaz esse requisito - oferecer ferramentas e ambientes sem custos de licença - além de ser compatível com bancos de dados de código aberto.

Outros requisitos funcionais precisam ser definidos na nova arquitetura do SHASIM, pois foram pouco explorados na proposta original. $\mathrm{Na}$ concepção original do SHASIM, o frame instrucional poderia ser formado por uma composição de signos instrucionais e de interação, o que poderia gerar uma interface muito complexa e com excesso de informação para o aluno. Deste modo, propõe-se como regra de composição para o frame instrucional um signo com aspecto perceptual textual, com informações e definições sobre a unidade de estudo corrente, e um signo complementar, selecionado através da persona do aluno como, por exemplo, um diagrama ou animação. A fim de permitir que o aluno possa acessar outros signos instrucionais além daquele selecionado pelo sistema, é necessário que existam controles de interação para seleção de outros signos de uma mesma unidade de estudo, se existirem. O frame instrucional será assim composto pelo signo textual e por um frame interno para o signo complementar. Ao se navegar por outros signos complementares, somente o frame interno é atualizado, mantendo-se o signo textual e outras partes da tela inalteradas, pois esta interação não deve provocar a alteração da unidade de estudo. 
Para a estrutura interna do Modelo do Usuário, define-se a utilização do modelo overlay, onde para cada conceito do domínio, é armazenado no Modelo do Usuário um valor representativo do nível do conhecimento do usuário em relação ao conceito (WU, 2002). A atualização de um atributo dependente do domínio ocorrerá no acesso (estratégia expositiva) ou execução (estratégia de exercício) de uma unidade de estudo. A seleção de outro signo instrucional complementar de uma mesma unidade de estudo não deve atualizar o Modelo do Usuário, já que não se trata de um novo acesso à unidade corrente.

\subsection{VISÃO LÓGICA}

De acordo com Kruchten (1995), na visão lógica o sistema é decomposto em uma série de abstrações na forma de objetos e classes de objetos a partir do domínio do problema. Na proposta de Puga (2008), esta visão do SHASIM já foi representada. No entanto, esta visão sofreu algumas modificações devido a ajustes na arquitetura original. As alterações decorrem principalmente da modularização da arquitetura em camadas, das quais se destacam a camada de apresentação e a camada de aplicação, conforme a arquitetura de referência descrita no capítulo 5. Os modelos que sofreram maiores alterações foram os Modelos de Adaptação e de Signos, pois nestes são encontradas operações que fazem parte tanto da construção da interface (responsabilidade da camada de apresentação) quanto de atualizações de signos e Modelo do Usuário (responsabilidade da camada de aplicação).

O termo "modelo" foi substituído pelo termo "módulo" na arquitetura proposta, pois a intenção é transformar cada um dos modelos em módulos da arquitetura, que em termos físicos serão representados por componentes de software. 


\subsubsection{Módulo de Usuário}

O Módulo de Usuário comporta as funções de manutenção de usuários e dos atributos do Modelo de Usuário. Na Figura 26 é mostrado o Modelo de Usuário proposto por Puga (2008) e o módulo para atender a nova arquitetura é exibido na Figura 27.

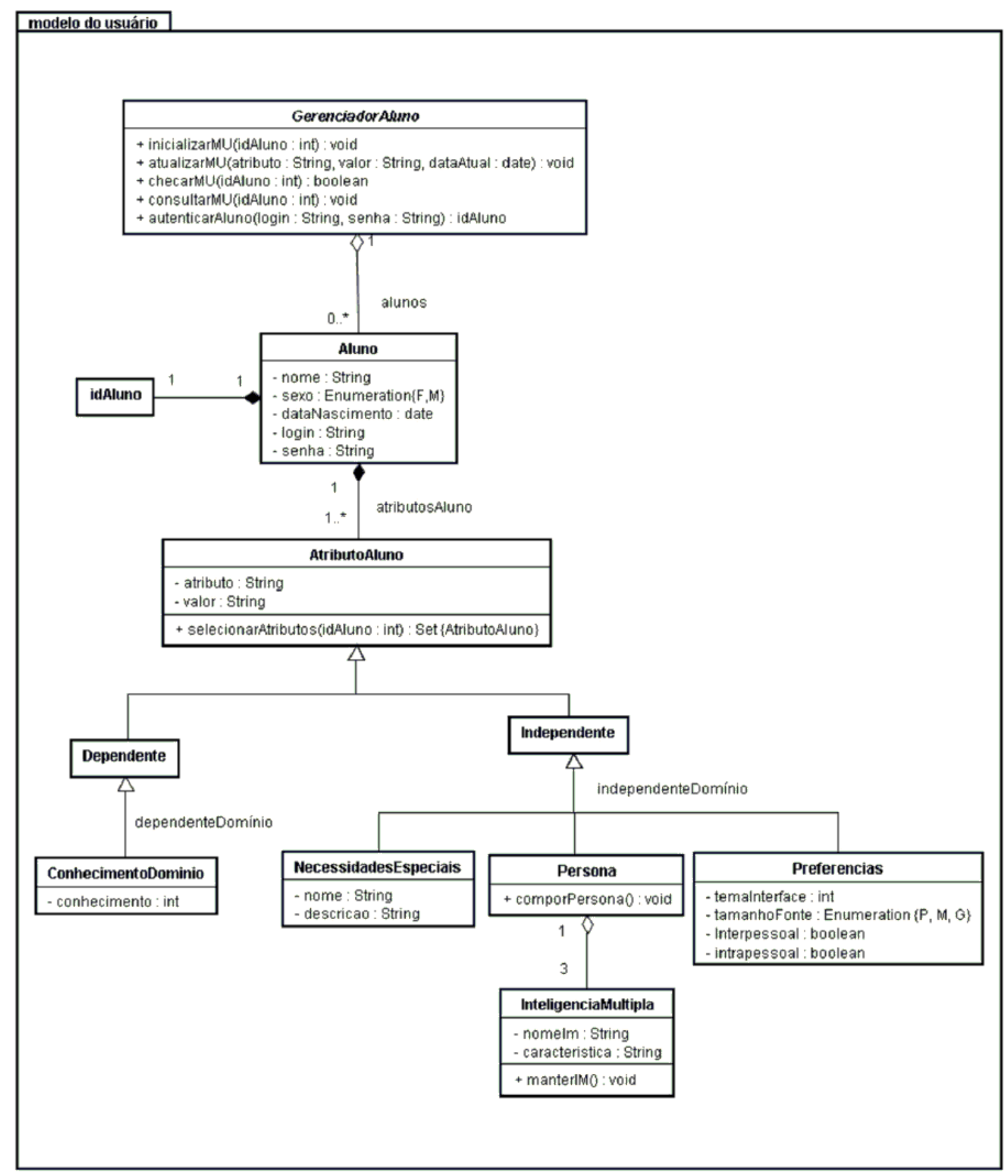

Figura 26 - Módulo de usuário original - extraído de Puga (2008, p. 111) 


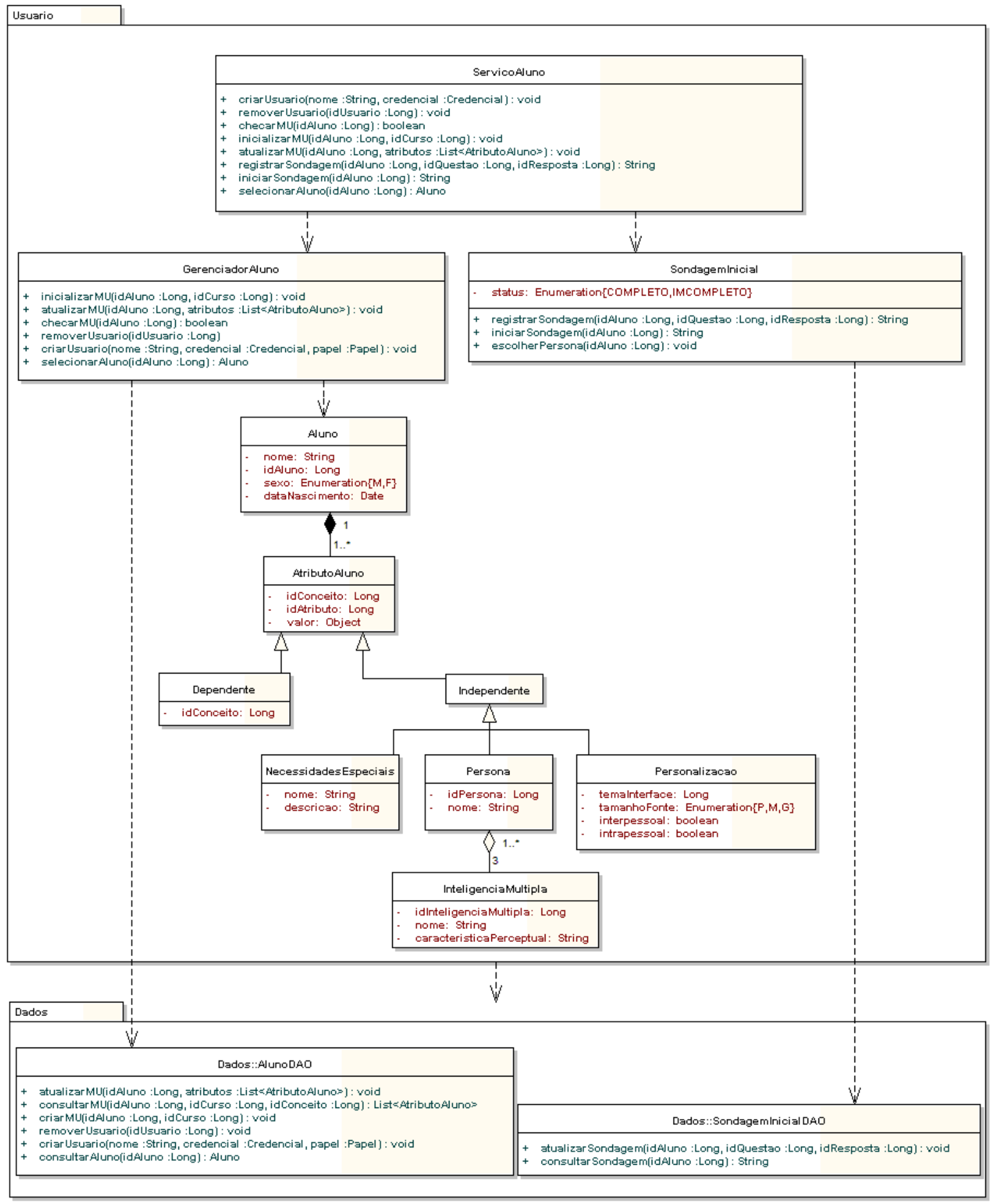

Figura 27 - Módulo de Usuário da arquitetura proposta para o SHASIM

O Módulo do Usuário é composto pela classe Aluno e pelos seus atributos dependentes e independentes de domínio. Os atributos dependentes refletem o conhecimento do aluno em relação ao domínio e os independentes representam as características e preferências do usuário. Em relação ao modelo original, foram realizadas poucas alterações nestas entidades. As informações de segurança (login e senha), consideradas atributos da classe Aluno no modelo original, foram 
realocadas para a classe Credencial do módulo de segurança criado na nova arquitetura. Além disso, a função selecionarAtributos da classe AtributoAluno foi movida e renomeada para selecionarAluno da classe GerenciadorAluno. Uma consulta a um aluno implica também na consulta dos seus atributos e, portanto, do seu modelo de usuário. Deste modo, a função consultarmu da classe GerenciarAluno no modelo original também foi omitida na nova modelagem.

Em relação ao modelo original, foi criada a classe ServicoAluno, com o propósito de tornar as funções do módulo acessíveis remotamente para outras camadas do sistema (camada de apresentação) conforme o padrão Service Layer explicado no capítulo 5. Para cada função da classe de serviço, deve ser informado o principal, que é o objeto que armazena a informação do usuário autenticado para verificação das permissões de execução do serviço. A classe de serviços invoca os métodos das classes GerenciadorAluno e SondagemInicial.

A classe GerenciadorAluno possui as principais funções relacionadas ao Modelo de Usuário. No novo módulo foram previstas funções adicionais para criação e remoção de usuários do sistema (criarUsuario e removerUsuario). A função de autenticação autenticarAluno foi movida do módulo de usuário para o novo módulo de segurança descrito na seção 6.2.2. As funções de inicialização (inicializarMU), atualização (atualizarMU) e checagem (checarMU) foram mantidas da modelagem original.

A sondagem inicial, representada pela classe SondagemInicial da Figura 27, é o processo pelo qual o aluno responde a um questionário, cujas respostas serão utilizadas pelo sistema para atribuição de uma persona ao aluno. No modelo original, as respostas ao questionário são armazenadas na sessão do usuário e persistidas somente no final do processo de sondagem. Esta abordagem possui o mesmo problema de confiabilidade encontrada na atualização do Modelo do Usuário em sessão, uma vez que não se garante a recuperação das respostas, se ocorrer algum problema durante a navegação do usuário. Em relação ao modelo de Puga (2008), foram realizadas as seguintes alterações com respeito à sondagem inicial:

1. Os métodos de sondagem inicial foram transformados em serviços do subsistema do aluno para que possam ser acessados pela camada de apresentação. Desta 
forma, todos os métodos devem retornar a localização da página com a próxima pergunta do questionário.

2. Foi criado o método iniciarSondagem, em que é informado o usuário e retornada a localização da página em que se deve iniciar (ou reiniciar) a sondagem.

3. O serviço registrarSondagem retorna a informação da página com a próxima questão da sondagem. Ao fim do questionário, este método deve executar a função escolherPersona para o cálculo e atribuição da persona do aluno.

Na Figura 27 está representada parte da camada de acesso aos dados referente à consulta e persistência dos objetos do Domínio de Usuário na base de dados. A classe AlunoDAO possui as operações de banco de dados relacionadas ao Módulo do Usuário e a classe SondagemInicialDAO possui as operações de banco de dados relacionadas à sondagem inicial.

\subsubsection{Módulo de Segurança}

O Módulo de Segurança é introduzido nesta arquitetura com o intuito de prover as funções de segurança necessárias para atender este requisito de qualidade. Este módulo segue a arquitetura proposta no capítulo 5 e está baseada no conceito de autenticação e autorização de acesso aos recursos do sistema baseado em papéis. Os papéis de usuários foram descritos na seção 6.1 e correspondem ao Aluno, Designer de Signos, Professor e Administrador, enumerados pela classe TipoPapel da Figura 28. 


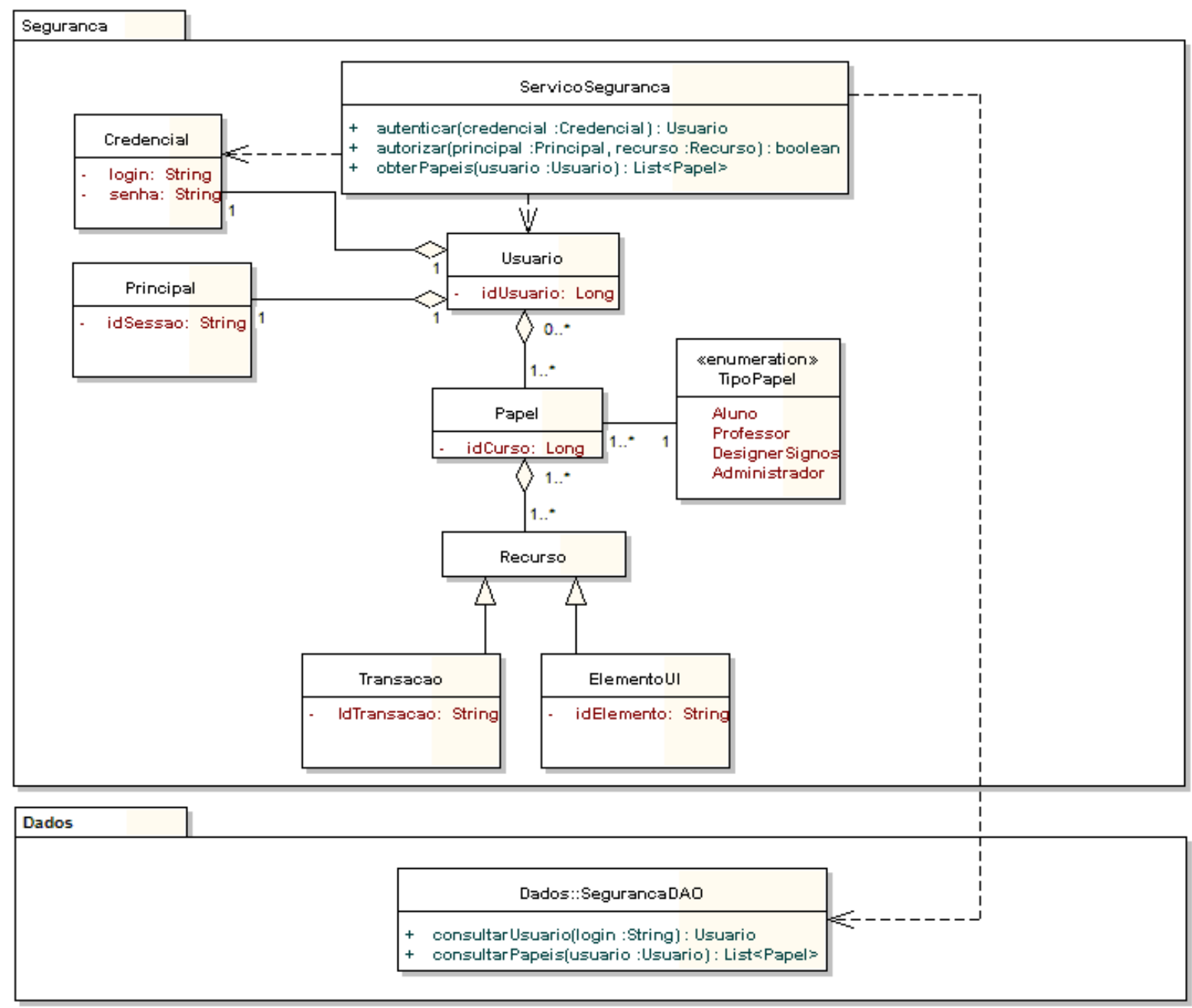

Figura 28 - Módulo de Segurança da arquitetura proposta para o SHASIM

A classe Principal agrega as informações de acesso de um usuário autenticado no sistema, como o atributo idSessao - utilizado para recuperar e verificar a validade da sessão do usuário - e os papéis desempenhados pelo usuário. Cada papel está associado a um tipo e a um curso, além das informações de acesso aos recursos. Deste modo, é possível saber quais os cursos e os recursos acessíveis a um aluno ou professor. Um recurso pode ser uma Transação (serviço da camada de aplicação) ou elemento da interface gráfica.

A classe ServicoSeguranca agrega as funções de segurança disponíveis para a camada de apresentação e para os demais módulos do sistema. A função autenticar, originalmente alocada na classe GerenciadorAluno, é responsável por autenticar os acessos dos usuários do sistema, baseando-se em algo que o usuário possua (credencial formada por login e senha). A função autorizar é 
utilizada pelos outros módulos da camada de aplicação para autorizar o acesso aos recursos oferecidos, que neste caso corresponde a uma transação (serviço). Para os módulos da camada de apresentação, é disponibilizada a função obterPapeis, para que seja possível a recuperação dos papéis e recursos acessíveis a um determinado usuário. Através da listagem dos papéis, a camada de apresentação consegue identificar os cursos disponíveis por papel e montar a interface de usuário de acordo com os recursos (elementos) de interface associados a cada papel.

O modulo de segurança depende do módulo de acesso aos dados (classe SegurancaDAO) para a consulta das informações do usuário e permissões de acesso armazenadas em banco de dados.

\subsubsection{Módulo de Domínio}

O Modelo de Domínio do SHASIM contempla as entidades do domínio educacional e está representado em sua forma original na Figura 29 e com as alterações propostas na Figura 30. 


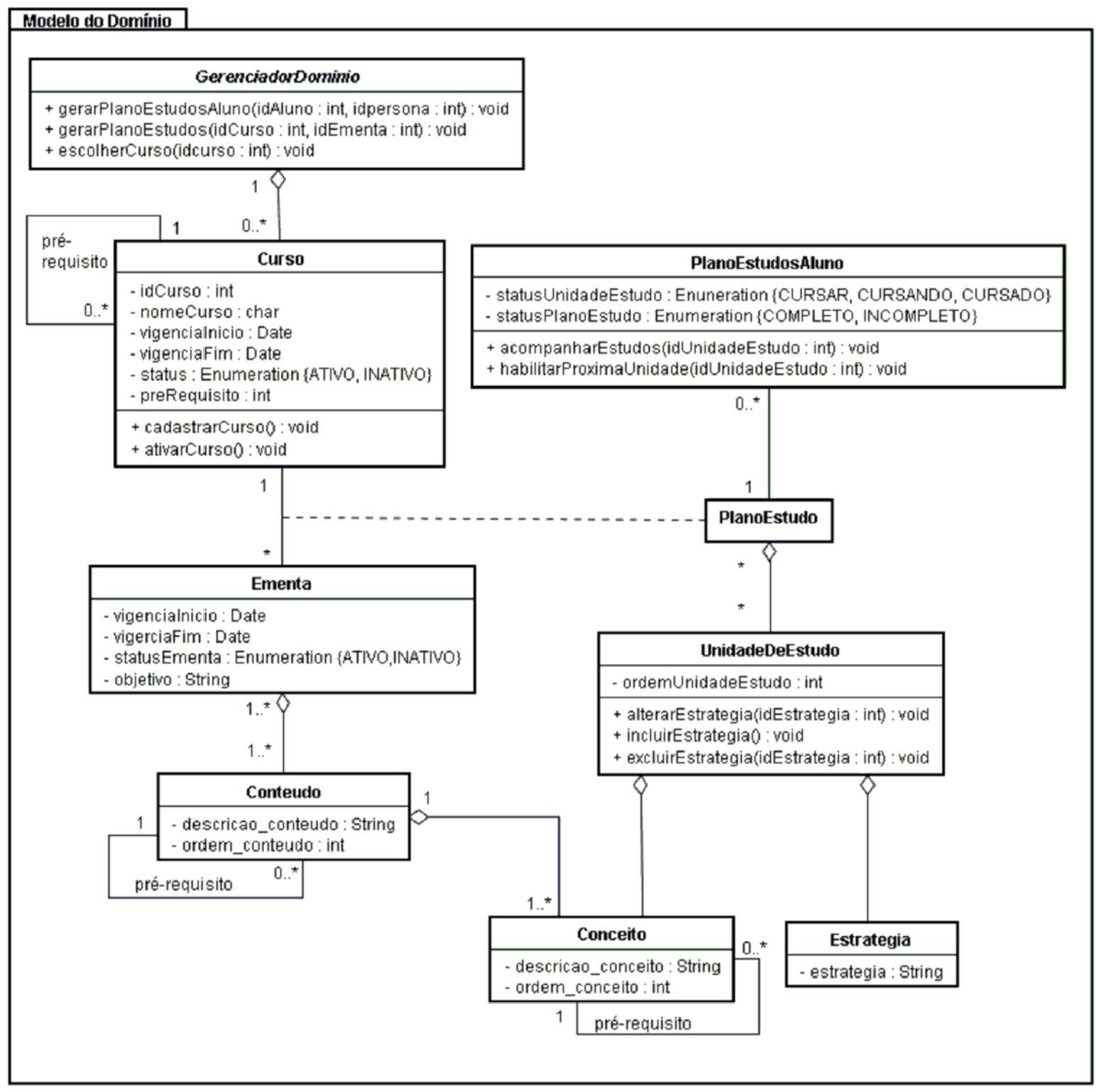

Figura 29 - Modelo de Domínio original - extraído de Puga (2008, p. 128) 


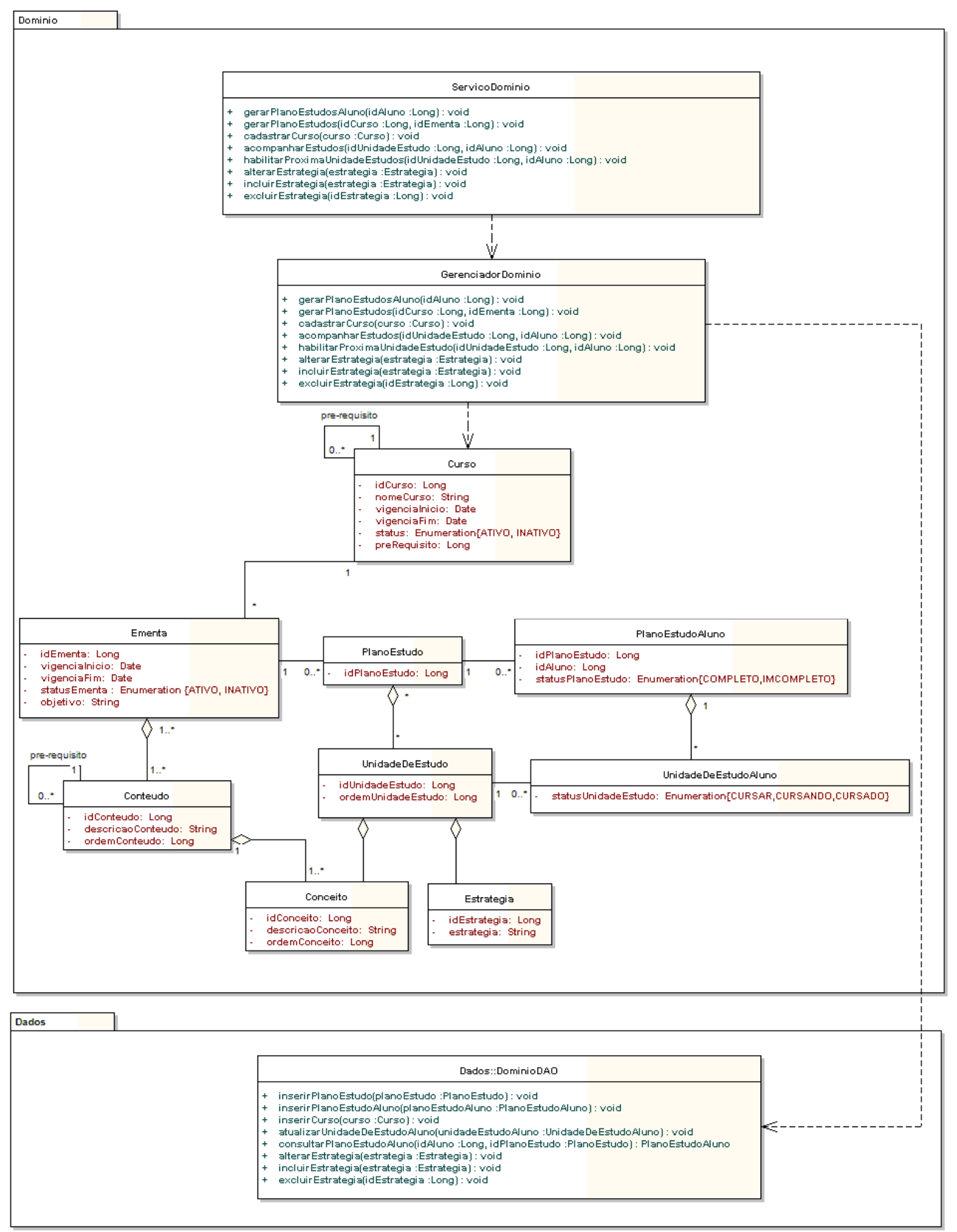

Figura 30 - Módulo de Domínio da arquitetura proposta para o SHASIM

O domínio é formado por cursos (classe Curso), identificados por um código e um nome e com status e período de vigência. No novo módulo, o método de cadastro foi movido para a classe GerenciadorDominio, pois a classe Curso é uma entidade 
que pode trafegar entre as camadas do sistema e o cadastro de curso é processado somente na camada da aplicação. Na camada de apresentação, por exemplo, os objetos de Curso são utilizados para montar a lista de cursos disponíveis ao aluno.

Um curso está associado a uma ementa (classe Ementa) vigente. Uma ementa é uma composição de conteúdos (classe conteudo), em que cada conteúdo pode ser formado por um ou mais conceitos (classe conceito), que é a menor unidade instrucional do domínio. O plano de estudos (classe PlanoEstudo) está associado a uma ementa e é gerado de acordo com os conteúdos dela. Um plano de estudos é formado por unidades de estudo (classe UnidadeDeEstudo), em que cada unidade de estudo é uma composição de um conceito e a estratégia de ensino deste conceito (exposição, exercício, simulação ou avaliação). As funções para manutenção de uma unidade de estudo (alterarEstrategia, incluirEstrategia e excluirEstrategia) foram realocadas para as classes GerenciadorDominio e ServicoDominio a fim de torná-las disponíveis para a camada de apresentação. A função acompanharEstudos é utilizada para atualizar os status das unidades de estudo conforme o progresso do aluno. Se uma unidade de estudo for concluída, o sistema deve atualizar o MU do aluno através do método atualizarMU do módulo do usuário. A função acompanharEstudos também foi realocada para as classes GerenciadorDominio e ServicoDominio, para torná-las acessíveis à camada de apresentação.

As classes PlanoEstudoAluno e UnidadeEstudoAluno pertencem ao domínio do aluno - diferentemente das classes PlanoEstudo e UnidadeDeEstudo que pertencem ao domínio da aplicação - e são utilizadas para acompanhar o progresso do aluno em relação a um plano e unidade de estudo. A classe UnidadeEstudoAluno foi incluída no novo módulo para que seja possível acompanhar o status de todas as unidades de estudo de um plano de estudo. $\mathrm{Na}$ proposta original, o status da unidade de estudo (atributo statusUnidadeEstudo) pertence a classe PlanoEstudoAluno, o que não permite este tipo de acompanhamento.

Na Figura 30 está representada parte da camada de acesso aos dados referente à consulta e persistência dos objetos do módulo de domínio na base de dados (classe DominioDAO). 


\subsubsection{Módulo de Adaptação}

O Modelo de Adaptação do SHASIM contempla o conjunto de funções para a realização da adaptação do sistema e atualização do Modelo do Usuário. O modelo está representado em sua forma original na Figura 31 e com as alterações propostas na Figura 32.

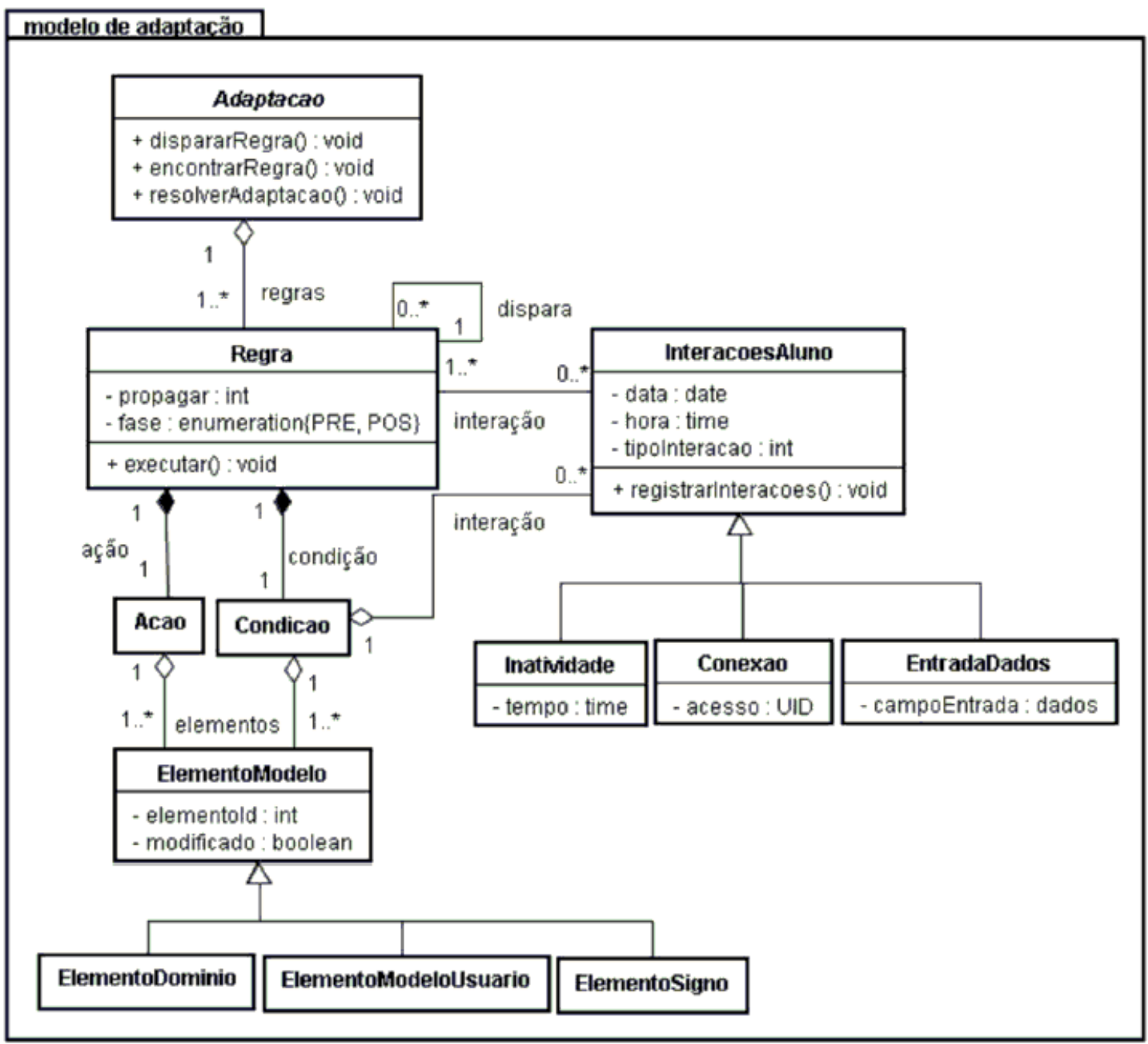

Figura 31 - Modelo de Domínio original - extraído de Puga (2008, p. 133) 


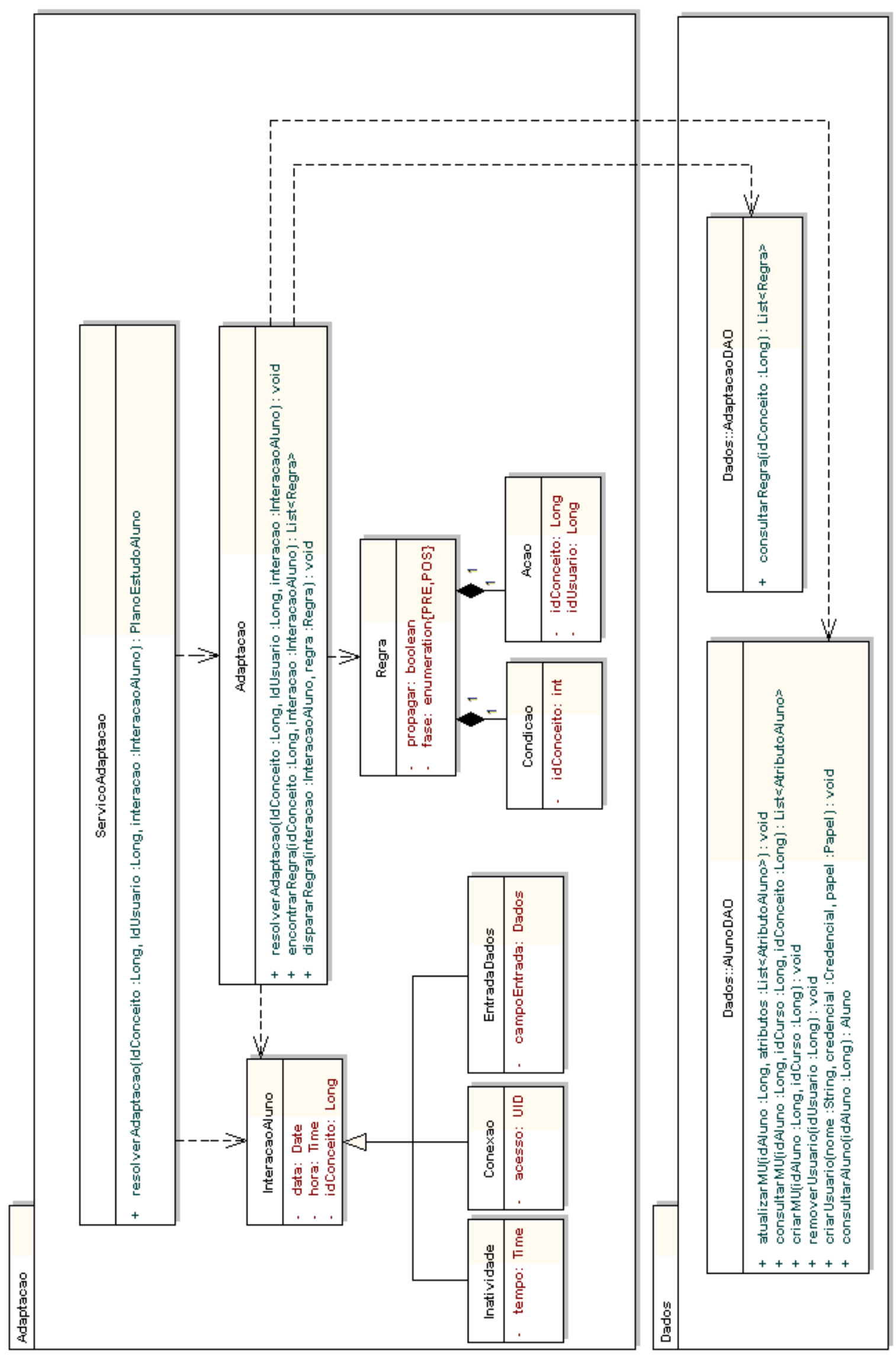

Figura 32 - Módulo de Adaptação da arquitetura proposta para o SHASIM 
As regras do Modelo de Adaptação no SHASIM seguem a classificação de Koch (2002), mas adequadas aos propósitos do modelo, conforme abaixo:

- Regras de construção - são as regras utilizadas na composição do conteúdo instrucional e relacionadas diretamente ao Modelo do Domínio.

- Regras de adaptação - são as regras responsáveis pela orientação dos procedimentos para a realização da adaptação da interface e seleção dos signos instrucionais que serão apresentados. As regras de adaptação consideram os Modelos do Domínio e Usuário para a obtenção do efeito adaptativo da interface.

- Regras de aquisição - são as regras responsáveis pela orientação dos processos de geração e atualização do Modelo do Usuário.

- Regras de signos são responsáveis pela associação de um signo às inteligências múltiplas e às unidades de estudo.

No Módulo de Adaptação da arquitetura proposta, são armazenadas e executadas somente as regras de aquisição, responsáveis pelos processo de atualização do Modelo do Usuário. A regra de composição do signo instrucional foi definida como a composição de um signo textual e outro selecionado de acordo com a persona do aluno e faz parte do Módulo de Apresentação (a ser explicado na seção 6.2.6). As regras de adaptação também fazem parte da camada de apresentação, pois tratam da adaptação da camada de apresentação ao usuário de acordo com suas inteligências múltiplas. As regras de signos estão logicamente relacionadas ao Modelo de Signos e, portanto, foram movidos do Módulo de Adaptação.

Observa-se pela Figura 32 que uma regra é composta por uma ação e uma condição, ou seja, se uma condição for satisfeita, a ação será realizada. A condição está associada a uma interação do aluno (classe InteracoesAluno) sobre um conceito do domínio como, por exemplo, o acesso a uma unidade de estudo, a entrada de dados ou mesmo a inatividade por um intervalo de tempo pré-definido. A ação correspondente à atualização de um conceito no Modelo do Usuário.

As principais funções deste módulo são: resolverAdaptacao, encontrarRegra e dispararRegra. O aluno, ao acessar ou introduzir um dado relativo a uma unidade de estudo, realiza uma ação que deverá alterar o seu Modelo de Usuário. Nesta interação, a função resolverAdaptacao do Módulo de Adaptação da 
camada de aplicação é invocada pela camada de apresentação. Para descobrir qual regra deve ser disparada nesta interação, a função encontrarRegra é chamada e posteriormente a função dispararRegra para executá-la. A execução de uma regra pode atualizar outros elementos do Modelo do Usuário, podendo ocasionar a execução de outras regras.

O modelo da Figura 32 possui como diferenças em relação ao modelo original da Figura 31 a criação da classe Servi coAdaptacao com os serviços expostos para a camada de apresentação e a ausência da classe ElementoModelo e subclasses. Tanto a ação quanto a condição relacionam-se a conceitos do domínio, o que torna os elementos do Modelo do Usuário (classe ElementoModeloUsuario) e Modelo de Signos (classe ElementoSigno) desnecessários.

O módulo de adaptação depende das classes AdaptacaoDAO e AlunoDAO pertencentes à camada de acesso ao banco de dados. A operação consultarRegra da classe AdaptacaoDAO consulta todas as regras armazenadas no banco de dados associadas a um conceito. A classe AlunoDAO é utilizada para atualizar o Modelo de Usuário do aluno no banco de dados, durante a execução de uma regra de adaptação.

\subsubsection{Módulos de Signos e Componentes}

De acordo com a especificação do SHASIM (PUGA, 2008), o Modelo de Signos é responsável pela seleção e organização dos signos que serão apresentados ao aluno. No entanto, segundo a divisão de responsabilidades da nova arquitetura, a montagem da interface de usuário é executada na camada de apresentação, o que acarretaria a transferência da funcionalidade de composição dos signos para a camada de apresentação (módulo de apresentação). O modelo original está representado na Figura 33 e o novo módulo na Figura 34. 


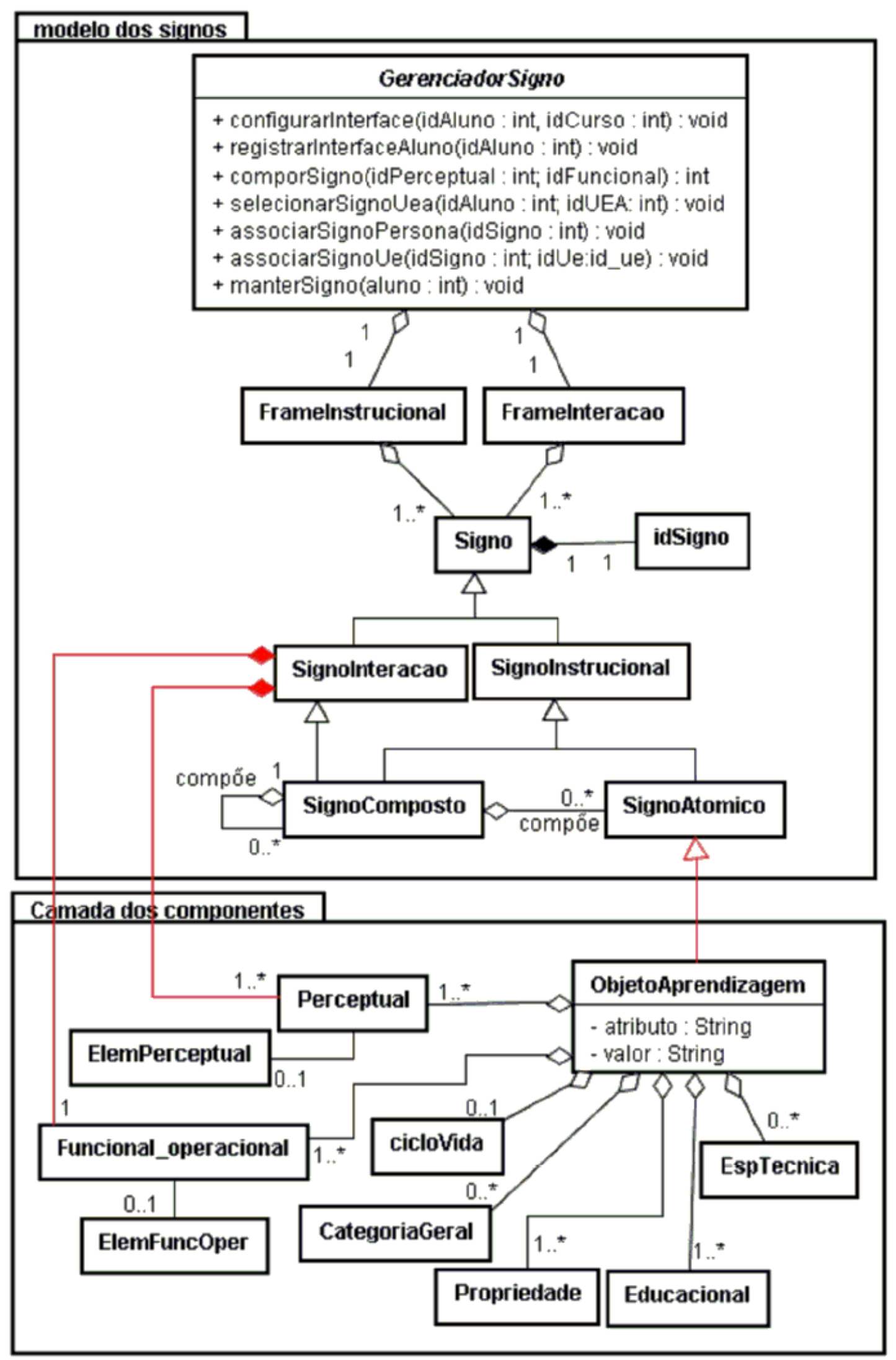

Figura 33 - Modelo de Signos original - extraído de Puga (2008, p. 146) 


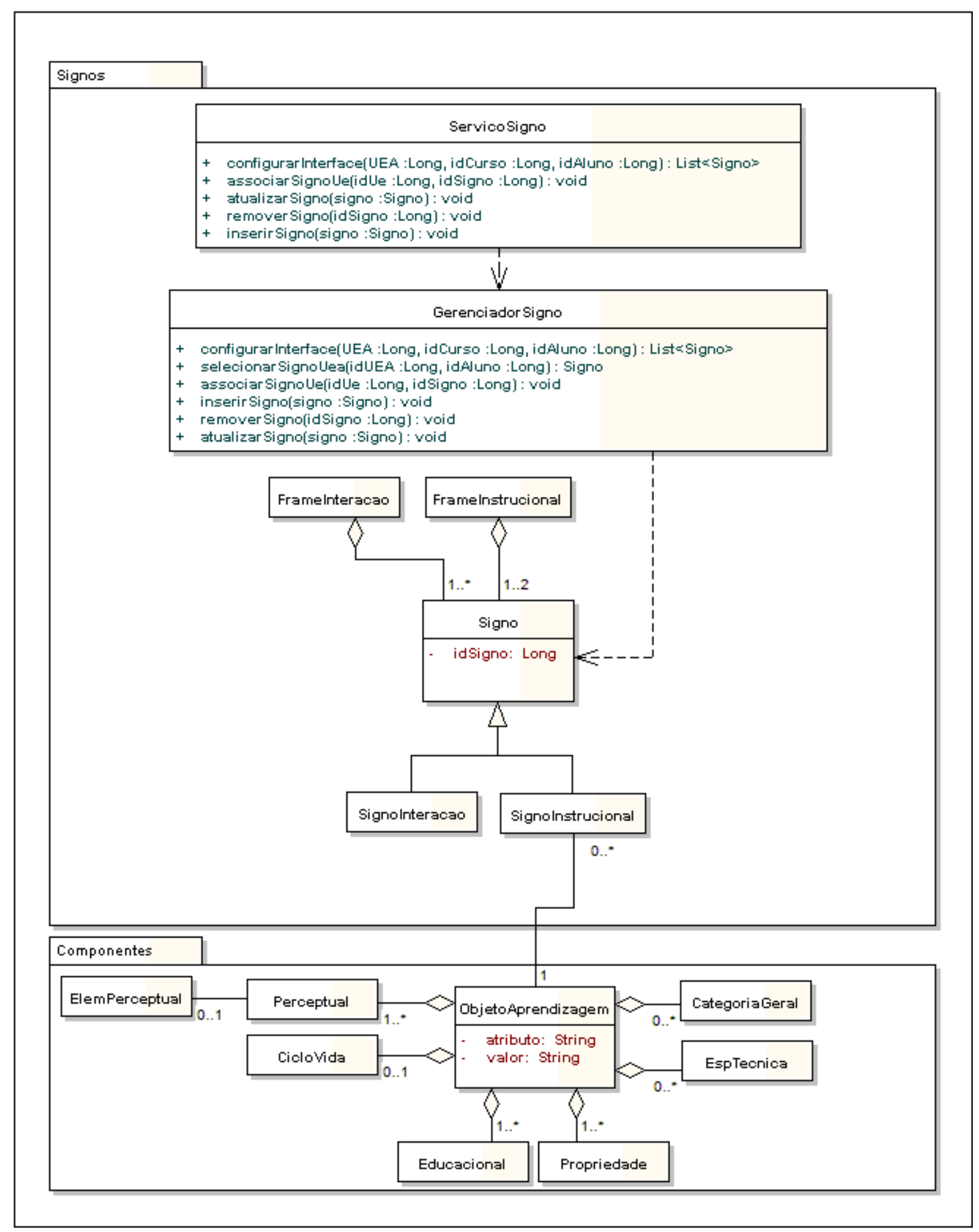

Figura 34 - Módulo de Signos da arquitetura proposta para o SHASIM

Uma alteração do Módulo de Signos da Figura 34 em relação à Figura 33 foi a eliminação do signo composto (classe SignoComposto) como a composição de signos atômicos (classe SignoAtomico). Isto se deve ao fato de que no modelo do SHASIM não é descrito como é realizada a composição de signos atômicos para 
formar um signo composto. Desta forma, foi adotada a premissa de que os signos são atômicos, com a composição do frame instrucional formado por um signo textual e outro selecionado pelo Módulo de Signos (método selecionarSignoUea). O método que será exposto como serviço para a camada de apresentação é o configurarInterface. Este método tem como objetivo selecionar, dentre os signos disponibilizados para a unidade de estudo corrente, o signo descritivo (percepção textual) e o signo selecionado através da persona do aluno (método selecionarSignoUea).

Devido à falta de padronização e à existência de diversos formatos de objetos de aprendizagem - por exemplo, o Learning Object Metadata $\left(\operatorname{LOM}^{6}\right)$, o Dublin Core ${ }^{7}$ e o SCORM $^{8}$-, a arquitetura não deve se restringir apenas a um formato específico. Desta forma, foi criada a camada de interface de objetos de aprendizagem, representada pelo Módulo de Componentes da Figura 34, com o objetivo de isolar a arquitetura do formato de objeto de aprendizagem a ser utilizado. Os mecanismos de interação com o repositório de objetos ficam restritos a esta camada. Com isso, o Módulo de Signos trabalha apenas com objetos Signo, independentemente do padrão de objeto de aprendizagem adotado. Um objeto de Signo encapsula um objeto ObjetoAprendizagem, que por sua vez encapsula um objeto de aprendizagem de um dos formatos existentes.

Alguns métodos da classe GerenciadorSigno do modelo original foram movidos ou removidos na nova modelagem. O método comporsigno foi omitido da nova modelagem, pois a função de composição de signos faz parte da camada de apresentação. O método registrarInterface para armazenamento da configuração dos signos da interface foi removido, pois a configuração da interface de usuário é um processo dinâmico realizado em tempo de execução, a cada interação do usuário, de acordo com o estado do seu Modelo de Usuário. O método mantersigno foi desmembrado em inserirSigno, removersigno e atualizarSigno, pois a agregação de muitas funcionalidades em um único método torna a reutilização e a manutenção mais difíceis.

\footnotetext{
${ }^{6}$ http://ieeeltsc.org/

${ }^{7} \mathrm{http}: / /$ dublincore.org/

${ }^{8} \mathrm{http}: / / w w w . a d l n e t . g o v /$
} 


\subsubsection{Módulo de Apresentação}

O Módulo de Apresentação é o componente principal da camada de apresentação da arquitetura, responsável por receber as ações do usuário sobre a interface, interpretá-las e construir a interface adaptativa.

A classe FrontController é responsável por receber as requisições do usuário, tanto com envio de dados (por exemplo, na execução de exercícios ou testes) quanto no simples acesso a uma unidade de estudo, sem envio de dados. Após a identificação do curso e unidade de estudos acessada, é necessário que as regras para atualização do Modelo do Usuário sejam executadas (módulo Adaptacao). Depois que o Modelo do Usuário for atualizado pela interação do aluno, é preciso que os signos instrucionais sejam selecionados para a unidade de estudos corrente e de acordo com a persona do aluno (módulo Signos). As classes AdaptadorApresentacao, AdaptadorConteudo e AdaptadorNavegacao correspondem às regras de adaptação do modelo SHASIM. A classe AdaptadorApresentacao adaptará a interface do usuário para as preferências selecionadas pelo aluno. A classe AdaptadorConteudo construirá o conteúdo instrucional da unidade de estudos para os signos selecionados no módulo de signos. Por fim, a classe AdaptadorNavegacao construirá o roteiro de estudos com o plano de estudos do aluno, adaptando os links, dependendo se a unidade já foi estudada ou se obedece aos pré-requisitos. Os elementos principais do Módulo de Apresentação e os relacionamentos estão representados na Figura 35. 


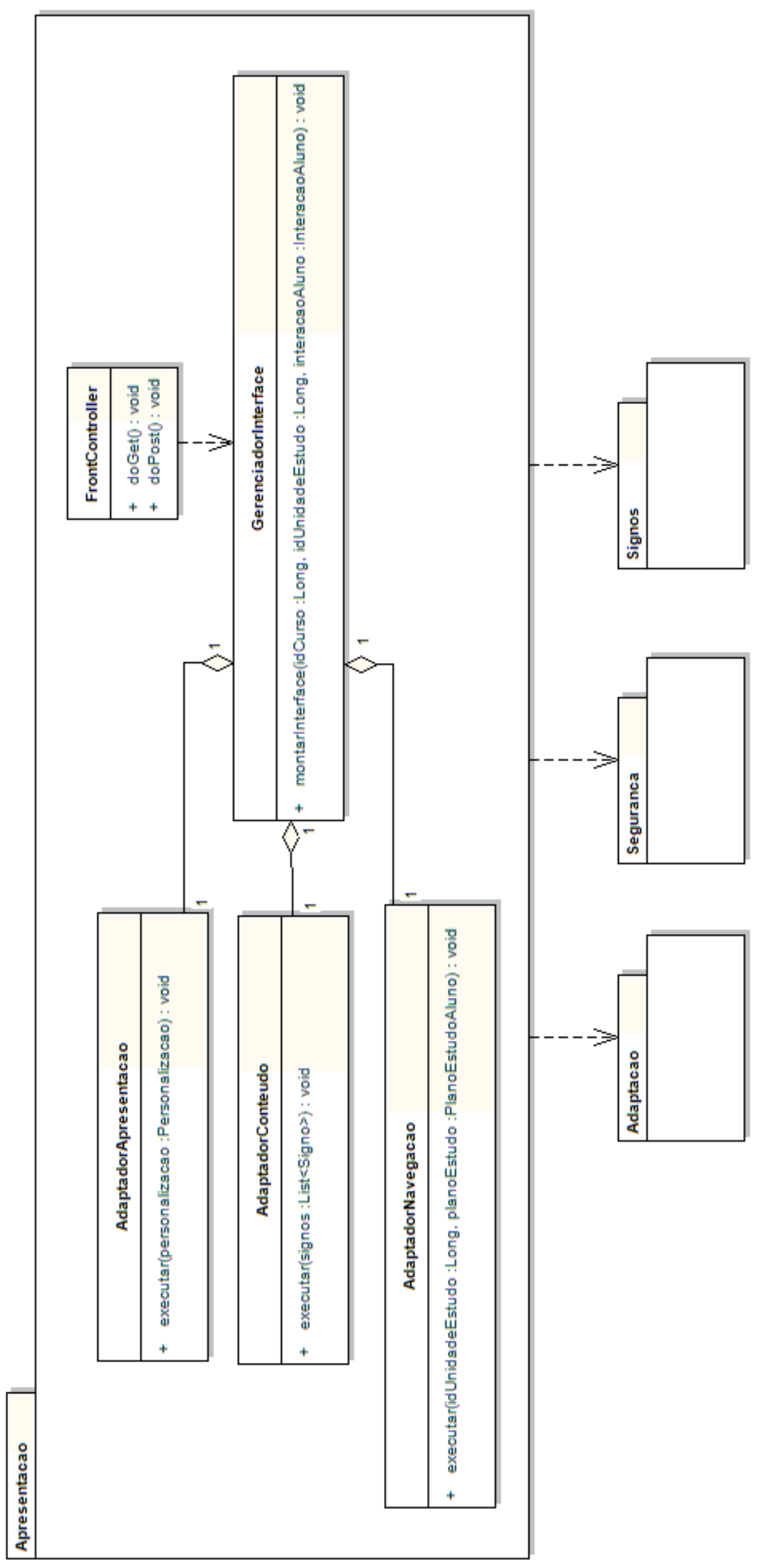

Figura 35 - Módulo de Apresentação da arquitetura proposta para o SHASIM 


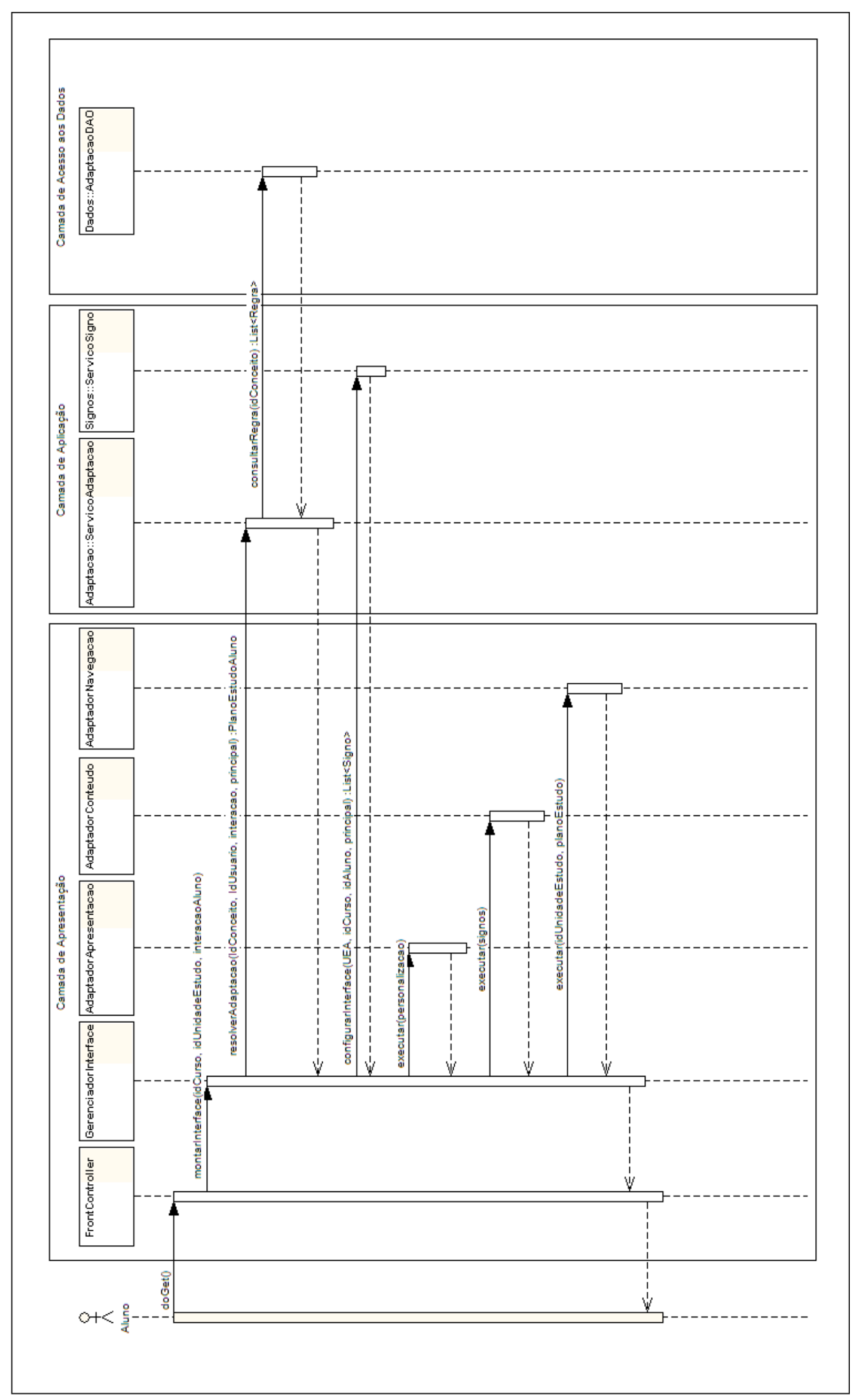

Figura 36 - Interação da Camada de Apresentação com os demais módulos da arquitetura proposta 
A camada de apresentação é o consumidor dos serviços oferecidos pelos módulos da camada de aplicação. A dinâmica de execuções das funções da camada de aplicação durante a montagem da interface adaptativa é apresentada no diagrama de sequência da Figura 36. Neste diagrama, é possível verificar a interação de maneira simplificada entre as três camadas principais do sistema (apresentação, aplicação e acesso a dados) desde a requisição até a resposta ao usuário.

\subsection{VISÃO DE DESENVOLVIMENTO}

A visão de desenvolvimento ou implementação descreve a organização estática dos módulos do software (código fonte, arquivos de dados, componentes, executáveis e outros artefatos de implementação) no ambiente de desenvolvimento em termos de empacotamento, camadas do sistema e gerenciamento de configuração. Esta visão tem como objetivo facilitar a visualização dos artefatos gerados no desenvolvimento.

O diagrama de atividades da UML é destinado a modelar a visão estática de implementação de um sistema, na forma dos artefatos gerados durante $\mathrm{O}$ desenvolvimento (código fonte e módulos físicos executáveis) (BOOCH; RUMBAUGH; JACOBSON, 2005). O diagrama de artefatos da Figura 37 mostra os principais componentes gerados pelas atividades de implementação e os relacionamentos com as classes da visão lógica. 


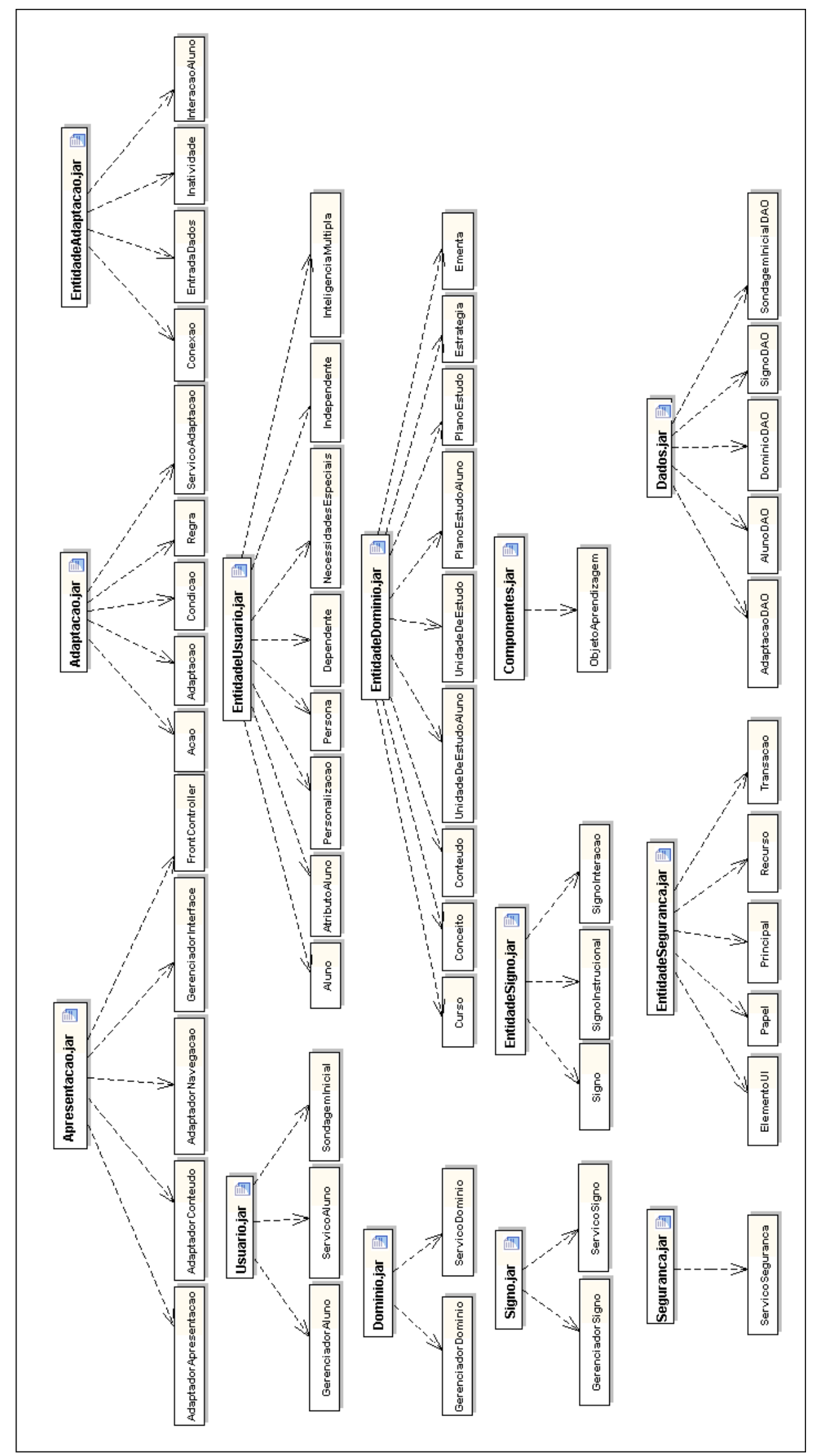

Figura 37 - Diagrama de artefatos da Visão de Implementação da arquitetura proposta para o SHASIM 
Em Java, os componentes são coleções de classes empacotadas em arquivos, com a extensão ".jar". O módulo de apresentação da camada de apresentação corresponde ao componente Apresentacao.jar. Este componente será executado no servidor Web, com a função de inserir na interface do usuário os signos selecionados na camada de aplicação.

Os módulos da camada de aplicação - Adaptacao, Usuario, Dominio, Signo e Seguranca - foram subdivididos em dois componentes físicos: um componente com os serviços oferecidos pelo módulo e outro com as classes de entidades que podem trafegar entre as camadas do sistema (objetos remotos serializáveis). Desta forma, o módulo de Adaptação da visão lógica, por exemplo, corresponde aos componentes Adaptacao.jar e EntidadeAdaptacao.jar. Esta divisão física é necessária pois os componentes de serviço são implantados apenas nos servidores de aplicação (camada de aplicação), enquanto que os componentes de entidades são distribuídos em todas as camadas do sistema (apresentação, aplicação e acesso à dados).

A camada de acesso aos dados é representada pelo componente Dados.jar. Este componente oferece serviços de consulta e atualização da base de dados à camada de aplicação e geralmente é localizada na mesma camada física (servidor de aplicação) que a camada de aplicação. Nesta proposta de arquitetura, como o repositório de dados é o banco de dados, este componente tem como responsabilidade transformar o modelo de objetos, representado pelas classes de entidades, no modelo relacional, representado pelas tabelas do banco de dados. Esta camada deve encapsular a utilização de recursos de persistência da tecnologia Java como a API (Application programming interface) para acesso ao gerenciador de banco de dados (por exemplo, JDBC, JPA etc.) e os comandos SQL para acessar os objetos do banco.

O diagrama que representa a visão de desenvolvimento permite a visualização dos artefatos que deverão ser desenvolvidos para o sistema e o mapeamento do código fonte em componentes de execução do sistema. Esta visão é importante para o gerenciamento das atividades de desenvolvimento, a estimativa de esforço envolvido e divisão de trabalho de implementação. 


\subsection{VISÃo FÍSICA}

A visão física ou visão de implantação mostra como os vários componentes executáveis são mapeados fisicamente nas plataformas ou nós de processamento. Esta visão aborda requisitos não funcionais tais como confiabilidade, desempenho, escalabilidade e segurança. A visão física da arquitetura mostrada na Figura 38 foi descrita através de um diagrama de implantação da UML. Diagramas de implantação são utilizados para a modelagem dos aspectos físicos de um sistema orientado a objetos, exibindo a configuração dos nós de processamento e os artefatos que residem neles. 


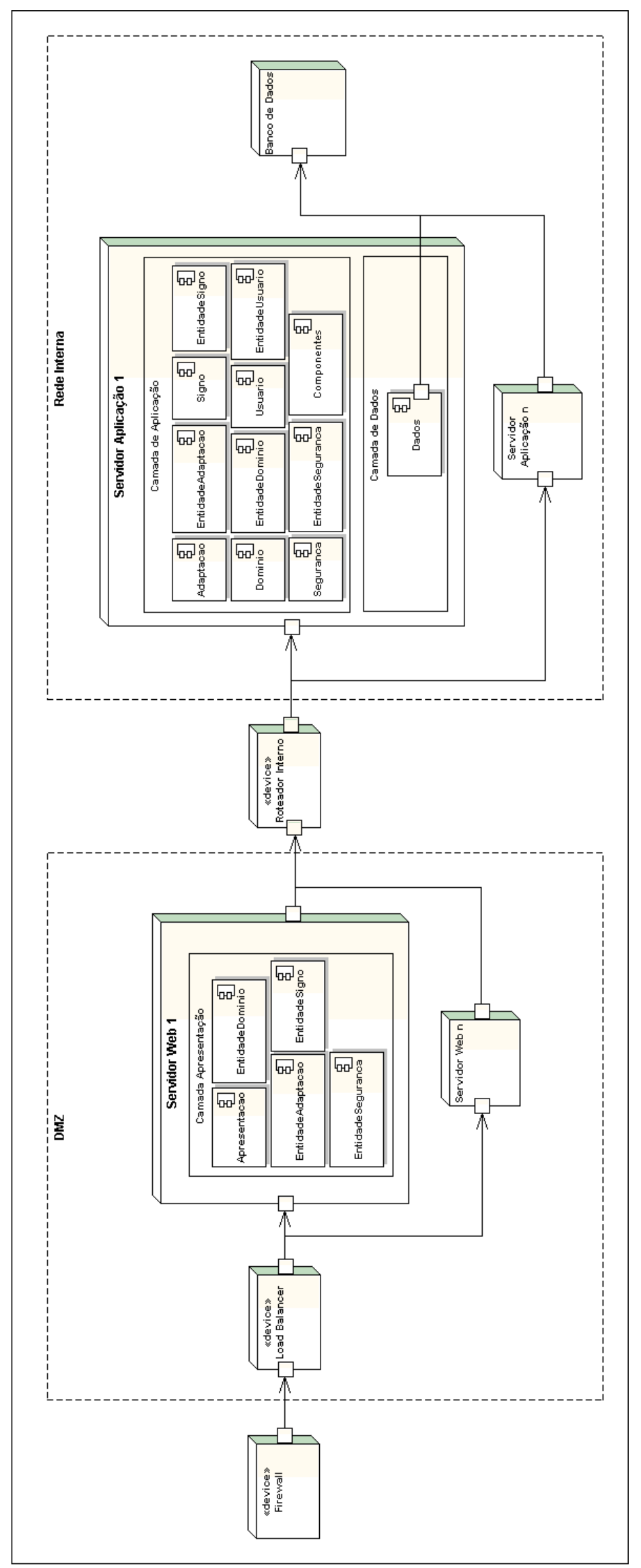

Figura 38 - Diagrama de implantação da Visão Física da arquitetura proposta para o SHASIM 
A nova arquitetura para o SHASIM segue a arquitetura de referência proposta no capítulo 5. Na arquitetura física do sistema, o aumento da confiabilidade é possível através da redundância de processamento dos servidores Web, representados pelo Servidor Web 1 e Servidor Web n da Figura 38, e de servidores de aplicação, representados pelo Servidor Aplicação 1 e Servidor Aplicação n da Figura 38. Esta configuração permite uma grande flexibilidade tanto em escalabilidade vertical, através do aumento do poder de processamento de cada nó, quanto em escalabilidade horizontal, através da introdução de novos nós nos clusters.

As requisições externas são distribuídas entre os nós de servidores Web pelo balanceador de carga (Load Balancer). No servidor Web (camada de apresentação) são implantados os componentes do módulo de apresentação (Apresentacao) e os objetos remotos do sistema (EntidadeDominio, EntidadeAdaptacao, EntidadeSigno e EntidadeSeguranca).

No servidor de aplicação, estão localizadas as camadas de aplicação e de acesso aos dados. Na camada de aplicação, estão dispostos os componentes do módulo de adaptação (Adaptacao e EntidadeAdaptacao), signos (Signo e EntidadeSigno), domínio (Dominio e EntidadeDominio), usuário (Usuario e EntidadeUsuario), componentes (Componentes) e segurança (Seguranca e EntidadeSeguranca). Na camada de acesso aos dados, é alocado apenas o componente Dados, que executará a transformação do modelo de objetos para o modelo relacional do banco de dados e encapsulará todos as chamadas ao gerenciador de banco de dados. Encapsulamento e concentração dos acessos ao banco de dados estão ilustrados na Figura 38 pela conexão entre o componente Dados e o servidor de banco de dados. Cada um dos componentes de serviços da camada de aplicação (Adaptacao, Signo, Dominio, Usuario e Seguranca) acessa o componente Dados para a leitura e atualização das informações armazenadas em banco de dados. Estas relações não foram representadas na Figura 38 para melhor legibilidade do diagrama.

A disposição física do sistema é motivada por questões de segurança. Os servidores Web, por interagirem diretamente com o tráfego da Internet, estão localizados em uma zona demilitarizada (delimitarized zone - DMZ), para que fiquem isolados da 
região onde estão localizados os recursos de negócio do sistema (servidores de aplicação e banco de dados). O roteador interno permite apenas que o tráfego originado dos servidores Web possa alcançar os servidores de aplicação e o banco de dados na rede interna. O tráfego na direção oposta, originado da rede interna, é permitido até os servidores Web, para que os usuários internos e administradores do sistema possam acessar estes servidores.

A definição de uma arquitetura é influenciada pelo ambiente onde será implantada, conforme estabelece a norma ISO/IEC 42010 (2007) para descrição arquitetural de sistemas de software. É possível uma segunda disposição física para os componentes de software nos elementos físicos do sistema, conforme é mostrado na Figura 39. 


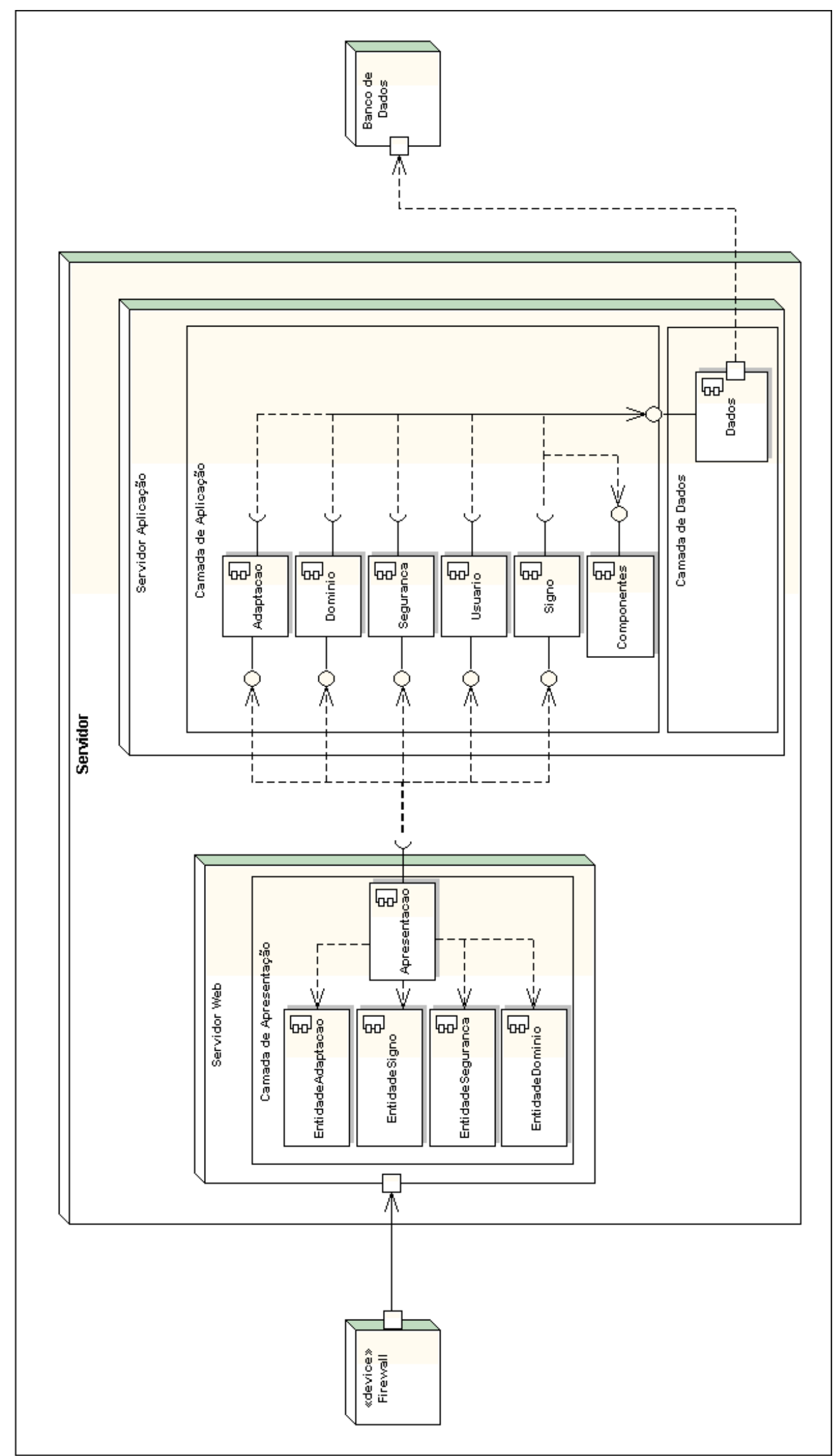

Figura 39 - Segunda alternativa da Visão Física da arquitetura proposta para o SHASIM 
Nesta configuração simplificada, os servidores Web e de aplicação (software) residem em um mesmo servidor físico. A segurança do sistema neste arranjo é menor, pois o servidor de aplicação agora reside na mesma área suscetível a ataques que o servidor Web. A escalabilidade horizontal dos servidores ainda é possível, mas não de forma independente entre as camadas Web e de aplicação. Esta configuração pode ser utilizada em situações em que não existe disponibilidade de servidores individuais para a camada de apresentação e de aplicação e com exigências de segurança menos restritivas como, por exemplo, para aplicação somente em Intranet.

\subsection{VISÃO DE PROCESSOS}

A visão de processo do Modelo de Visão "4+1" tem como objetivo abordar os aspectos de concorrência e paralelismo do sistema em tempo de execução tarefas, threads ou processos -, bem como as suas interações. Em sistemas para a Web, uma das funcionalidades dos servidores Web e dos servidores de aplicação é controlar a instanciação, concorrência e isolamento entre threads de processamento. A concorrência de acessos aos mesmos objetos no banco de dados é controlada pelo gerenciador do banco de dados. Deste modo, cada requisição do cliente pode ser considerada como um processo isolado, que não interfere nos demais.

\subsection{CONSIDERAÇÕES FINAIS}

Neste capítulo foi apresentada a proposta de arquitetura para o SHASIM. Para a definição de uma arquitetura, todos os requisitos funcionais e não funcionais devem ser considerados. Na proposta inicial do SHASIM, o foco principal foi nas funcionalidades responsáveis pelas características adaptativas do sistema, sem 
fazer referências a qualidades de software importantes como confiabilidade, segurança e manutenibilidade.

A arquitetura proposta mapeou as entidades funcionais do SHASIM em elementos de software e ambientes de processamento. Para a descrição da arquitetura foi utilizado o modelo de visões "4+1" do RUP, devido à sua forte ligação com a técnica de orientação a objetos. Cada visão do modelo "4+1" está relacionada a um ou mais diagramas UML, que é a linguagem mais utilizada para a modelagem de arquitetura de software. 


\section{CONCLUSÕES}

Este trabalho apresentou a arquitetura de software como uma importante disciplina para o desenvolvimento de sistemas de software, mas que muitas vezes é negligenciada ou utilizada de forma incorreta. No domínio dos sistemas hipermídia adaptativos, por exemplo, pouco foi explorado em relação aos atributos de qualidade destes sistemas, levando-se a arquiteturas deficientes ou incompletas.

Para a concepção de uma arquitetura de software, além dos requisitos funcionais e não funcionais, devem ser considerados também as condições do ambiente envolvido, como regras e restrições de negócio da instituição ou organização, em conformidade com a norma ISO/IEC 42010 (2007). Esta norma aborda uma questão bastante enfatizada neste trabalho que é a descrição da arquitetura de software. A documentação de uma arquitetura deve ser completa o suficiente para atender às expectativas de todas as partes interessadas (stakeholders) no sistema.

Na seção 7.1 são descritas as contribuições geradas com este trabalho no campo da arquitetura de sistemas hipermídia adaptativos e na seção 7.2 são relacionados os trabalhos futuros para esta pesquisa.

\subsection{CONTRIBUIÇÕES DO TRABALHO}

A principal contribuição do trabalho foi a de propor uma complementação no desenvolvimento de arquiteturas de sistemas hipermídia adaptativos baseada em atributos de qualidade, os quais somente podem ser representados através de um conjunto de visões arquiteturais. Conforme já mencionado ao longo do trabalho, os modelos existentes de hipermídia adaptativa focam-se nos requisitos funcionais como, por exemplo, nas funções adaptativas, ignorando ou concedendo pouco enfoque aos requisitos não funcionais.

Este trabalho enfatizou a importância da arquitetura de software e da forma como ela deve ser descrita, através de visões que possibilitem o entendimento do sistema sob 
diferentes perspectivas. A norma ISO/IEC 42010 (2007) foi utilizada para formalizar os aspectos de influência sobre a concepção e documentação da arquitetura.

Os modelos de referência, como o modelo Munich, apresentam apenas os módulos funcionais, conforme é o propósito de um modelo de referência. Através de atributos de qualidade considerados importantes para um sistema hipermídia adaptativo e de táticas e padrões arquiteturais para se atingir estes atributos, foi desenvolvida uma arquitetura de referência baseada no modelo Munich. Uma arquitetura de referência representa um passo adicional em direção a uma arquitetura final de software, pois tangibiliza um modelo abstrato (modelo de referência) em um modelo de software. Falta ainda à arquitetura de referência que sejam considerados outros fatores extrínsecos ao sistema, como restrições tecnológicas, regulamentares e de recursos.

O SHASIM foi escolhido como o modelo sobre o qual se desenvolveu uma nova arquitetura de software, trabalho este que foi realizado em duas etapas. A primeira foi o levantamento de atributos de qualidade não considerados na proposta original. A segunda, foi a redefinição da arquitetura, pois, tendo sido implementada uma versão inicial do sistema baseada no modelo sem considerar todas os requisitos de qualidade necessários, foi preciso aprofundar o estudo destas características para futuras implementações do sistema de forma mais robusta. A nova arquitetura do SHASIM representou um caso prático da abordagem de arquitetura de software de sistemas hipermídia adaptativos baseada em atributos de qualidade.

\subsection{TRABALHOS FUTUROS}

Para a arquitetura proposta para o SHASIM, algumas premissas não puderam ser assumidas, pois dependem do ambiente pretendido para o sistema. Os recursos computacionais disponibilizados e o ambiente dos usuários do sistema (Internet ou Intranet), por exemplo, constituem fatores que interferem na disposição física dos módulos de software, o que pode gerar mais de uma visão física para o sistema, conforme discutido no capítulo 6 . Como trabalho futuro, há a necessidade de desenvolver esta arquitetura em um ambiente com todas as restrições definidas. 
O Módulo de Componentes foi projetado para isolar a arquitetura e torná-la independente das diversas especificações de objetos de aprendizagem. Por este motivo, os detalhes deste módulo não puderam ser aprofundados, pois dependem da escolha do padrão de objetos de aprendizagem. Uma proposta de trabalho futuro seria o detalhamento funcional deste módulo a partir de um dos modelos de objetos de aprendizagem conhecidos tais como o Learning Object Metadata (LOM), o Dublin Core e o SCORM.

Embora o foco deste trabalho seja na arquitetura de SHA, as visões apresentadas contém detalhes de projeto, para que pudessem ser comparadas com as representações de modelos como o Munich e o SHASIM, que chegam a este nível de detalhe. Estas visões poderão ser mais bem detalhadas em trabalhos futuros, inclusive com a utilização de padrões de projeto que eventualmente não tenham sido identificados. 


\section{REFERÊNCIAS}

ALMEIDA JR., J. Segurança em Sistemas Críticos e em Sistemas de Informação Um Estudo Comparativo. 2003. 191p. Tese (Livre Docência) - Escola Politécnica, Universidade de São Paulo, São Paulo, 2003.

ALUR, D.; CRUPI, J.; MALKS, D. Core J2EE Patterns: Best Practices and Design Strategies. $2^{\text {nd }}$ ed. Palo Alto, CA: Prentice Hall, 2003. 650 p.

ASSOCIAÇÃO BRASILEIRA DE NORMAS TÉCNICAS. NBR ISO/IEC 9126-1, Engenharia de software - Qualidade de produto - Parte 1: Modelo de qualidade. Rio de Janeiro, 2003.

BASS, L.; CLEMENTS, P.; KAZMAN, R. Software Architecture in pratice. $2^{\text {nd }}$ ed. Boston, MA: Addison Wesley, 2002. 560 p.

BECKER, S.; MOTTAY, F. A Global perspective on Web site usability. IEEE Software, Los Alamitos, v. 18, n. 1, p. 54-61, 2001.

$\mathrm{BOOCH}, \mathrm{G}$. Object-oriented analysis and design with applications. $2^{\text {nd }}$ ed. Redwood City, CA: Benjamin Cummings, 1994. 608p.

BOOCH, G.; RUMBAUGH, J.; JACOBSON, I., The Unified Modeling Language user guide. $2^{\text {nd }}$ ed. Westford, MA: Addison Wesley, 2005, 496p.

BRUSILOVSKY, P. Methods and techniques of Adaptive Hypermedia. User Modeling and User-Adapted Interaction, Dordrecht, v. 6, n. 2, p. 87-129, 1996.

BRUSILOVSKY, P. Adaptive navigation support in educational hypermedia: The role of student knowledge level and the case for meta-adaptation. British Journal of Educational Technology, v. 45, n. 4, p. 487-497, 2003.

BRUSILOVSKY, P.; EKLUND, J.; SCHWARZ, E. Web-based education for all: A tool for developing adaptive courseware. In: INTERNATIONAL WORLD WIDE WEB CONFERENCE, 7., 1998, Brisbane. Computer Networks and ISDN Systems. Amsterdam: Elsevier Science Publishers, 1998. p. 291-300. Disponível em: <http://www2.sis. pitt.edu/ peterb/papers/www98.pdf >. Acesso em: 4 jan. 2009. 
BRUSILOVSKY, P.; MAYBURY, M. From adaptive hypermedia to the adaptive Web. Communications of the ACM, New York, v. 45, n. 5, p. 30-33, 2002.

BUGAY, E. O Modelo AHAM - MI: Modelo de hipermídia adaptativa utilizando inteligências múltiplas. 2006. 213 p. Tese (Doutorado) - Universidade Federal de Santa Catarina, Florianópolis, 2006.

BUSCHMANN, F.; HENNEY, K.; SCHMIDT, D. Pattern-oriented software architecture volume 4: A Pattern language for distributed computing. Chichester: Wiley, 2007. 636 p.

BUSCHMANN, F. et al. Pattern-oriented software architecture volume 1: A System of patterns. Chichester: Wiley, 1996. $476 \mathrm{p}$.

CLEMENTS, P. et al. Documenting software architectures, views and beyond. Addison-Wesley, 2002. $560 \mathrm{p}$.

DE BRA, P.; CALVI, L. Creating adaptive hyperdocuments for and on the Web. In: WORLD CONFERENCE ON THE WWW AND INTERNET, 2., 1997, Toronto. WebNet Proceedings. Toronto: AACE, 1997. p. 149-154.

DE BRA, P.; SMITS, D.; STASH, N. The design of AHA!. In: ACM HYPERTEXT CONFERENCE, 17., 2006, Odense. Conference on Hypertext and Hypermedia. Odense, Denmark: ACM, 2006. p. 133. Disponível em: $<$ http://wwwis.win.tue.nl/ debra/dm-elearning.pdf>. Acesso em: 08 jan. 2009.

EGYHAZY, C.; MUKHERJI, R. Interoperability architecture using RM-ODP. Communications of the ACM, New York, v. 47, n. 2, p. 93-97, 2004.

ESTEFAN, J. et al. (ed.). Reference architecture for Service Oriented Architecture version 1.0, public review draft 1. OASIS, 2008. Disponível em: < http://docs.oasis-open.org/soa-rm/soa-ra/v1.0/soa-ra-pr-01.pdf>. Acesso em: 08 fev. 2009.

EKLUND J.; ZEILIGER, R. Navigating the Web: possibilities and practicalities for adaptive navigational support. In: AUSTRALIAN WORLD WIDE WEB CONFERENCE (AUSWEB), 3., 1997, Lismore. Proceedings...[ S.I.:s.n.]. Disponível em:

<http://ausweb.scu.edu.au/aw96/tech/eklund1/paper.htm>. Acesso em: 20 set. 2009. 
FOWLER, M. et al. Patterns of enterprise application architecture. Boston, MA: Addison Wesley, 2002. $560 \mathrm{p}$.

FROHLICH, P.; NEJDL, W.; WOLPERS, M. KBS-HYPERBOOK - An open hyperbook system for education. In: WORLD CONF. ON EDUCATIONAL MEDIA AND HYPERMEDIA (EDMEDIA'98), 10., 1998, Freiburg. Proceedings...[ S.I.:s.n.]. Disponível em: <http://www.kbs.unihannover.de/paper/98/edmedia98/edmedia98.doc>. Acesso em: 05 out. 2009.

GARDNER, H. Inteligências Múltiplas - A teoria na prática. Tradução de Maria Adriana Veríssimo Veronese. Porto Alegre: Artes Médicas, 1995. 257 p.

GARLAND, J.; ANTHONY, R. Large-scale software architecture: a practical guide using UML. New York, NY: Wiley, 2002. 278 p.

HALASZ, F.; SCHWARTZ, M. The Dexter hypertext reference model. Communications of the ACM, New York, v. 37, n. 2, p. 30-39, 1994.

HENDERSON, C. Building scalable Web sites: building, scaling, and optimizing the next generation of Web applications. Sebastopol, CA: O'Reilly, 2006. 330 p.

HOFMEISTER, C.; NORD, R.; SONI, D. Applied software architecture. Reading, MA: Addison-Wesley, 2000. 432 p.

INTERNATIONAL ORGANIZATION FOR STANDARDIZATION. ISO/IEC-9126-2, Software engineering - product quality - part 2: external metrics. Genebra, 2003.

INTERNATIONAL ORGANIZATION FOR STANDARDIZATION. ISO/IEC-19476-3. Reference model of open distributed processing (ODP), part 3: architecture. Genebra, 1995.

INTERNATIONAL ORGANIZATION FOR STANDARDIZATION. ISO/IEC 42010::IEEE Std 1471-2000. Systems and software engineering - recommended practice for architectural description of software-intensive systems. Genebra, 2007.

JACOBSON, I. et al. Object-oriented software engineering: a use case driven approach. Addison-Wesley, 1992. 552 p. 
$\mathrm{KOCH}, \mathrm{N}$. Software engineering for Adaptive Hypermedia Systems: reference model, modeling techniques and development process. Tese. LudwigMaximilians-Universität, Munique, Alemanha, 2000. Disponível em: <http://www.pst.informatik.uni-muenchen.de/ kochn/PhDThesisNoraKoch.pdf>. Acesso em: 12 dez. 2008.

$\mathrm{KOCH}, \mathrm{N}$;; WIRSING, M. The Munich Reference Model for Adaptive Hypermedia applications. In: INTERNATIONAL CONFERENCE ON ADAPTIVE HYPERMEDIA AND ADAPTIVE WEB-BASED SYSTEMS, 2., 2002, London. Lecture Notes in Computer Science. London: Springer-Verlag, 2002. p.213-222. Disponível em: $<$ http://www.pst.informatik.unimuenchen.de/personen/kochn/munich-koch-wirsingfinal.pdf>. Acesso em: 03 out. 2008.

KRUCHTEN, P. The 4+1 view model of architecture. IEEE Software, v. 12, n. 6, p. 42-50, 1995.

KRUCHTEN, P. Common misconceptions about software architecture. The Rational Edge, 2001. Disponível em:

<http://www.ibm.com/developerworks/rational/library/content/RationalEdge/apr01/Co mmonMisconceptionsaboutSoftwareArchitectureApr01.pdf> . Acesso em: 30 dez. 2008.

KRUCHTEN, P. The Rational Unified Process: an introduction. $3^{\text {rd }}$ ed. Boston, MA: Addison Wesley, 2003. 336 p.

LARMAN, C. Applying UML and Patterns. $2^{\text {nd }}$. ed. Upper Saddle River, NJ: Prentice-Hall, 2002. $616 \mathrm{p}$.

MACKENZIE, C et al. (ed.). Reference model for Service Oriented Architecture version 1.0. Committee Specification 1,. OASIS, 2006.

MATOS, J. Concepção de arquitetura de software com base nos estilos de arquitetura e requisitos não funcionais. 2005. 181 p. Tese (Doutorado) - Escola Politécnica, Universidade de São Paulo, São Paulo, 2005.

OFFUTT, J. Quality attributes of Web software applications. IEEE Software, Los Alamitos, CA, v. 19, n. 2, p. 25-32, 2002.

PATERNO F.; MANCINI C. Designing Web interfaces adaptable to different types of use. In: WORKSHOP MUSEUMS AND THE WEB, 3., 1999, New Orleans. 
Proceedings...[ S.I.:s.n.], 1999. Disponível em: <http://www.archimuse.com/mw99/papers/paterno/paterno.html>. Acesso em: 02 maio 2009.

PUGA, S. Sistemas hipermídia adaptativos para a educação baseada na Web: uma visão semiótica. 2008. 222 p. Tese (Doutorado) - Escola Politécnica, Universidade de São Paulo, São Paulo, 2008.

PUGA, S. G.; FERREIRA, M. A. G. V. Ética, privacidade e segurança em Sistemas Hipermídia Adaptativos para educação baseada em Web. In: CONFERÊNCIA IBERO AMERICANA WWW/INTERNET, 5., 2007, Vila Real - PO. Actas. 2007. p. 160-168.

RAJARAVIVARMA, V.; BELLARMINE, G. Web application clusters. In: IEEE SOUTHEASTCON, 8., 2007, Richmond, VA. Proceedings...[ S.I.:s.n.], 2007. p. 1-6.

RAMACHANDRAN, J. Designing security architecture solutions. New York, NY :Wiley, 2002. 480 p.

RAYMOND, K. Reference model of open distributed processing: introduction. In: IFIP TC6 INTERNATIONAL CONFERENCE ON OPEN DISTRIBUTED PROCESSING, 3., 1995, Brisbane. Proceedings...[ S.I.:s.n.], 1995, p.3-14. Disponível em:<http://reference.kfupm.edu.sa/content/r/e/reference_model_of_open_distributed _proc_821834.pdf >. Acesso em 20 jan. 2009.

ROMAN , E.; AMBLER, S.; MARINESCU, F. Mastering enterprise javabeans. $2^{\text {nd }}$ ed. New York, NY: Wiley, 2001. 672 p.

RUMBAUGH, J. et al. Object-oriented modeling and design. Englewood Cliffs: Prentice-Hall, 1991. 528 p.

SCHUMACHER, M. et al. Security patterns: integrating security and systems engineering. Chichester: Wiley, 2006. 600 p.

SHAW, M.; GARLAN, D. Software architecture. Perspectives on an emerging discipline. Upper Saddle River, NJ: Prentice Hall, 1996. 242 p.

SHAW, M.; CLEMENTS, P. The Golden age ofsSoftware architecture. IEEE Software, v. 23, n. 2, p. 31-39, 2006. 
WEBER, G.; KUHL, H.; WEIBELZAHL, S. Developing adaptive Internet based courses with the authoring system NetCoach. Hypermedia: Openness, Structural Awareness, and Adaptivity, v. 2266, p. 222-223, 2002.

WU, H. A Reference architecture for Adaptive Hypermedia applications. Tese. Technische Universiteit, Eindhoven, 2002.

WU, H; HOUBEN, G.; DE BRA, P. AHAM: A reference model to support adaptive hypermedia authoring. THE ZESDE INTERDICIPLINAIRE CONFERENTIE INFORMATIE WETENSHAPPEN, 10., 1998, Darmstadt. Conference on Hypertext and Hypermedia. New York: ACM, 1999. p. 147-156.

$X U$, L. et al. Towards modeling non-functional requirements in software architecture. In: EARLY ASPECTS 2005: ASPECT-ORIENTED REQUIREMENTS ENGINEERING AND ARCHITECTURE DESIGN, 5., 2005, Chicago. Proceedings...[ S.I.:s.n.], 2005. Disponível em:

$<$ http://trese.cs.utwente.nl/early-aspectsAOSD2005/Papers/12_XuZivRichardsonLiu_UCIrvineCSFullerton.pdf > . Acesso em 19 dez. 2008. 


\section{ANEXO A - AUTORIZAÇÃO DE SANDRA PUGA}

Autorização de Sandra Puga para utilização das figuras de sua tese entitulada "Sistemas hipermídia adaptativos para a educação baseada na Web: uma visão semiótica".

\section{Autorização para Utilização de Figuras de Tese}

sandrapuga <sandrapuga@uol.com.br>

Para: Fernando Takikawa <fernandotakikawa@gmail.com>

Cc: mariaalice.varella@gmail.com

Caro Fernando,

Autorizo a utilização das figuras em sua tese.

atenciosamente,

sandrapuga

Em 26/10/2009 22:10, Fernando Takikawa < fernandotakikawa@gmail.com > escreveu:

Olá Sandra, tudo bem ?

Conforme mencionado pela prof Maria Alice, estou solicitando a você a autorização para utilização das figuras da sua tese "Sistemas Hipermídia Adaptativos para a Educação Baseada na Web: Uma Visão Semiótica".

Na minha tese existe um capítulo sobre a arquitetura do SHASIM e precisaria ilustrá-lo com alguns diagramas da sua tese.

Abaixo segue as informações da minha dissertação:

Título: ARQUITETURA DE SISTEMAS HIPERMIDIA ADAPTATIVOS BASEADA EM ATRIBUTOS DE QUALIDADE

Autor: Fernando Kazuyoshi Takikawa

Orientador: Profa. Dr². Maria Alice Grigas Varella Ferreira

Desde já agradeço sua atenção.

Atenciosamente,

Fernando K. Takikawa 